\author{
Universidade de São Paulo \\ Escola de Engenharia de São Carlos \\ Departamento de Engenharia Elétrica
}

\title{
Ambiente de Apoio ao Desenvolvimento de Aplicações Distribuídas e Reconfiguráveis Utilizando Agentes de Busca e Classificação Inteligentes
}

\author{
Aluno: Ednilson Geraldo Rossi \\ Dissertação de mestrado apresentada \\ ao Programa de Pós-Graduação em \\ Engenharia Elétrica como parte dos \\ requisitos para obtenção do título de \\ Mestre em Engenharia Elétrica.
}

Orientador: Prof. Dr. Evandro Luís Linhari Rodrigues

São Carlos - SP 
Ficha Catalográfica 
Dedico este trabalho aos meus pais, Maria e Edson e à minha querida irmã Priscila 


\section{Agradecimentos}

A Deus, por ter propiciado a oportunidade de iniciar o caminho do mestrado e por me dar coragem e forças para concluir o trabalho.

Ao meu orientador, Prof. Dr. Evandro Luís Linhari Rodrigues, pela oportunidade de realizar o mestrado, pela orientação e amizade, e por acreditar que eu seria capaz de concluir o trabalho apesar dos pesares.

Aos meus pais que me deram incentivo, apoio e condições para a realização deste trabalho.

De forma especial à minha irmã Priscila, que colaborou de forma direta na correção e revisão desta dissertação.

A todos amigos do Laboratório de Visão Computacional II pela amizade.

À amiga Evandra pelo incentivo e amizade.

Agradecimento especial ao meu amigo Frank, sem o qual não teria iniciado este trabalho.

A todos os funcionários do SEL/EESC/USP.

A todos, que de alguma forma, contribuíram para a realização deste trabalho. 


\section{Resumo}

ROSSI, E. G. Ambiente de Apoio ao Desenvolvimento de Aplicações Distribuídas e Reconfiguráveis Utilizando Agentes de Busca e Classificação Inteligentes, 2009. 130f. Dissertação (Mestrado) - Departamento de Engenharia Elétrica da Escola de Engenharia de São Carlos, Universidade de São Paulo, São Carlos, 2009.

A área de engenharia de software passou por muitas alterações desde sua criação. Vista como uma técnica para aumentar a produtividade e baixar os custos, a reutilização de software é um dos principais estudos dos pesquisadores da área de computação. Como a reconfiguração de software é na verdade a reutilização de um software, porém com algumas adaptações, este trabalho tem por objetivo desenvolver uma metodologia e um conjunto de ferramentas que agilizem e facilitem o processo de reutilização/reconfiguração de componentes de software. A associação destas ferramentas constitui um mecanismo de armazenamento, indexação, busca e recuperação de artefatos de software. Este mecanismo trabalha com a estrutura dos projetos de software e também com as relações semânticas existentes entre os termos utilizados no software. Para representar a estrutura interna do software (características e relacionamentos) utiliza-se de um meta-modelo. Já as relações semânticas são representadas por meio de um tesauro. Por fim, todas as informações do metamodelo e do tesauro são armazenadas em um repositório de software que é manipulado por agentes de software.

Palavras-Chave: Reconfiguração de Software; Reuso de Software; Busca e Classificação; Agentes de Software; Reflexão Computacional. 



\title{
Abstract
}

\author{
ROSSI, E. G. Environment to Aid the Development of Distributed and \\ Reconfigurable Applications Using Software Agents to Intelligent Search and \\ Classification, 2009. 130f. Dissertation (Master's) - Departamento de Engenharia Elétrica da \\ Escola de Engenharia de São Carlos, Universidade de São Paulo, São Carlos, 2009.
}

Software engineering area suffered many transformations since its creation. Usually seen as a technique to raise productivity and decrease costs, softwares reusing is one of the main studies in computer field. Since softwares reconfiguration is, in essence, a software reuse, although with some adaptations, this work aims to develop a methodology and a set of tools that speed up and facilitate the process of reuse/reconfiguration of software components. These tools association constitute a mechanism of storing, indexing, search and recovering of software artifacts. This mechanism works with the structure of software projects and also with semantic relationships that exist between the software's terms. To represent software's inner structure (features and relationships) a meta-model is used. Semantic relationships are represented by a thesaurus. Finally, all the informations from meta-model and thesaurus are stored in a software repository, which is manipulated by software agents.

Keywords: Software Reconfiguration; Software Reutilization; Search and Classification; Software Agents; Computational Reflection. 



\section{Sumário}

Capítulo 1 - Introdução................................................................................................. 1

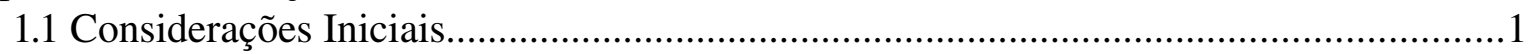

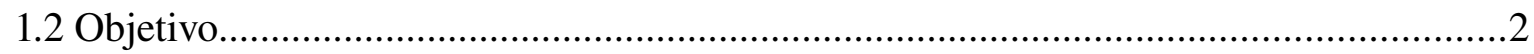

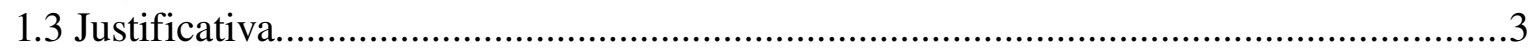

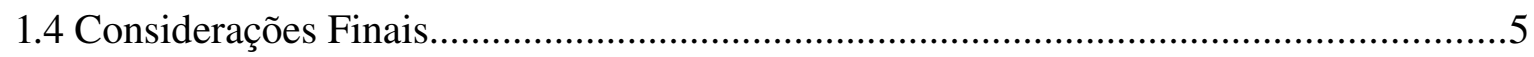

Capítulo 2 - Metodologias Utilizadas para o Desenvolvimento do Ambiente............................ 7

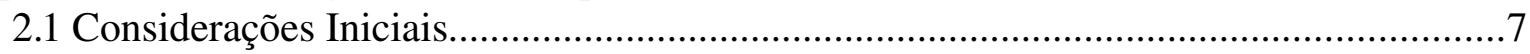

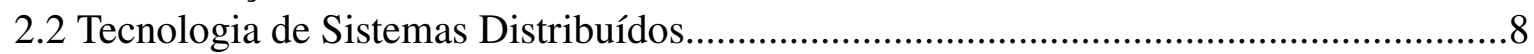

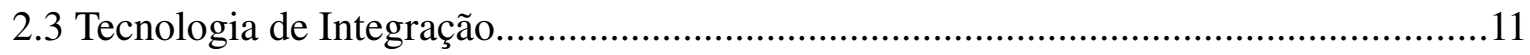

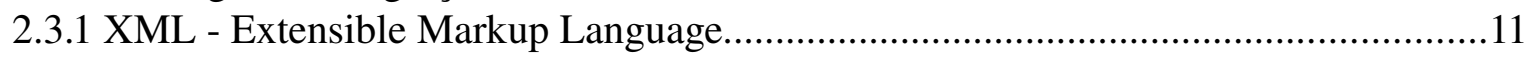

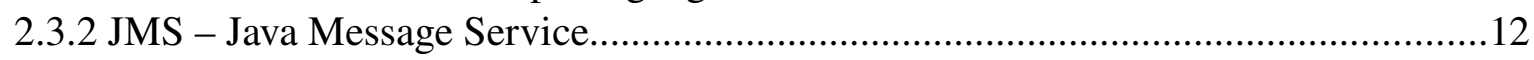

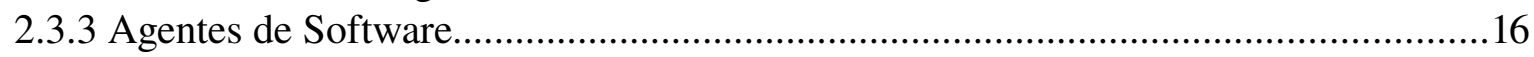

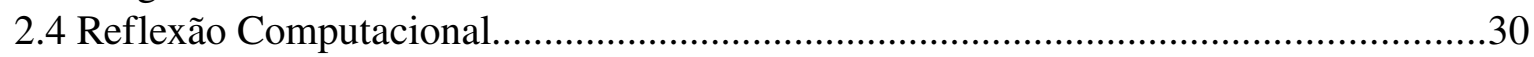

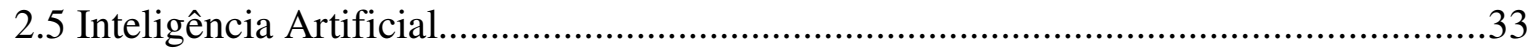

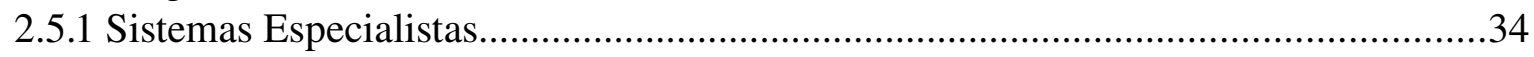

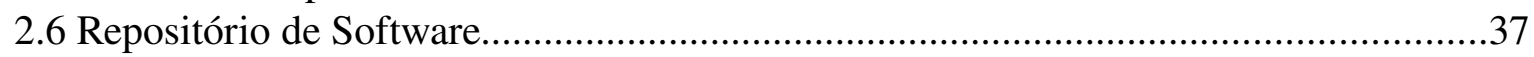

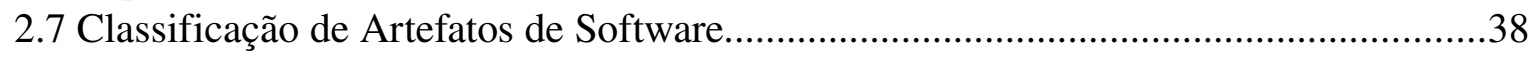

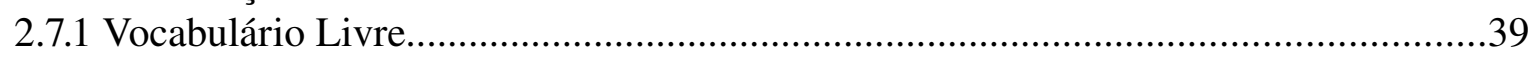

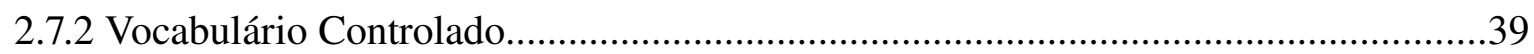

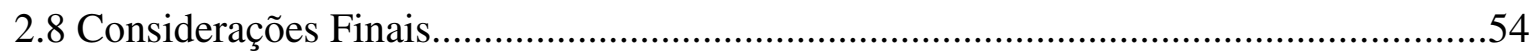

Capítulo 3 - Ambiente de Apoio ao Desenvolvimento de Software Reconfigurável................59

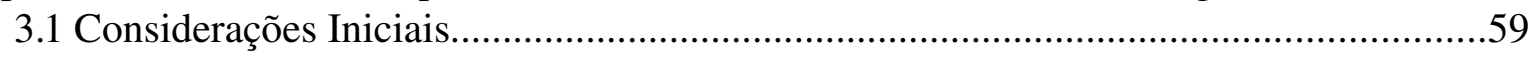

3.2 Metodologia de Desenvolvimento de Software Reconfigurável..................................60

3.3 Metodologias Auxiliares ao Ambiente de Desenvolvimento de Software

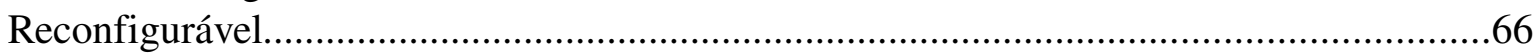

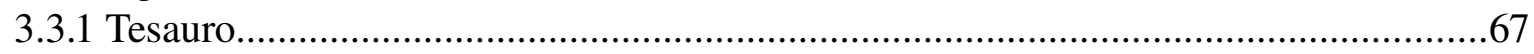

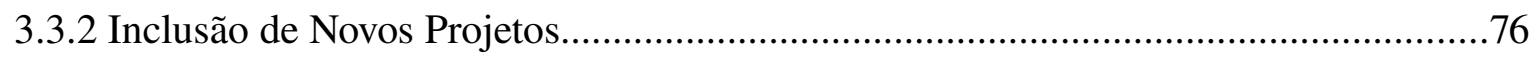

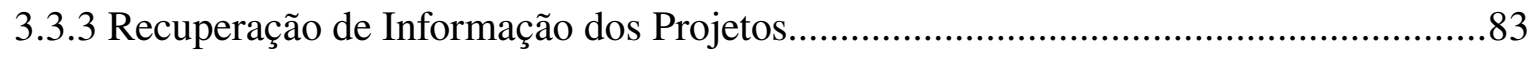

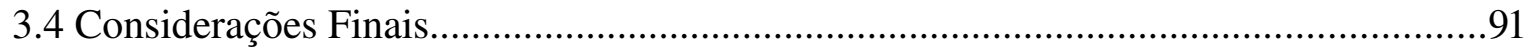

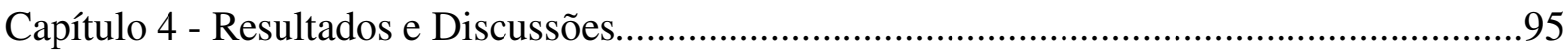

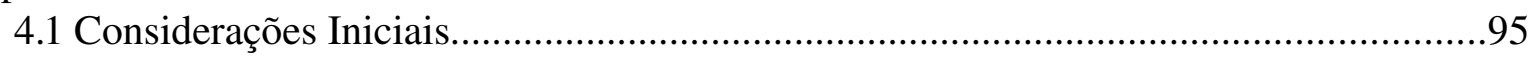

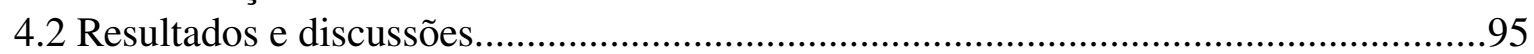

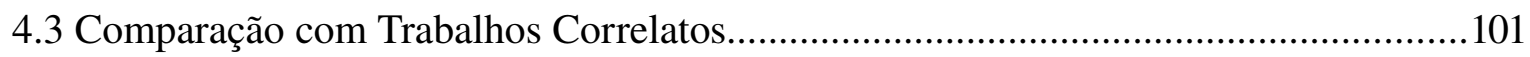

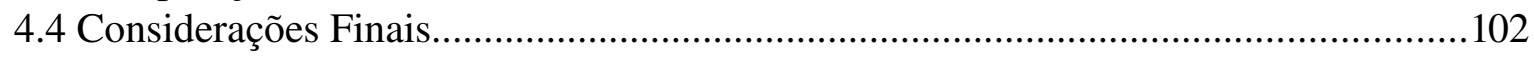

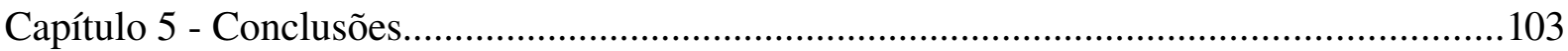

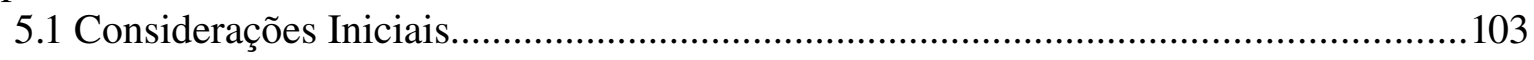

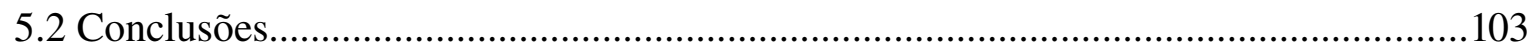

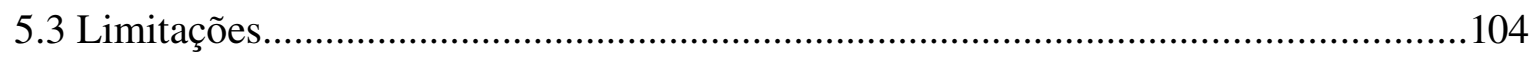

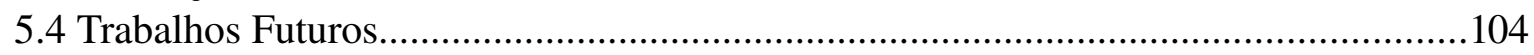

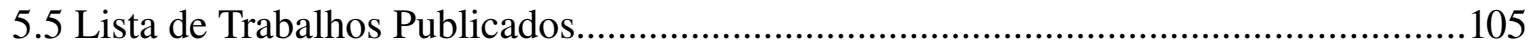

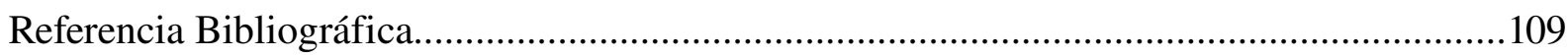




\section{Lista de Figuras}

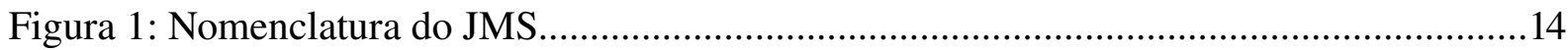

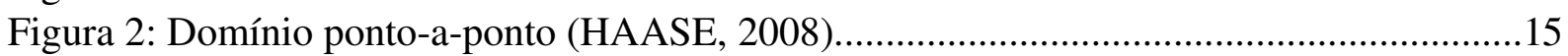

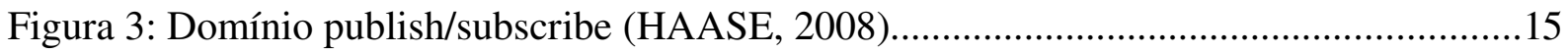

Figura 4: Representação gráfica de um agente e seu ambiente..............................................18

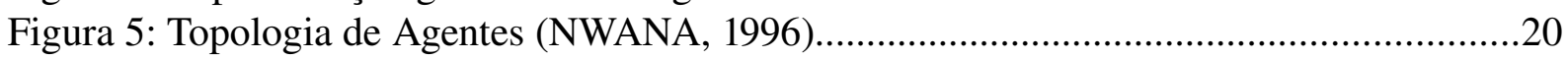

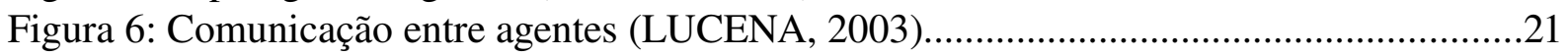

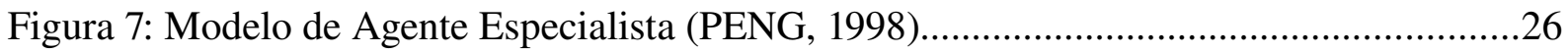

Figura 8: Arquitetura Jade (RIBEIRO \& ESCOBAR, 2006).............................................28

Figura 9: Modelo padrão de plataforma de agentes definido pela FIPA (MORAIS \& SILVA,

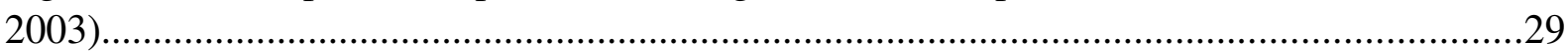

Figura 10: Fluxo de comunicação entre objetos e meta-objetos (AFFONSO, 2009)................32

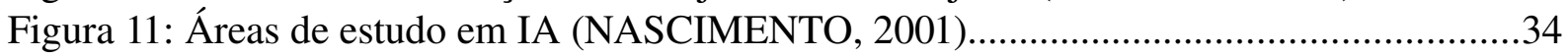

Figura 12: Grupos de termos relacionados (CARLO, 1999) .................................................48

Figura 13: Associação de grupos de termos relacionados(CARLO, 1999)...............................48

Figura 14: Repositório de Software (ROSSI; AFFONSO; RODRIGUES, 2008).....................62

Figura 15: Estrutura do Repositório de Características.......................................................62

Figura 16: Metodologia de Desenvolvimento de Software Reconfigurável (AFFONSO;

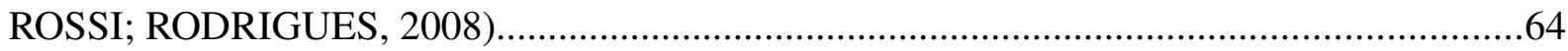

Figura 17: Ambiente de Desenvolvimento de Software Reconfigurável (AFFONSO, 2009)...65

Figura 18: Representação dos relacionamentos de equivalência...........................................69

Figura 19: Representação dos relacionamentos de hierarquia...............................................

Figura 20: Representação das relações associatividade..................................................... 71

Figura 21: Interface gráfica para a definição dos domínio tratados no ambiente.....................73

Figura 22: Interface para definir as relaçõos semânticas do tesauro.......................................74

Figura 23: Parte da Codificação que representa os relacionamentos do tesauro........................75

Figura 24: Fração de arquivo XML que representa um tesauro............................................75

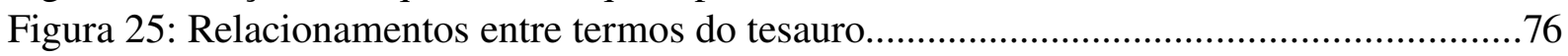

Figura 26: Meta-modelo gerado pela extração de características dos projetos..........................78

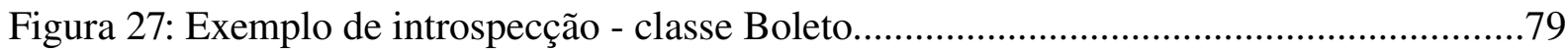

Figura 28: Arquivo XML gerado a partir da introspecção da classe Boleto............................80

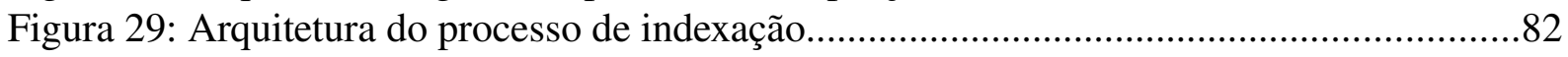

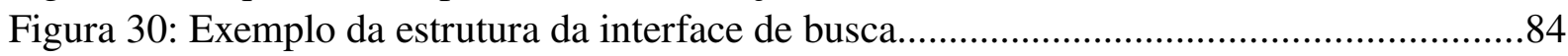

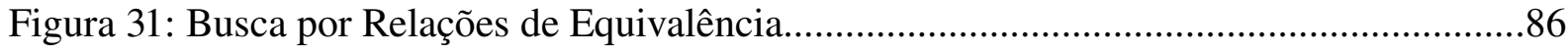

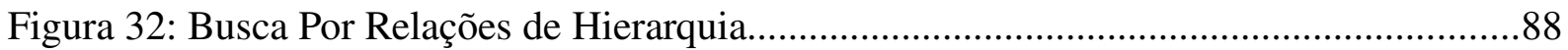

Figura 33: Busca por Relações de Associatividade............................................................90 


\section{Lista de Tabelas}

Tabela 1: Propriedades dos agentes (BERNARDES, 1999)................................................18

Tabela 2: Exemplo de entradas no dicionário de termos (CARLO, 1999)...............................45 


\section{Lista de Abreviaturas e Siglas}

ACC Agent Communication Channel

ACL Agent Communication Language

AID Agent Identifier

API Application Program Interface

BT Broader Term

BTP Broader Term Partitive

DF Directory Facilitator

ED Especialista de Domínio

ES Engenheiro de Software

FIPA Foundation for Intelligent Physical Agents

HTML HiperText Markup Language

IA Inteligência Artificial

JEE JAVA Enterprise Edition

JADE Java Agent Development Framework

JMS Java Message Service

JVM Java Virtual Machine

KQML Knowledge Query Manipulation Language

LAN Local Area Network

NT Narrower Term

NTP Narrower Term Partitive

PC Personal Computer

POO Programação Orientada a Objetos

RMI Remote Method Invocation

RT Related Term

TNP Termo Não-Preferencial

TP Termo Preferencial

UF Used For 
USE Use

XML Extensible Markup Language 


\section{Capítulo 1}

\section{Introdução}

\subsection{Considerações Iniciais}

O desenvolvimento de software é uma área em pleno desenvolvimento, sendo assunto de muitos trabalhos de diversas áreas do conhecimento. Como resultados dos estudos, foram definidas diversas metodologias para o desenvolvimento de software, dentre as quais podemos citar a programação estrutural e procedimental, a programação orientada a objetos e orientada a aspectos, a programação de sistemas distribuídos e baseada em webservices, entre outras.

O desenvolvimento de software de forma estruturada e procedimental foi a forma de desenvolvimento de software mais empregada nos softwares comerciais. Porém uma mudança nos conceitos de desenvolvimento de software fez com que o paradigma de orientação a objetos começasse a ganhar terreno. Fato este que se dá devido a um fator de extrema importância para a computação como um todo, a reutilização de software.

Muitos problemas computacionais tem sua solução baseada na resolução de problemas similares, porém muitas vezes é necessária alguma adaptação para enquadrar esta resolução ao problema em questão. Assim, partes de software já desenvolvidos podem ser utilizados novamente para auxiliar a solução de um novo problema. Segundo Prieto-Díaz (1993) a 
reutilização de software tem ocorrido desde que a programação foi inventada, porém de forma informal.

O fato de reutilizar uma parte do software, adaptando-o de alguma forma, seja agregando novas funcionalidades ou alterando suas características atuais, é considerado por Affonso et. al.(2008) como sendo uma reconfiguração.

Em uma análise rápida pode-se observar que reconfigurar e reutilizar um software são termos similares e muito próximos um do outro. Assim, o presente trabalho tende a englobar os dois significados apresentados.

\subsection{Objetivo}

Para o emprego da metodologia de desenvolvimento de software reconfigurável proposta por Affonso et. al. (2008), é necessária a formalização de uma metodologia de trabalho, porque a reconfiguração um software traz consigo vários problemas, entre eles qual software deve ser reconfigurado.

Este trabalho tem como objetivo formalizar uma metodologia de trabalho para ser agregada à proposta de Affonso et. al. (2008). Esta metodologia é apoiada pelo desenvolvimento de ferramentas que facilitem e agilizem o processo de reconfiguração.

Para isso, são especificados alguns repositórios, denominados repositórios de software, que na verdade são um conjunto de repositórios que permitem armazenar todas as características de um projeto de software.

Estes repositórios devem, além de armazenar os softwares produzidos, permitir uma rápida e eficiente recuperação dos softwares que serão reconfigurados. Para permitir que isso aconteça, os projetos de software passam por um processo de extração de características 
(introspecção).

Segundo Pressman (2000), um repositório de software deve possuir um meta-modelo, ou seja, um modelo de informação que descreva a estrutura, os relacionamentos e a semântica dos dados nele armazenados. Assim, após o processo de introspecção do projeto, é definido um meta-modelo para representar todo o projeto e todas as informações deste projeto.

Os processos de classificação e busca dos softwares armazenados também estão baseados na estrutura do software. Assim, após o processo de introspecção do projeto, o mesmo é indexado em um tesauro que fornece uma imensa riqueza de relacionamentos semânticos, permitindo assim a busca e recuperação dos projetos.

Portanto, o objetivo deste trabalho pode ser dividido em duas partes. A primeira, quando um projeto de software termina de ser desenvolvido, os engenheiros devem inserir este projeto nos repositórios, para que mais tarde possam ser reutilizados e/ou reconfigurados em outros projetos. Porém para que isso seja possível, o software deve ser indexado e catalogado no tesauro para depois ser armazenado no repositório.

A segunda parte do trabalho é encarregada de extrair um projeto do repositório. Para que isso ocorra, é necessário realizar uma busca em todos os projetos armazenados nos repositórios (no plural, pois podem existir mais de um repositório de software). Busca que deve devolver ao usuário somente resultados relevantes, mesmo que o usuário não saiba exatamente qual software está procurando.

\subsection{Justificativa}

Como já abordado, o desenvolvimento de um software muitas vezes resulta em desperdício de esforços, pois muito dos trabalhos desenvolvidos já foram feitos em outros 
projetos. Isso devido a grande similaridade existente no desenvolvimento de software. Assim grande parte dos softwares já desenvolvidos podem ser reutilizados em novos projetos com o intuito de diminuir esforços.

Para confirmar a similaridade entre os projetos, Tracz (TRACZ, 1986 apud ROSSI, 2004) apresenta dados de um estudo relativo ao reuso de código-fonte em diferentes projetos:

- $40 \%$ a $60 \%$ de todos o código-fonte são reutilizáveis de uma aplicação para outra;

- $60 \%$ de projeto e código sobre aplicações de negócio são reutilizáveis;

- $75 \%$ de funções de programas são comuns a mais de um programa;

- $15 \%$ de código encontrado na maioria dos programas são únicos e específicos de uma aplicação.

Estudos apontam que a produtividade no desenvolvimento de software está diretamente relacionada com a implementação da reutilização. Estudos apontam uma redução de até 50\% nos custos da produção de software (BASS, 2001 apud ROSSI, 2004). Considerando estes dados observa-se que a reutilização/reconfiguração é uma alternativa para se alcançar a produtividade e baixar custos no processo de desenvolvimento de software. A qualidade também é outro fator importante, pois quando reutiliza-se um software agrega-se todas as características que este software possui, como, por exemplo, todos os testes que este software sofreu durante seu desenvolvimento e sua utilização em outros projetos. Assim, a reutilização e a reconfiguração tornam-se ferramentas importantes para o aproveitamento das partes similares dos projetos, os quais podem ser armazenados em repositórios.

Os repositórios definidos por Rossi et al. (2008) tratam-se, na verdade, de um conjunto de repositórios específicos que necessitam de um gerenciamento das informações contidas 
nesses repositórios. É necessário, portanto, que o gerenciador destes repositórios seja capaz de armazenar, indexar e recuperar de forma eficiente os projetos de software. É importante ressaltar que podem existir vários repositórios de software divididos no ambiente de desenvolvimento. Para solucionar este requisito, a proposta aqui apresentada será apoiada pelo uso de agentes de software, que terão papel importante na integração dos vários repositórios possíveis.

A indexação, busca e recuperação dos projetos de software dar-se-á baseada em tesauros, que são dicionários capazes de representar um grande número de relações semânticas entre os termos de um domínio. Estes processos são o ponto chave do sucesso deste trabalho, pois a eficiência da busca por projetos de software será o fator determinante entre a adoção da metodologia e seu abandono.

Conclui-se, portanto, que o desenvolvimento deste ambiente é relevante para apoiar a metodologia de desenvolvimento de software reconfigurável, uma vez que disponibilizará uma estrutura para os repositório de software, além de permitir a busca e recuperação de projetos relevantes ao usuário.

\subsection{Considerações Finais}

O capítulo 2, Revisão Bibliográfica, apresenta os tópicos referentes ao trabalho. Pela presença de diversas áreas de pesquisa, os tópicos foram organizados em seções com o intuito de apresentá-los de maneira organizada e objetiva, destacando quais as contribuições que cada uma delas oferece ao trabalho.

O capítulo 3, Ambiente de Apoio ao Desenvolvimento de Software Reconfigurável, apresenta um conjunto de diretrizes para auxiliar no desenvolvimento de software 
reconfigurável, fornecendo meios para uma maior reutilização de softwares já desenvolvidos. Este capítulo aborda também todos os módulos que farão parte do ambiente, descrevendo assim a metodologia empregada neste trabalho.

O capítulo 4, Resultados e Discussões, contempla os resultados obtidos com a utilização do projeto, assim como faz um comparativo com outros trabalhos relacionados. Por fim, o Capítulo 5 mostra as conclusões obtidas com o desenvolvimento do trabalho. 


\section{Capítulo 2}

\section{Metodologias Ulitizadas para o Desenvolvimento do Ambiente}

\subsection{Considerações Iniciais}

Neste capítulo são apresentados os assuntos encontrados na literatura especializada que fornecem suporte para o desenvolvimento deste trabalho. Por sua natureza multidisciplinar, os assuntos foram organizados da seguinte maneira: na seção 2.2 são apresentadas as tecnologias para o desenvolvimento de Sistemas Distribuídos; na seção 2.3 são apresentadas as tecnologias envolvidas na integração dos Sistemas Distribuídos; na seção 2.4 são abordados os conceitos de Reflexão Computacional para que se possa fazer uma reflexão nos objetos envolvidos nos projetos; na seção 2.5 são apresentados os recursos de inteligência artificial que dão base à Programação Baseada em Regras de negócio; já na seção 2.6 são abordados os tópicos sobre classificação dos artefatos de software, onde a estrutura do software e a informação semântica contida nesta estrutura permitem sua classificação, e por fim, na seção 2.7 são apresentadas as considerações finais. 


\subsection{Tecnologia de Sistemas Distribuídos}

Em 1945, com o despertar da era computacional, os computadores se baseavam em grandes máquinas de processamento, conhecidas como "mainframes", que tinha baixa capacidade computacional, em comparação com os atuais computadores pessoais (PCs), além de um custo muito elevado. Assim sendo, as empresas tinham poucos computadores, os quais eram operados de forma independente. Porém, dois fatores contribuíram para a mudança deste cenário. O primeiro foi a evolução dos processadores, que a cada nova geração tinham seu tamanho reduzido e seu poder de processamento aumentado. Além disso, com a produção em alta escala, os preços dos equipamentos tornaram-se mais acessíveis, tanto às empresas como ao público em geral. O segundo fator, foi o desenvolvimento das redes de computadores, mais especificamente "Local Area Networks" (LANs), as quais interligam, dentre os mais diversos tipos de dispositivos, vários computadores que podem assim dividir o trabalho realizado pelos processadores, fazendo com que sistemas sejam processados em paralelo. A este tipo de sistema dá-se o nome de sistema distribuído.

Mesmo partindo de uma ideologia que visava a minimização de custos e aumento do poder computacional, os sistemas distribuídos não encontraram seu apogeu neste período, pois com a redução de preços e o aumento escalar no poder computacional dos microprocessadores que dava um poder de processamento muito grande aos computadores, os sistemas distribuídos encontraram uma barreira, o software (TANENBAUM, 2003). Isso ocorreu pois os sistemas distribuídos precisavam ser gerenciados de forma correta e precisa, o que exigia uma tecnologia ainda imatura para a época. Desta forma, os sistemas centralizados ganharam espaço e até pouco tempo eram considerados a única forma de se desenvolver 
sistemas.

Já em 1993, surgiu uma nova fase da computação no mundo, iniciou-se a era da Internet, o que causa uma grande revolução na organização das empresas e também uma grande mudança na concepção de sistemas computacionais (DEITEL \& DEITEL, 2005). A Internet surge como uma rede de computadores, que interliga diferentes centros de pesquisas e de conhecimento, como as universidades e bases militares nos Estados Unidos da América (EUA). Mas o grande potencial desta rede fez com que ela se tornasse uma rede pública, interligando agora diferentes empresas, organizações e pessoas por todo o mundo.

Com o despontamento da Internet e seu crescente número de usuários, os desenvolvedores observam que os sistemas centralizados não seriam capazes de atender à nova demanda de sistemas que a Internet trouxe. Assim sendo, iniciou-se uma corrida para o desenvolvimento de diferentes tipos de tecnologias que permitissem que sistemas complexos fossem disponibilizados para os usuários da Internet.

Entre as várias tecnologias surge, em 1995, a linguagem Java, desenvolvida pela SUN Microsystems (SUN), que é caracterizada, segundo Deitel e Deitel (2005), como uma linguagem orientada a objetos, robusta, portável, interoperável, multiplataforma e utilizada em vários ambientes de implementação computacional.

Porém, a tecnologia Java não pode ser considerada apenas como mais uma linguagem de programação. Devido à sua complexidade e abrangência das diversas facetas desta tecnologia, foi criado o que se pode chamar de Universo Java, cujos principais elementos incluem uma linguagem de programação orientada a objetos, bibliotecas e frameworks de desenvolvimento básicos e avançados, protótipos e especificações de aplicações e modelos computacionais, listas de discussão na Internet, repositórios de documentos, applets e 
aplicações na Web como webservices. Assim sendo, a tecnologia Java pode ser empregada no desenvolvimento de sistemas desktop, voltados para Web, distribuídos, móveis, orientados a componentes e orientados a serviços. Além destes, outras Applications Program Interface (API) oferecem recursos fundamentais de implementação, tais como XML, JavaCard, JavaMedia, JavaMail, Webservices, entre outras (SUN-JAVA, 2009).

No início do emprego da tecnologia Java, utilizou-se basicamente a arquitetura cliente/ servidor, que consiste em dividir o processamento das informações em dois módulos distintos. Um módulo é responsável pelo processamento e manutenção da informação, sendo denominado servidor, pois serve aos interesses de outros, neste caso aos interesses dos programas clientes. Por outro lado, o módulo que é responsável pela obtenção dos dados do usuário e pela interface com o usuário, é denominado programa cliente.

Contudo, devido à sua alta usabilidade, a tecnologia Java permitiu o surgimento de novas modalidades de desenvolvimento, como por exemplo a utilização de webservices, que segundo Girardi (2003), são aplicações auto-contidas e que descrevem uma coleção de operações acessíveis através da rede, independentemente da tecnologia empregada na implementação do serviço. Simplificando, um webservice pode ser entendido como um componente que possui suas funcionalidades acessíveis pela rede.

A utilização dos webservices, trouxe novamente a realidade dos sistemas distribuídos à tona, pois agora os serviços estão disponíveis através da Internet. Isso facilita a implementação de muitas funcionalidades de um software, pois, com a reutilização dos serviços já em operação, o desenvolvimento é agilizado, trazendo um ganho financeiro e de tempo para os desenvolvedores de software. 
Com a grande utilização destes serviços, diferentes sistemas necessitam agora da troca de informações entre si, e surge aí o conceito de middleware, que tem a função de integrar os diversos sistemas existentes e também outras tecnologias. Os middlewares e demais tecnologias de integração entre sistemas serão o assunto do próximo capítulo.

\subsection{Tecnologia de Integração}

\subsubsection{XML - Extensible Markup Language}

Extensible Markup Language (XML) é uma linguagem de marcação de dados (metamarkup language) que provê um formato para descrever dados de forma estrutural. Isso facilita declarações mais precisas do conteúdo e resultados mais significativos de buscas através de múltiplas plataformas. O XML é uma tecnologia muito simples, porém complementada por outras tecnologias torna-se maior e mais poderosa, fornecendo ao XML uma grande usabilidade. Além disso, o XML não é simplesmente uma linguagem de marcação pré-definida, e sim uma meta-linguagem que permite aos seus usuários definir suas próprias marcações e atender inúmeras classes de diferentes documentos (W3C-XML, 2008).

A linguagem XML é suportada por várias tecnologias e também por várias linguagens de programação, que faz com que o XML assuma a função de compartilhar dados entre diferentes tipos de aplicações, sejam elas baseadas em Web ou Desktop. Sendo assim, o XML tem um papel importantíssimo no mundo atual, que tende à globalização e à compatibilidade entre sistemas e também entre linguagens de programação, pois segundo W3C-XML(2008), a 
tecnologia XML é suportada por linguagens como Java, $\mathrm{C}++$, Object Pascal entre outras. Outros dois pontos a se destacarem sobre o XML são: a) sua capacidade de adaptação, que representa as mudanças que um XML pode sofrer para representar qualquer tipo de informação e b) sua simplicidade de representação, pois faz o uso de TAGs (marcações) assim como a linguagem HTML, HiperText Markup Language, utilizada para construção de páginas na $W e b$.

Ainda discutindo sobre tecnologias de integração, os próximos itens abordados darão fundamentação nas tecnologias mais recentes, que utilizando do XML, fornecem todo o aparato tecnológico utilizado para a elaboração deste trabalho.

\subsubsection{JMS - Java Message Service}

Além do XML, outra tecnologia de integração utilizada neste trabalho é o Java Message Service (JMS), que consiste em uma API que permite que aplicações criem, enviem, recebam e analisem mensagens enviadas por outras aplicações, além de auxiliar o suporte de ambientes heterogêneos e em situações onde a conexão é estabelecida de modo intermitente. Esta troca de mensagens pode ocorrer de modo síncrono ou assíncrono mas a API JMS garante que a mensagem seja entregue apenas uma única vez (NUMAZAKI \& WAENY, 2004). Deve-se salientar que a API JMS permite a troca de mensagens entre diferentes sistemas, diferentemente de um e-mail (eletronic mail) que permite a troca de mensagens entre usuário-usuário ou sistema-usuário. Outra característica importante da API JMS é a possibilidade de se integrar sistemas escritos em diferentes linguagens de programação e também diferentes plataformas (HAASE, 2002). 
As mensagens trocadas pelo JMS são um método de comunicação entre componentes de software ou aplicações. Um sistema de mensagens é considerado um sistema peer-to-peer (P2P), ou seja ponto-a-ponto, pois a comunicação se dá entre dois computadores (hosts). Uma aplicação cliente pode enviar mensagens para outro cliente e receber mensagens de qualquer cliente ou até mesmo do próprio cliente para quem enviou a mensagem. Cada cliente se conecta a um JMS Provider, que consiste em uma aplicação servidora que implementa as interfaces do padrão JMS e, da mesma forma, implementa ferramentas administrativas e de controle para os serviços prestados. Este Provider é o responsável pela conexão da aplicação com as mensagens.

Outra característica importante do JMS é que os componentes de software clientes, não necessitam conhecer uns aos outros, ou seja, o cliente que envia a mensagem não precisa saber como foi implementado o cliente que recebe a mensagem e vice-versa. Este conceito de mensagem difere de outras tecnologias como Remote Method Invocation (RMI), outra tecnologia muito utilizada na integração de sistemas, pois em RMI uma aplicação necessita saber como se conectar a outra. Assim, o JMS permite que se integrem diferentes componentes de software, que podem também ser desenvolvidos em diferentes linguagens de programação, pois os clientes envolvidos na comunicação por mensagens apenas devem saber interpretar as mensagens que chegam a eles (HAASE, 2002).

Já os JMS Clientes, são aplicações simples, sua funcionalidade consiste em enviar ou receber uma mensagem, através do Provider, e interpreta-la. Estes clientes podem, de acordo com o conteúdo da mensagem, tomar determinadas decisões, alterando o estado de uma aplicação. A Figura 1 representa a funcionalidade dos JMS Clientes. 


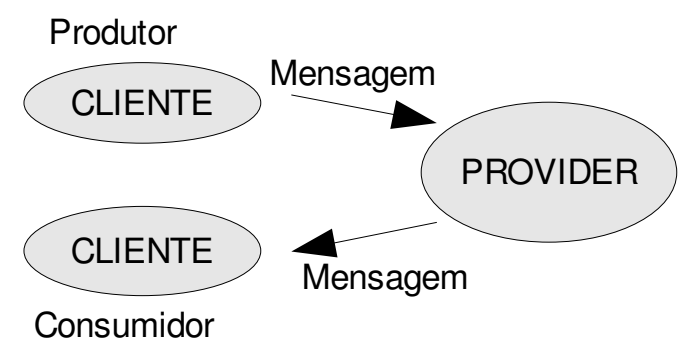

Figura 1: Nomenclatura do JMS

As mensagens carregam informações sobre as regras de negócio das aplicações. Estas regras são responsáveis pela funcionalidade do sistema como um todo. As mensagens são objetos serializáveis que, através de um conjunto de JMS Providers, trocam informações ou executam procedimentos entre os vários JMS Clients envolvidos.

As mensagens em JMS podem ser associadas a domínios diferentes, isto é, elas podem ser de tipos diferentes. As mensagens, enfim, podem ser distribuídas por meio de dois domínios diferentes, um ponto-a-ponto e outro no formato publish/subscribe.

As mensagens trocadas no domínio ponto-a-ponto (P2P) são enviadas a uma única fila, tratada pela API como queue. Nesta fila chegam todas as mensagens e qualquer consumidor de mensagens, autorizado a acessar a fila, pode retirar mensagens da fila. É importante ressaltar que uma vez que a mensagem deixe a fila, ela não mais estará disponível a outros consumidores, assim sendo, o primeiro que pegar a mensagem deve interpreta-la, pois ninguém mais o fará. A Figura 2 representa o conceito P2P.

Por outro lado, no domínio publish/subscribe as mensagens são duplicadas e enviadas a vários clientes. A API JMS trata este domínio como topic. Os clientes que acessam o topic são conhecidos como associados, e existe um topic para cada associado; ao chegar uma mensagem, o Provider insere uma cópia da mensagem em cada topic. Assim quando o cliente 
desejar receber as mensagens, acessa seu topic e pode receber as mensagens destinadas a ele.

A Figura 3 representa este tipo de domínio.

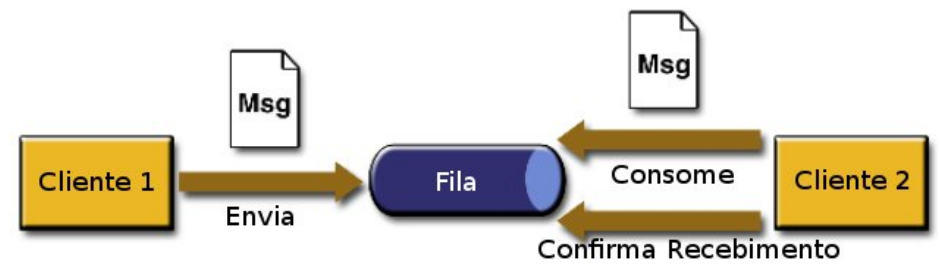

Figura 2: Domínio ponto-a-ponto (HAASE, 2008)

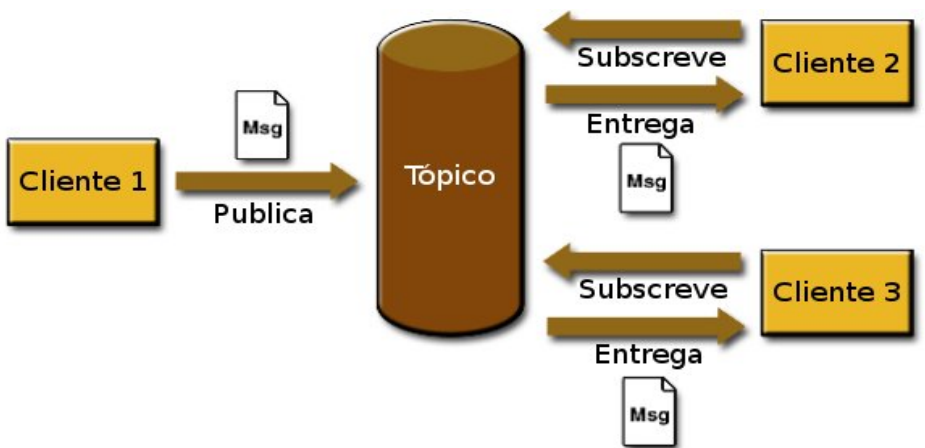

Figura 3: Domínio publish/subscribe (HAASE, 2008)

Porém, deve-se ter ciência que as mensagens não são mantidas, ou seja, em caso de pane no sistema, o Provider não provê meios para recuperar as mensagens. Em várias situações este fato não representa um problema em potencial. Todavia, é necessário que o Provider consiga recuperar o estado anterior ao problema. Nestes casos, as mensagens deverão ser persistidas por meio de alguma tecnologia fornecida pelo JMS, que permite inclusive que se configure o tempo de vida que as respectivas mensagens permanecerão armazenadas (NUMAZAKI \& WAENY, 2004). 
Pode-se afirmar que o JMS não apresenta muitas complicações para o desenvolvimento de softwares, porém como já foi visto, o JMS necessita de um agente responsável pela manipulação e gerência das filas, que é o JMS Provider. Neste trabalho o JMS Provider utilizado é o servidor JBOSS.

O JBOSS Enterprise Middleware (JBOSS) é um avançado software de código aberto que possibilita a seus clientes a criação, implementação, integração e a orquestração de aplicações e serviços Web em uma Arquitetura Orientada a Serviços (Service Oriented Arquiteture - SOA) (RED-HAT-JBOSS, 2008). O JBOSS oferece uma forma simples, aberta e acessível de modernizar a infra-estrutura de aplicações no legado. E segundo a RED-HATJBOSS (2008), ele reduz a complexidade envolvida no desenvolvimento, melhora a experiência do usuário e resolve processos corporativos.

\subsubsection{Agentes de Software}

Há muito tempo os seres humanos são fascinados com a possibilidade de criar agentes artificiais capazes de imitar o comportamento humano, nem que seja para a execução de pequenas tarefas. Exemplos deste desejo humano podem ser observados em Lucena (2003), onde são mostrados desde brinquedos até a utilização do cinema para representar criações artificiais dotadas de autonomia e inteligência. Seguindo este sentimento, o matemático Alan Turing, propôs que uma máquina poderia ser considerada inteligente se o ser humano não pudesse distinguir o comportamento de uma máquina do comportamento de outro ser humano. A este foi dado o nome de teste de Turing (LUCENA, 2003). 
Porém, muito tempo passou e a ficção mostrada nos filmes continua apenas sendo ficção, mas os esforços em criar máquinas inteligentes não deixou de existir, houve apenas uma mudança de foco. Os estudiosos da área de inteligência artificial voltaram seus esforços para resolver problemas mais específicos, cujos resultados possuem maior aplicabilidade e contribuição para a sociedade. Seguindo esta linha de raciocínio surge o termo agente, que consiste em uma entidade dotada de autonomia capaz de realizar algumas tarefas em nome de um usuário (LUCENA, 2003).

Contudo, o termo agente pode ser caracterizado de várias formas. O dicionário Aurélio define o termo agente como: "1. o que opera, agencia, age. 2. pessoa agente. 3 . quem trata de negócios alheios.”. Os agentes humanos são geralmente especialistas que realizam tarefas para outras pessoas, sendo que, estes especialistas tem conhecimento e autonomia para realizar tarefas para as quais foram designados. $\mathrm{O}$ agente humano muitas vezes deve tomar decisões em nome de outras pessoas.

Segundo Lucena (2003), o paradigma de agentes de software propõe que se atribua tarefas a softwares, agentes capazes de realizar ações de interesse do usuário sem que este precise intervir na execução da tarefa. Estes softwares seriam dotados de autonomia e inteligência, o que os tornam aptos a executarem processos para que alcancem um determinado objetivo, sendo este estipulado pelo usuário. Os objetivos de um agente podem ser os mais variados possíveis, indo desde uma busca de conteúdo na internet até os mais variados tipos de negociação envolvendo outros agentes de software e/ou agentes humanos.

Apesar de existirem muitas definições sobre agentes de software onde a palavra autonomia é utilizada na maioria delas, Lucena (2003) define que "um agente é um software capaz de agenciar ou realizar algo para o usuário de forma automática". Pode-se observar na 
Figura 4 uma representação do que seria um agente que percebe e interage com o ambiente onde está inserido, sempre buscando atingir seus objetivos.

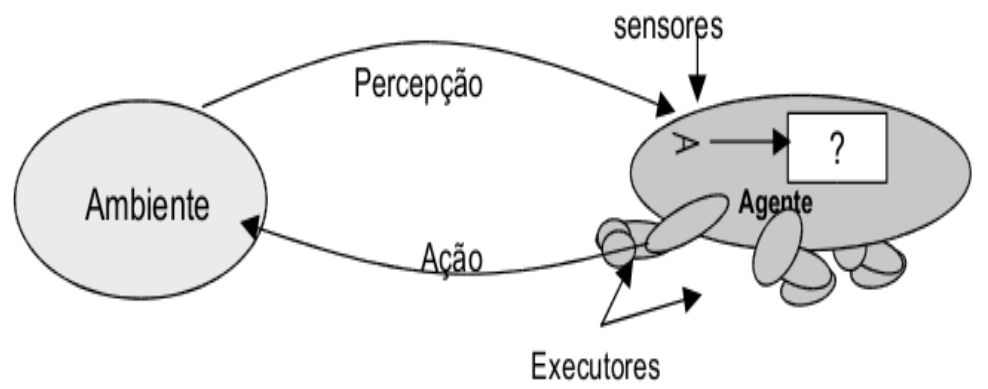

Figura 4: Representação gráfica de um agente e seu ambiente.

Assim como existem muitas definições para agentes, existem também algumas propriedades que lhes podem ser atribuídas. A Tabela 1, exibe as propriedades levantadas por Bernardes (1999).

Tabela 1: Propriedades dos agentes (BERNARDES, 1999).

\begin{tabular}{|c|c|c|}
\hline Propriedade & Sinônimo & Significado \\
\hline Reativo & Percepção e Ação & Responde conforme as mudanças do ambiente \\
\hline Autônomo & & Exerce controle sobre suas próprias ações \\
\hline Orientado a metas & $\begin{array}{l}\text { Com propósito pró- } \\
\text { ativo }\end{array}$ & Não age simplesmente em função do ambiente \\
\hline Contínuo & & É um processo executado continuamente \\
\hline Comunicativo & Socialmente capaz & $\begin{array}{l}\text { Comunica-se com outros agentes, } \\
\text { possivelmente humanos }\end{array}$ \\
\hline Inteligente & Adaptável & $\begin{array}{l}\text { Muda seu comportamento com base em } \\
\text { experiências anteriores }\end{array}$ \\
\hline Móvel & & Capaz de se mover de uma máquina para outra \\
\hline Flexível & & Ações não são definidas através de scripts \\
\hline Caráter & & Personalidade e estado emocional críveis \\
\hline
\end{tabular}


No entanto, além das propriedades abordadas, pode-se classificar os tipos de agentes existentes em diferentes classes, fazendo-se a apresentação de uma taxonomia de agentes. Tavares (2002) apresenta várias dimensões para a classificação dos agentes. A primeira, classifica os agentes de acordo com sua capacidade de mobilidade entre diversos computadores de uma rede. O agente que há pouco estava sendo executado em uma máquina, transferiu-se, por completo (código e estado), para outra máquina da rede; isto o classifica em móvel ou estático. A segunda, classifica o agente analisando o seu modo de funcionamento deliberativo ou reativo, onde o agente deliberativo possui um mecanismo interno que lhe permite um "raciocínio" simbólico interno, planejando a negociação das tarefas com outros agentes. Por outro lado, os agentes reativos apresentam um comportamento estímulo/resposta pelo qual o agente responde aos estímulos pressentidos no ambiente em que está inserido e faz alterações nesse ambiente. A terceira, classifica o agente de acordo com propriedades ideais e fundamentais que um agente deveria ter: autonomia, aprendizado e cooperação. A quarta dimensão classifica o agente de acordo com o papel assumido por ele na aplicação na qual está inserido. E por último, tem-se a classificação dos agentes híbridos, aqueles que combinam uma ou mais dimensões no mesmo agente.

Segundo Nwana (1996), é possível resumir as topologias através da combinação de três características básicas esperadas em um agente de software, que são: autonomia, aprendizado e cooperação. A Figura 5 representa quatro tipos de agentes que podem ser incluídos na topologia de agentes: agentes colaborativos, agentes colaborativos com aprendizagem, agentes de interface e agentes inteligentes.

Outro ponto a ser considerado na tecnologia de agentes, que é destacado por Bellifemine et al. (2004), é a comunicação que deve existir entre os agentes em um mesmo 
ambiente, onde vários agentes podem estar interagindo. A este tipo de ambiente dá-se o nome de sistema multi-agentes. Este tipo de sistema será utilizado no ambiente de desenvolvimento de software reconfigurável, onde vários agentes estarão interagindo no mesmo ambiente para que, individualmente alcancem seus objetivos.

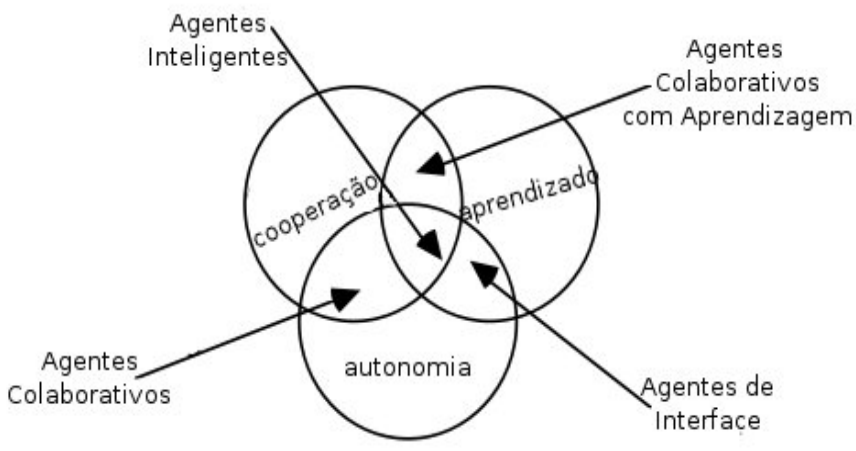

Figura 5: Topologia de Agentes (NWANA, 1996)

É fato que os agentes necessitam se comunicar com usuários, com o sistema ambiente e com outros agentes, pois eles precisam cooperar, colaborar e negociar. Em particular, os agentes interagem uns com os outros através de linguagens específicas chamadas linguagens de comunicação de agentes, termo vindo do inglês agent communication language (ACL).

Este tipo de comunicação se faz através da comunicação direta entre os agentes, assim sendo, é necessário que cada agente saiba os nomes e endereços que formam o sistema para que as mensagens possam ser trocadas. Mas com o objetivo de simplificar esta troca de mensagens, a maioria dos sistemas que seguem este modelo de comunicação, utilizam-se dos agentes facilitadores, mais conhecidos como páginas amarela (yellow pages) pois realizam realmente o serviço de fornecer informações (nome, endereço e serviços oferecidos pelos agentes) de serviços publicados, em analogia com uma lista telefônica (LUCENA, 2003). A 
Figura 6 ilustra esta comunicação.

Segundo Lucena (2003), quando um agente necessita se comunicar com outro agente, este solicita ao agente facilitador que encontre o agente procurado pelo nome (através das white pages) ou pelo tipo de agente ou ainda pelo serviço oferecido (através das yellow pages). Dependendo do tipo do sistema implementado os agentes podem acessar as white pages e yellow pages diretamente, descartando assim a figura do agente facilitador.

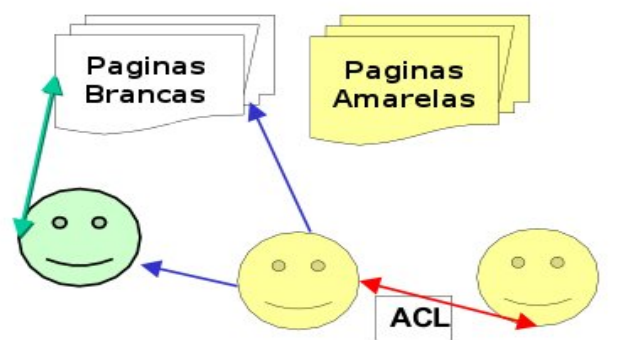

Figura 6: Comunicação entre agentes (LUCENA, 2003)

A ACL define o tipo de mensagem que os agentes utilizarão para se comunicar. As duas linguagens de maior aceitação atualmente são: a Knowledge Query Manipulation Language (KQML) e a Foundation for Intelligent Physical Agents ACL (FIPA ACL). Estas linguagens utilizam o conceito de performativas, que deriva da "teoria dos atos da fala". Segundo esta teoria, a comunicação se dá através de atos tais como: requisições, sugestões, promessas, ameaças, entre outros (LUCENA, 2003).

Proença (2003) ressalta que, um sistema multi-agentes consiste na incorporação de vários agentes para resolver um problema complexo para a solução por um único agente. Assim sendo, pode-se tirar vantagem da capacidade e característica de cada agente implementando-se processos interativos que podem conduzir facilmente à realização dos objetivos. Um sistema multi-agentes possui características particulares, tais como 
(PROENÇA, 2003):

- Um único agente não é capaz de resolver o problema por si só. Por falta de informação ou capacidade, um único agente não consegue isoladamente resolver o problema; caso contrário, não haveria necessidade de implementar um sistema multiagentes, e sim um único agente capaz de solucionar problemas;

- Sistema de controle descentralizado. Este é o fator que fornece robustez a um sistema deste tipo, pois sem uma entidade de controle direto, este sistema não fica dependente da consistência de elemento particulares;

- Distribuição da informação. Esta característica dá mais confiabilidade aos sistemas multi-agentes, pois ao se distribuir a informação entre vários agentes, diminui-se a probabilidade de perda de informações;

- Computação assíncrona. Com a possibilidade da computação estar distribuída em diferentes pontos físicos, aumenta-se a capacidade de processamento da informação; porém é necessário um sincronismo entre os agentes no momento da comunicação entre os mesmos;

- Auto-organização. O fato de não haver uma entidade central faz com que cada um dos agentes do sistema se auto-organize para que consiga atingir seus objetivos, e isso faz com que cada agente reaja e se adeque às mudanças no ambiente;

- Competição e colaboração são as formas mais usuais utilizadas para o relacionamento entre os agentes integrantes de um mesmo sistema. Os processos de competição e colaboração podem conduzir mais facilmente à obtenção de objetivos comuns;

- Organização em rede, pois os agentes normalmente estão distribuídos em 
ambiente de rede onde adquirem o conceito de paralelismo, dinamismo ou concorrência;

- Inteligência emergente. Mesmo quando não são implementados agentes inteligentes, da interação de vários agentes podem emergir processos inteligentes, isto se for analisado o comportamento geral do sistema.

Outra definição para sistemas multi-agentes é dada por Paula (2005) que afirma que um sistema multi-agentes é um programa de computador com solucionadores de problemas (agentes) localizados em ambientes interativos, que são capazes de ações flexíveis, autônomas, socialmente organizadas e podem se dirigir para a obtenção de metas.

Um projeto de sistema multi-agentes necessita levar em consideração vários aspectos como por exemplo: tipo ou classe do problema a ser tratado; níveis de autonomia atribuído aos agentes; formas de representação do conhecimento; protocolos de comunicação; organização do sistema como um todo; modelagem de dados; modelos de coordenação, cooperação e resolução de conflitos (PAULA, 2005).

Ainda, segundo Paula (2005), sistemas multi-agentes são ideais para representar problemas que incluem diversos métodos diferentes para a solução de um mesmo problema, vários pontos de vista e múltiplas entidades. Assim sendo, sistemas multi-agentes oferecem vantagens na solução de problemas para a programação concorrente e distribuída, assim como as vantagens dos esquemas sofisticados de interação. Exemplos de interação incluem a cooperação no trabalho para se atingir um objetivo comum, a coordenação na organização das atividades da solução do problema, a fim de se evitar interações prejudiciais e possibilitar a exploração de possibilidades benéficas, e a negociação de restrições de subproblemas, fazendo com que se alcance um desempenho satisfatório. É a flexibilidade de tais interações sociais 
que diferencia os sistemas multi-agentes dos softwares convencionais e aumenta o interesse no paradigma de agentes.

Contudo, o conceito de sistema multi-agentes não se faz suficiente para a conclusão deste trabalho, fazendo necessário, também, a abordagem do conceito de agente móvel que, segundo Pereira Filho (2005), são agentes que possuem a capacidade de se mover através da rede. Este tipo de agente deve possuir a capacidade de executar operações em qualquer máquina preparada para recebê-los dentro da rede, independentemente da plataforma utilizada.

Em modelos baseados em agentes móveis, um agente, que é enviado por um usuário, é responsável por realizar as tarefas necessárias para atingir seus objetivos, sendo que o agente irá migrar para o servidor, interagindo com ele localmente, e em seguida, retornar os resultados obtidos para o usuário (OYAMADA \& ITO, 1998). Uma característica de um agente móvel é que o mesmo não necessita que a máquina, onde este teve sua tarefa iniciada, esteja ativa na rede. Esta característica também remete à possibilidade de melhorar a performance do agente, pois caso necessite de um processamento mais intenso pode migar para uma máquina com maior poder de processamento, desta forma sendo interessante para o balanceamento de carga.

Segundo Pereira Filho (2005), os agentes móveis são constituídos de código, estado e atributos, onde o código de um agente é o programa que define o seu comportamento. $\mathrm{O}$ estado do agente é utilizado para que o mesmo possa retomar suas atividades a partir do ponto donde havia parado antes de se mover. E os atributos são utilizados para descrever o agente, sendo que, entre eles existe um identificador único de cada agente, um endereço para onde enviar os resultados, o tempo e a história do agente. 
Finalmente, pode-se referenciar outro termo no mundo dos agentes, os agentes inteligentes. Lucena (2003), enfatiza que, para que os agentes inteligentes "raciocinem" é preciso que estes possuam um modelo do domínio sobre o qual atuam. A abordagem clássica para incorporar conhecimento na construção de agentes propõe o uso de um modelo simbólico do mundo, cujas decisões (ações) sejam tomadas a partir de um raciocínio lógico baseado no casamento de padrões e manipulações simbólicas.

Para se agregar conhecimento a um agente, é necessária a utilização de linguagens de representação de conhecimento, as quais permitem criar bases de conhecimento através de linguagens formais e manipular conhecimento através de máquinas de inferência.

Maes (1997), ressalta que embora os agentes especialistas costumem usufruir da mesma estrutura de sistemas especialistas para armazenar e manipular conhecimento, estes não precisam ter um conhecimento altamente especializado. No geral, agentes especialistas possuem conhecimento de tarefas triviais que gerenciam informações úteis para seus usuários. Conhecimento dinâmico costuma ser outra característica específica de agentes especialistas, pois podem incorporar novos conhecimentos através de interações com outros agentes, usuários e fontes de informação. Este tipo de agente costuma agregar este novo conhecimento de maneira automática, ao contrário dos sistemas especialistas, onde a base de conhecimento é alimentada pelo usuário ou engenheiro de conhecimento. Assim sendo, além de ter o conhecimento necessário, um agente pode agir, ou seja, de acordo com o resultado de um "raciocínio", o agente pode alterar o estado do ambiente, como ilustrado pela Figura 7. Esta figura ilustra um modelo proposto para a criação de agentes especialistas, e segundo o modelo: 
- O agente adiciona à base de conhecimento novas informações que recebe;

- Consulta que ação deve executar;

- Então, executa a ação apropriada.

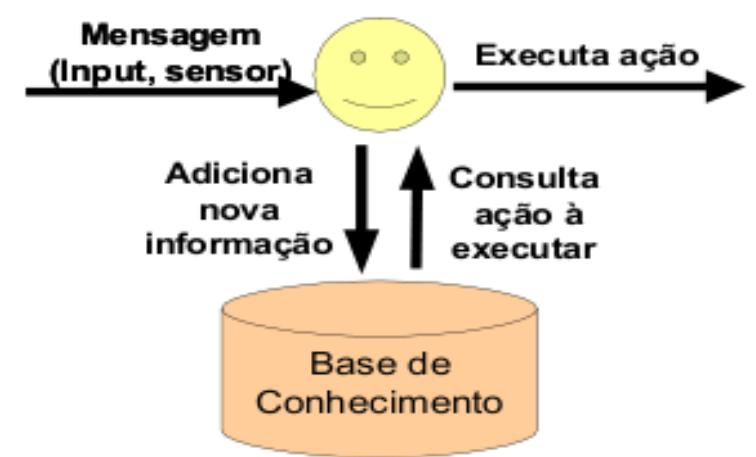

Figura 7: Modelo de Agente Especialista (PENG, 1998)

Devido à complexidade de se gerenciar todas as características que um agente pode assumir, para uma implementação mais eficiente deste trabalho será utilizado o framework JADE, Java Agent Development Framework, que segundo Ribeiro e Escobar (2006) é um framework totalmente implementado na linguagem de programação Java e desenvolvido pelo TILAB, um laboratório de pesquisas incorporado pela Telecom Italia Group. O JADE simplifica a implementação de sistemas multi-agentes baseados na arquitetura de comunicação ponto-a-ponto, por meio de um middleware que segue as especificações da FIPA e de um conjunto de ferramentas que auxilam nas fases de correção de erros e deployment. $\mathrm{O}$ middleware JADE contém um ambiente de execução para os agentes, uma biblioteca de classes e um conjunto de ferramentas gráficas. Além disso o JADE segue os seguintes princípios (RIBEIRO \& ESCOBAR, 2006) (BELLIFEMINE et al, 2004):

- Interoperabilidade: seguindo as especificações da FIPA, os agentes JADE podem interoperar com outros agentes; 
- Uniformidade e portabilidade: o JADE fornece APIs homogêneas independente da versão do Java e da rede utilizada;

- Facilidade de uso: a complexidade do middleware é escondida por um conjunto simples e intuitivo de APIs;

- Filosofia do pay-as-you-go: os programadores não precisam utilizar todas as funções fornecidas pelo JADE.

O JADE possui uma arquitetura robusta que se adapta às mais variáveis restrições de ambientes, desde ambientes com recursos limitados até com arquiteturas complexas. A Figura 8 ilustra de maneira simplificada, a arquitetura do JADE.

Segundo Bellifemine et al, (2004), o principal objetivo do JADE é simplificar e facilitar o desenvolvimento de sistemas multi-agentes garantindo um padrão de interoperabilidade entre sistemas multi-agentes através de um abrangente conjunto de agentes de serviços de sistema, os quais podem facilitar ou até mesmo possibilitar a comunicação entre os agentes, de acordo com as especificações da FIPA que são: 1. serviço de nomes (naming service); 2. páginas amarelas (yellow-page service); 3. transporte de mensagens; 4. serviço de codificação e decodificação de mensagens; 5. biblioteca de protocolos de interação (MORAIS E SILVA, 2003). Um ponto importante a ser destacado é que toda a comunicação entre os agentes é feita através da troca de mensagens. 


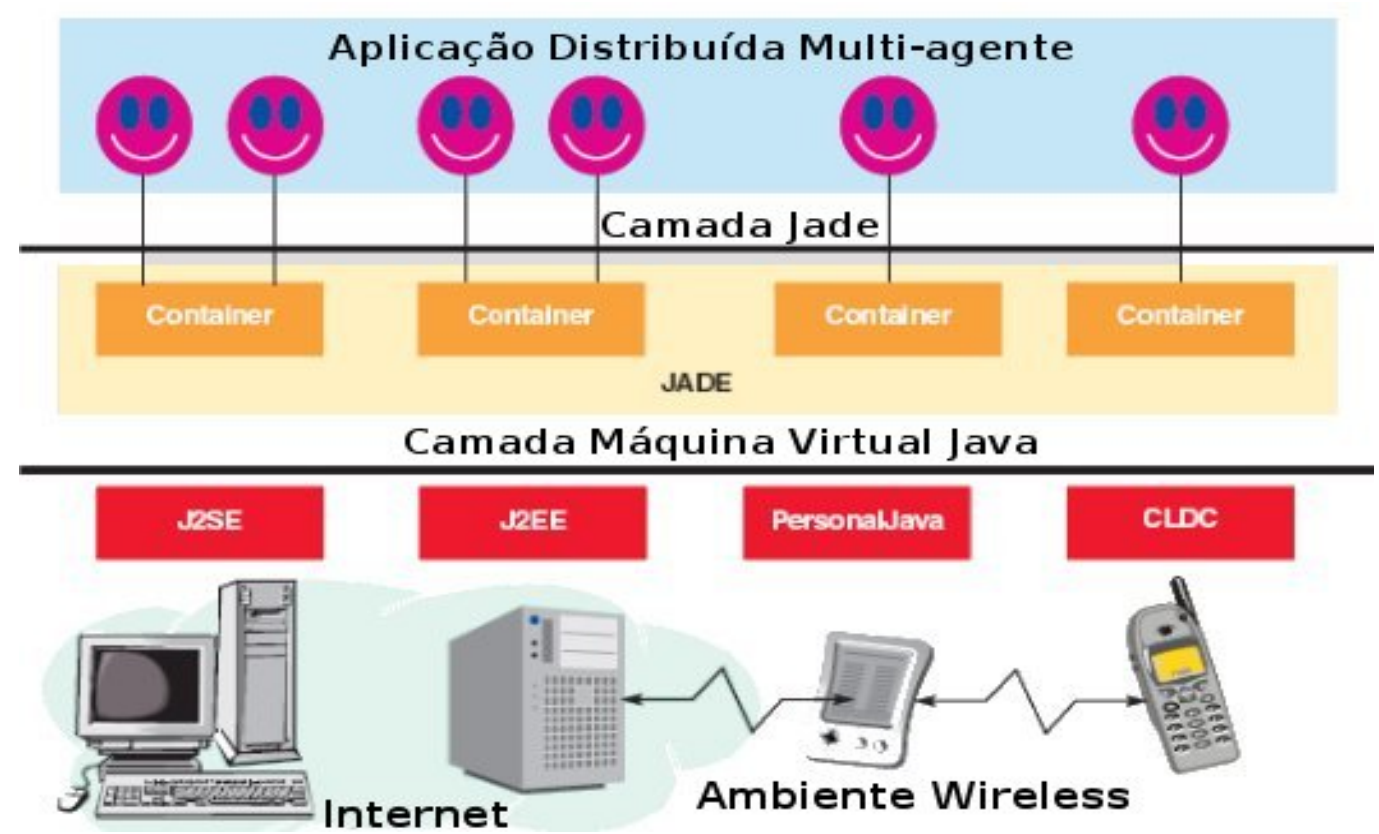

Figura 8: Arquitetura Jade (RIBEIRO \& ESCOBAR, 2006)

Em Morais e Silva (2003), são descritas algumas características que o JADE oferece para a programação de sistemas multi-agentes:

- Plataforma distribuída de agentes;

- GUI (Graphical User Interface - Interface Gráfica de Usuário);

- Ferramentas de debugging;

- Suporte à execução de atividades múltiplas, paralelas e concorrentes de agentes;

- Ambiente de agentes complacente à FIPA;

- Transporte de mensagens;

- Biblioteca de protocolos FIPA;

- Automação de registros;

- Serviços de nomes (Naming Service) em conformidade com os padrões FIPA;

- Integração; 


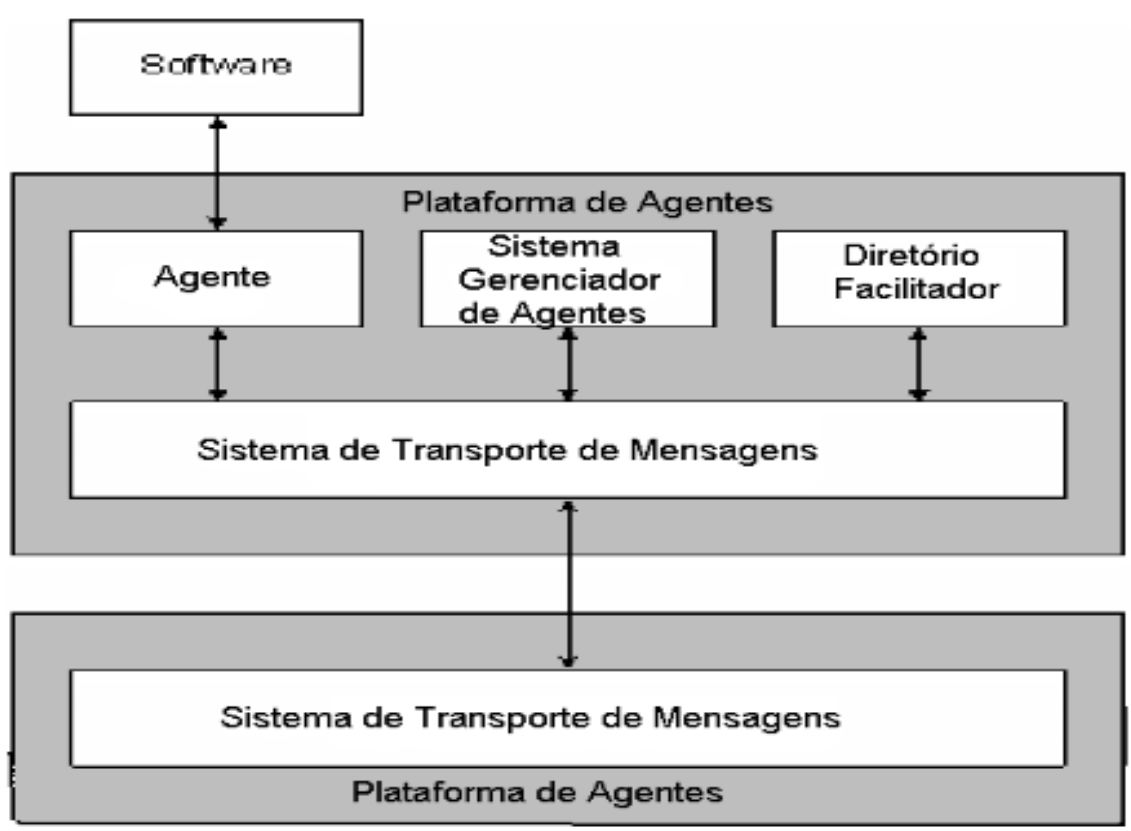

Figura 9: Modelo padrão de plataforma de agentes definido pela FIPA (MORAIS \& SILVA, 2003)

O JADE segue o padrão especificado pela FIPA em sua plataforma, e em Morais e Silva (2003), é descrito um modelo desse padrão. Para melhor ilustrar o padrão deve-se observar a Figura 9.

O modelo é composto pela seguinte estrutura:

- O Agente, é o agente propriamente dito, cujas tarefas são definidas de acordo com o objetivo da aplicação. O agente se encontra dentro da Plataforma de Agentes e realiza toda a sua comunicação, com outros agentes e softwares externos, através da troca de mensagens;

- O Sistema Gerenciador de Agentes, é o agente responsável por supervisionar o acesso e o uso da plataforma de agentes. Deve-se observar que em uma plataforma de agentes existe somente um único Sistema Gerenciador de Agentes. Ele também é responsável por prover o guia de endereços (white pages) e controle de ciclo-de-vida mantendo um diretório de identificadores de agentes (AID - Agent IDentifier) e estado 
de agentes. Cada agente, deve obrigatoriamente, registrar-se no Sistema Gerenciador de Agentes para obter um AID válido;

- O Diretório Facilitador (Directory Facilitator - DF) é o agente responsável pelo serviço de páginas amarelas da plataforma;

- O sistema de transporte de mensagens, também conhecido como canal de comunicação dos agentes (Agent Communication Channel - ACC) é o responsável por toda a comunicação entre agentes dentro e fora da plataforma. Observa-se que todos os agentes, sem exceção, utilizam este canal de comunicação;

Uma característica importante do JADE, a qual também favoreceu a sua escolha para este trabalho, é o fato que o JADE não especifica como o agente deve ser implementado, ou seja, o JADE é neutro no que diz respeito ao agente, não limitando ou especificando que tipo de agente pode ser construído pela plataforma (MORAIS E SILVA, 2003).

\subsection{Reflexão Computacional}

Segundo Souza e Grott (2004), a reflexão computacional refere-se à capacidade de um sistema raciocinar e agir sobre si mesmo. Assim sendo, um sistema reflexivo é o único que provê a representação do seu comportamento, sensíveis à inspeção e adaptação, fazendo com que mudanças sejam visíveis no seu estado ou comportamento, e vice-versa.

Já segundo Hugo e Gadotti (2003), o conceito paradigma de reflexão computacional não é exatamente nova, pois este conceito teve origem na lógica matemática e recentemente, mecanismos de alto nível tornam o esquema de reflexão um aliado na adição de características operacionais a módulos já implementados. 
O termo reflexão remete a dois conceitos distintos no domínio da linguagem natural. Primeiramente o conceito é reflexão com o sentido de introspecção, ou seja, o ato de examinar a própria consciência ou espírito. Outro conceito descreve reflexão como uma forma de redirecionamento da luz. Já no domínio da Ciência da Computação, reflexão computacional retrata ambas as conotações: introspecção e redirecionamento. A primeira denota a capacidade de um sistema computacional examinar sua própria estrutura, estado e representação. A estes três fatores é dado o nome de meta-informação, a qual representa toda e qualquer informação contida e manipulável por um sistema computacional que referencie a si próprio. Por sua vez, a conotação de redirecionamento confere a um sistema computacional a capacidade da auto-modificação de comportamento. Assim sendo, os conceitos de redirecionamento e introspecção, são tipicamente materializados em linguagens de programação sob a forma de interceptação na execução de primitivas da linguagem (SENRA, 2001).

No ponto de vista da Engenharia de Software, reflexão computacional é uma ferramenta de divisão de interesses (separation of concerns), sendo assim, a reflexão computacional permite que programadores desenvolvam programas com um alto nível de abstração e com uma boa modularidade (HUGO \& GADOTTI, 2003).

Souza e Grott (2004), destacam que arquiteturas reflexivas compõem-se de dois níveis: meta-nível e nível-base. No primeiro encontram-se as estruturas de dados e ações que são executadas sobre o sistema objeto que está presente no nível-base. Assim sendo, Fernandes (2009) ressalta que, para que um meta-objeto (meta-nível) monitore um determinado objeto (nível-base), é necessário que se crie uma conexão e associação entre eles. Esta comunicação entre níveis, meta e base, requer um Protocolo de Meta-Objetos (PMO), que permite a troca 
de mensagens e a passagem da execução do programa. No modelo de reflexão computacional, um meta-objeto é responsável por interceptar a solicitação de um objeto, encaminhar esta para outro meta-objeto, que a entregará ao objeto de tutoria capaz de executar a solicitação. O caminho inverso também é considerado. A associação entre os níveis base e meta ligados pelo PMO e a troca de mensagens de objetos é representado na Figura 10.

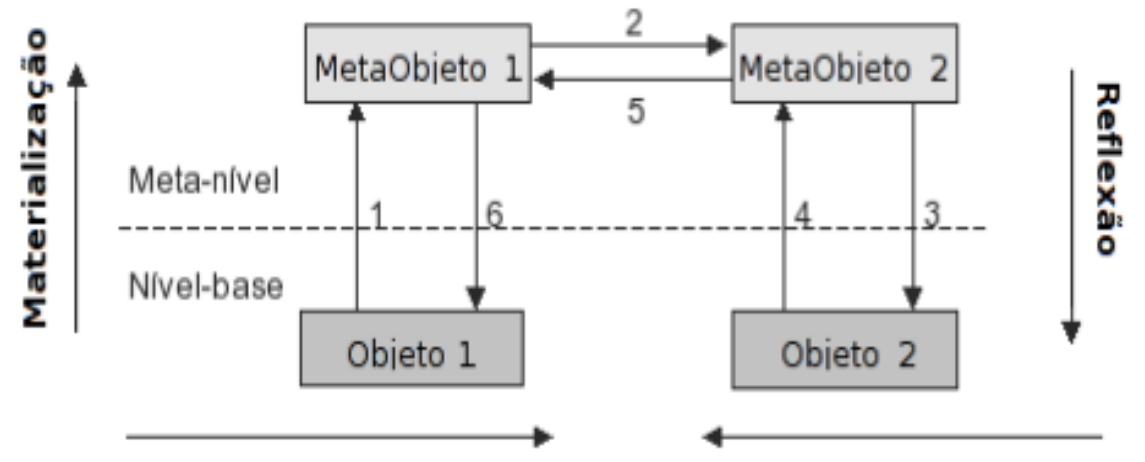

Intercepta, encaminha, entrega, processa, devolve, encaminha, entrega

Figura 10: Fluxo de comunicação entre objetos e meta-objetos (AFFONSO, 2009)

Neste trabalho a reflexão computacional terá um papel importante para a constituição do ambiente onde será feita a busca pelo melhor artefato de software. Assim sendo, o sistema ambiente não fará uma reflexão de si mesmo, mas fará a reflexão nos artefatos de softwares desenvolvidos e que serão reutilizados. Neste contexto de utilização, SUN-REFLECT (2009) descreve que a reflexão computacional, baseada na tecnologia Java, pode ser empregada com o objetivo de se descobrir várias informações que fazem parte dos objetos que compõem o sistema, tais como: atributos, métodos, construtores e classes carregadas na Java Virtual Machine (JVM).

Assim sendo, a Reflexão Computacional agirá como uma ferramenta para decompor os artefatos de software, e irá gerar o conteúdo a ser pesquisado pelos agentes de software na busca dos artefatos a serem reutilizados. Em outras palavras, é por meio da reflexão que se 
extrai toda a lógica dos sistemas.

\subsection{Inteligência Artificial}

A Inteligência Artificial (IA) possui inúmeras definições como a encontrada em Weber-Lee (1998), que a conceitua como um ramo da Ciência da Computação dedicado ao estudo das técnicas computacionais que representam algum aspecto da cognição humana. Nascimento (2001) simplifica a conceitualização de IA, pois a define como o esforço de desenvolver sistemas baseados em computadores que possam simular os seres humanos, ou seja, organizar a solução de problemas de acordo com etapas e passos idênticos ao de um ser humano. Desta forma, com IA as máquinas teriam a capacidade de raciocinar e aprender funções normalmente associadas com a inteligência humana.

Ainda segundo Nascimento (2001), tais sistemas seriam capazes de aprender linguagens naturais, realizar tarefas físicas coordenadas (robótica), usar aparelhos de percepção que informam seu comportamento e linguagem, e ainda emular as ações de um especialista e a tomada de decisão humana. Tais sistemas podem mostrar lógica, raciocínio, intuição e as qualidades de bom senso, as quais são associadas a seres humanos. A inteligência artificial consolidou-se como um campo de estudo em 1956 com a Conferência sobre Inteligência Artificial organizada por MacCarthy com o objetivo de reunir os pesquisadores da época. A Figura 11 mostra algumas áreas de estudo relacionadas com IA.

Para Nascimento (2001), o sucesso dos sistemas de IA está baseado na especialidade, conhecimento e padrões de raciocínio humanos filtrados, porém este tipo de sistema não exibirá a inteligência de um ser humano. Observa-se que a existência de sistemas baseados em 
IA não propõem soluções novas e originais para a solução de problemas, mas sim aplica métodos já estudados pelo homem. Além disso, a existência destes sistemas expande os poderes dos especialistas, mas de maneira alguma os substituem ou são capazes de obter conhecimento superior ao dos especialistas humanos.

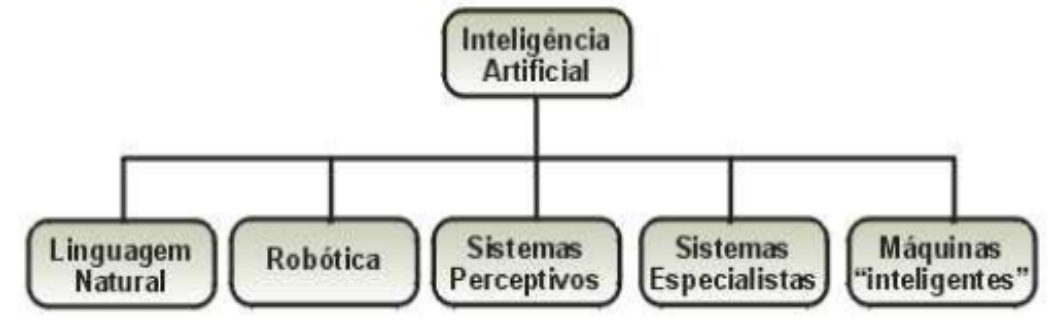

Figura 11: Áreas de estudo em IA (NASCIMENTO, 2001)

Os sistemas baseados em IA estão, a cada dia, mais aplicáveis tanto no meio acadêmico como no meio corporativo, porém, como visto na Figura 11, existem várias áreas que compõem a IA, dentre estas se destacam neste trabalho os sistemas especialistas.

\subsubsection{Sistemas Especialistas}

O conhecimento especialista pode ser definido como uma combinação de um entendimento teórico do problema, com uma coleção de regras heurísticas para resolver problemas, que a experiência demostrou ser efetiva quando aplicada naquele domínio. Assim sendo, os sistemas especialistas são construídos através da extração do conhecimento de um especialista humano, representando-o de uma forma que o computador possa processar e aplicar a problemas semelhantes (LUGER, 2004).

Um sistema especialista típico é composto por (LUGER, 2004): 
a) Interface de Usuário: o usuário interage com o sistema através de uma interface que tem por objetivo simplificar a comunicação e ocultar boa parte da complexidade, como a estrutura interna da base de regras. As interfaces de sistemas especialistas empregam uma série de estilos de usuários, com as interfaces do tipo pergunta e resposta, orientada a menu ou as interfaces gráficas;

b) Base de Conhecimento: é o coração do sistema especialista, pois contém o conhecimento de um domínio particular de aplicação. Num sistema especialista baseado em regras, este conhecimento é representado na forma de regras se...então.... A base de conhecimento armazena tanto o conhecimento geral como informações específicas do caso;

c) Motor de Inferência: aplica o conhecimento, que se encontra na base de conhecimento, na solução de problemas reais. Ele é, essencialmente, um interpretador da base de conhecimento. Em sistemas de produção, o motor de inferência executa o ciclo de controle reconhece-atua. Luger (2004) destaca que é importante manter a base de conhecimento separada do motor de inferência pois:

- esta separação torna possível representar o conhecimento numa forma mais natural. As regras se...então... são mais próximas do modo como as pessoas descrevem suas habilidades para resolver problemas;

- com a base de conhecimento estando separada das estruturas de controle de mais baixo nível, os construtores de sistemas especialistas podem se concentrar em capturar e organizar o conhecimento para solução do problema, deixando de se preocupar com os detalhes de sua implementação;

- estando separados, a alteração em qualquer uma das partes não causa efeitos colaterais em outras partes; 
- separando-se a estrutura de controle do programa e o conhecimento, permite que o mesmo software de controle e de interface seja reutilizado em vários sistemas.

d) Dados Específicos do Caso: o sistema especialista deve manter este tipo de informação que compreende: os fatos, conclusões e outras informações relevantes ao caso em consideração. Estas informações são armazenadas separadamente da base de conhecimento;

e) Subsistema de Explanação: permite que o programa explique sua linha de raciocínio ao usuário. Explanações estas que incluem justificativas para as conclusões do sistema;

f) Editor da Base de Conhecimento: estes editores ajudam o programador a localizar e corrigir erros na execução do programa, frequentemente acessando a informação fornecida pelo subsistema de explanação. Estes editores também podem auxiliar na adição de conhecimento novo.

Seguindo os conceitos abordados anteriormente, surgiram vários sistemas especialistas no mercado, porém cada qual implementava um motor de inferência diferente, isso devido à falta de um padrão a ser seguido para este tipo de sistema. Assim sendo, a Sun Microsystems definiu a Java Rule Engine API (JSR 94), pois observou-se que a utilização de regras de negócio poderia tornar mais ágil o desenvolvimento de algumas aplicações (SUN-JSR94). Desta forma, a Sun Mycrosystems disponibilizou um motor de inferência (rule engine) para sistemas baseados em sua tecnologia Java. Por sua vez, vários sistemas foram criados seguindo a JSR94; dentre eles pode-se destacar o Drools.

O Drools foi lançado pela Codehaus e posteriormente incorporado pela JBoss como um de seus projetos, fase em que foi conhecido como JBoss Rules, porém o nome Drools, da 
versão comunitária, prevaleceu. O Drools consiste em uma ferramenta de código aberto (open-source) e baseada nas regras de negócio (standards-based business rule engine) que facilita o acesso, gerenciamento de políticas de negócio (regras) de forma simples, rápida e eficiente. Ele permite separar as regras de negócio do código fonte da aplicação, e com isto, analistas de negócios e processos, auditores e até mesmo gerentes corporativos podem gerenciar esta política, sem que para isso possuam conhecimento técnico de como a aplicação foi projetada e implementada.

\subsection{Repositório de Software}

Vários trabalhos que tem o foco na reutilização de software descrevem que o repositório de software, tratado como repositório de componentes pela área, é um dos fatores que determina o sucesso de um projeto de reutilização. Assim Lucrédio e Prado (2004) apresenta um conjunto de requisitos para um mecanismo eficiente de busca e recuperação de componentes, a saber:

- Elevada precisão e recuperação. Elevada precisão quer dizer que a maioria dos componentes recuperados são relevantes. Elevada recuperação quer dizer que poucos elementos relevantes são identificados, sem ser recuperados;

- Segurança. O acesso aos repositórios deve ser restritos a pessoas que realmente necessitem, inclusive se tais repositórios estiverem disponíveis em uma rede com acesso à Internet;

- Formulação de consultas. O mecanismo de busca deve fornecer meios de 
auxiliar o usuário na formulação das consultas;

- Descrição dos componentes. O mecanismo de busca é responsável por identificar os componentes relevantes ao usuário de acordo com a consulta formulada e executada sobre as descrições dos componentes;

- Familiaridade no repositório. O reuso ocorre com mais frequência através de componentes bem conhecidos. Entretanto, o mecanismo de busca deve explorar e recuperar componentes familiares ao que seria o alvo inicial da busca.

- Interoperabilidade. Em um cenário que envolve diversos repositórios distribuídos, é inevitável pensar em interoperabilidade. Assim, um mecanismo de busca deve ser baseado em tecnologias que facilitem sua expansão e integração com outros sistemas;

\subsection{Classificação de Artefatos de Software}

Um dos pontos de maior relevância deste trabalho é a recuperação dos artefatos de software para que possam ser reconfigurados e/ou reutilizados em outros projetos. Contudo, para tornar a reconfiguração de software viável, é essencial que se desenvolvam maneiras eficientes de classificar um grande conjunto de projetos, tendo em vista uma recuperação eficaz destas informações. Caso contrário, a reconfiguração perde seu sentido, pois todo o processo de seleção, compreensão e reconfiguração seria tão ineficiente que se tornaria mais simples desenvolver um novo artefato do que localizá-lo nos repositórios de software.

Pimenta (1998) ressalta duas técnicas de indexação para a classificação de artefatos de software: vocabulário livre e vocabulário controlado. Ainda segundo Pimenta (1998), a 
indexação é uma forma implícita de classificação, pois componentes que possuem termos indexados em comum são efetivamente membros de uma classe ou grupo de componentes.

\subsubsection{Vocabulário Livre}

Para a classificação de artefatos de software a partir de um vocabulário livre, deve-se elencar um número de termos, os quais após serem indexados são utilizados para representar um artefato de software. A recuperação é baseada na indexação simples da coleção de artefatos usando termos relevantes, assim sendo, o indexador pode atribuir as palavras chaves com total liberdade.

Segundo Pimenta (1998), existem duas maneiras de explorar um vocabulário livre, variando a forma em que os termos são associados aos componentes. Os termos podem ser associados manualmente; este tipo de associação tende a resultar na representação inconsistente dos componentes. Outra forma de associação dos termos é derivá-los automaticamente da documentação do software.

Pimenta (1998) destaca, ainda, que a principal crítica feita ao uso deste modelo de classificação é a inconsistência que ele proporciona.

\subsubsection{Vocabulário Controlado}

A principal diferença desta técnica é o conjunto restrito de termos para representar e indexar componentes. Os sistemas que usufruem deste tipo de classificação podem incluir uma lista simples de termos indexados. A combinação destes termos é utilizada para representar qualquer artefato, e a indexação simples implementa a recuperação de artefatos de 
software.

Segundo Pimenta (1998), tal técnica fornece melhor consistência que as ferramentas que utilizam a técnica de vocabulário livre, pois o poder efetivo do vocabulário controlado está na capacidade de impor uma classificação utilizando seu próprio vocabulário. Garante-se assim, uma melhor consistência interna.

A técnica de vocabulário controlado pode, ainda, ser implementada de diversas maneiras, sempre levando em conta como os termos estão relacionados. A seguir tem-se algumas formas de utilização da técnica de vocabulário controlado.

\section{Classificação por Faceta}

Segundo Mello (2005), um esquema de classificação por faceta consiste na representação de artefatos de software através de descritores construídos por termos pertencentes a categorias pré-definidas de um domínio particular, onde cada categoria ou faceta é identificada por um nome e um conjunto de termos, os quais fazem parte do vocabulário controlado. Tal vocabulário descreve aspectos relevantes da faceta.

Pimenta (PIMENTA, 1998) lembra que quando o classificador usa essa tecnologia, ele deve expressar uma classe composta e determinar, como facetas, o arranjo de grupos de classes elementares. Os elementos que compõem as facetas são denominados termos.

Melo (2004) afirma que a classificação baseada em facetas foi proposta originalmente por um aluno e uma bibliotecária, como uma técnica eficaz para a gerência de informação da biblioteca. Melo (2004) complementa que classificação por faceta é considerada a principal concorrente do sistema de classificação decimal de Dewey para a classificação de coleções 
bibliográficas e ressalta ainda, que Prieto-Diaz e Freeman (PRIETO-DÍAZ \& FREEMAN, 1987) foram os primeiros a sugerir a possibilidade de adotar o esquema facetas para a classificação e recuperação de artefatos de software.

Portanto, uma faceta pode ser definida como uma coleção de termos de um domínio, na qual podem ser incluídos todos os possíveis valores de atributo. Simplificando o entendimento, uma faceta não é mais que um par atributo-valor, onde tem-se um atributo fixado pela faceta e vários valores associados ao atributo. $\mathrm{O}$ interessante do esquema de facetas é que as facetas podem variar em número, tamanho e natureza, o que permite sua vasta utilização e combinação com outras tecnicas de classificação.

\section{Classificação por Palavra-Chave}

Mello (2005) descreve que existem várias abordagens que adotam mecanismos de indexação na representação de componente em repositórios. A indexação, ou seja, o processo de identificar as palavras-chave e armazená-las em uma estrutura de índice, pode ser realizado de forma manual ou automática. Assim sendo, na técnica manual, um usuário deve indicar palavras-chave que definem o artefato. Por outro lado, a indexação automática torna o sistema responsável por identificar as palavras-chave através de uma análise na documentação ou nos comentários dos códigos fonte.

\section{Classificação Baseada na Estrutura do Componente}

Outra forma de recuperação dos artefatos de software é através da indexação dos próprios elementos que compõem a estrutura deste software, como: nome de classes, nome e 
tipo dos atributos, nome, parâmetros e tipo de retorno dos métodos, etc. Mello (2005) apresenta com destaque dois trabalhos que utilizam esta abordagem.

O primeiro trabalho é de Zarenmki e Wing (1995) que propõem um método de recuperação de artefatos baseado na busca pelas assinaturas das funções. Segundo Mello (2005), este método descreve o comportamento de uma operação usando uma linguagem de especificação formal, Larch/ML. O autor destaca ainda que este método descreve o comportamento através dos parâmetros nas assinaturas das operações, e sem levar em consideração a semântica completa do artefato.

Outro trabalho apresentado por Mello (2005) é o sistema “Agora”, criado por Seacord et al. (1998), o qual orienta que os componentes sejam representados por cinco campos: componentes, nomes, propriedades, métodos e eventos. Essas informações são obtidas através de mecanismos de introspecção, que permitem ao programa extrair estas informações de sua própria estrutura. Uma importante característica deste método é que ele não armazena propriamente o componente, mas somente as informações de representação e sua localização.

Este último método se assemelha muito ao método proposto no presente trabalho, onde as informações que serão indexadas fazem parte da estrutura do software em questão. Assim sendo, todo projeto de software passa por um mecanismo de introspecção, baseado na tecnologia de reflexão computacional abordada no capítulo 2.4 , onde são extraídas todas as informações da estrutura do projeto. Após essa extração, as propriedades do projeto são armazenadas em repositórios de busca, que estarão disponíveis para a recuperação desta informação. 


\section{Classificação por Meio de Informação Semântica}

Outro meio de executar a recuperação de artefatos seria através da utilização de informações semânticas, como, por exemplo, a utilização de ontologias. Sugumaran e Stoney (2003) propõem este tipo de abordagem para a classificação e recuperação de componentes. Os autores utilizam-se de ontologias e modelos de domínios para melhorar a eficácia de buscas por componentes. Os modelos de domínio estão organizados em objetivos, processos e ações. Para complementar as informações do modelo de domínio é utilizada uma ontologia que apresenta sinônimos e relaciona os termos do domínio. Assim sendo, é feita a classificação dos componentes através destas informações.

Neste trabalho também faz-se uso da classificação por meio de informação semântica, onde os dados extraídos da estrutura do projeto são indexados levando em consideração sua informação semântica. Esta indexação dar-se-á através de um tesauro, assunto abordado na seção 2.7.

Contudo, ao se levantar o assunto de classificação através da semântica das palavras, surgem vários problemas como a vasta quantidade de termos (palavras simples ou compostas) existentes, o que torna difícil a tarefa de classificar e selecionar componentes. Para minimizar estes problemas, além do conceito de tesauro utilizados neste trabalho, outras técnicas como dicionário de termos e a rede de termos semanticamente relacionados são abordadas por Carlo (1999) em seu trabalho. 


\section{Dicionário de Termos}

Descrever o código de um componente através de uma tupla formada por alguns termos apresenta, segundo Carlo (1999), um pequeno problema: a presença de termos sinônimos. Este é um problema, uma vez que os sinônimos podem produzir descrições diferentes para um mesmo componente de software, gerando assim uma certa confusão no momento da classificação do mesmo. Por isso, Carlo (1999) propõe a criação de um dicionário de termos sinônimos baseado em um vocabulário controlado.

Um dicionário de termos é necessário para agrupar todos os sinônimos sob um único conceito. O termo que melhor descreve o conceito é selecionado como termo representativo e a este é associado um conjunto de sinônimos, reduzindo assim as ambigüidades da classificação e melhorando consideravelmente a qualidade dos resultados de uma busca nos repositórios (CARLO, 1999). Ainda segundo Carlo (1999), outra vantagem no emprego de um dicionário de termo é a possibilidade de controlar da quantidade de termos preferenciais que estarão presentes nele, pois, aumentando-se o número de termos associados a um grupo particular, ou quebrando-se os grupos em subgrupos, consegue-se variar a quantidade de termos disponíveis para a classificação (PIETRO-DÍAZ e FREEMAN, 1987). Um exemplo da estrutura de um dicionário de termos é mostrado em Tabela 2.

Com o dicionário de termos consegue-se eliminar a ambigüidade de alguns termos, selecionando um contexto específico através da lista dos termos representativos.

Durante a fase de seleção, o dicionário é utilizado na escolha dos termos que descrevem o componente desejado pelo usuário. Segundo Carlo (1999), este deve necessariamente montar a descrição do componente a partir do conjunto de termos 
representativos, evitando assim, o emprego de sinônimos.

Tabela 2: Exemplo de entradas no dicionário de termos (CARLO, 1999)

\begin{tabular}{|c|c|}
\hline \multicolumn{2}{|c|}{ Atributo Função } \\
\hline Termo Representativo & Sinônimos \\
\hline adicionar & incrementar/somar/totalizar \\
\hline comparar & testar/casar/checar/verificar \\
\hline complementar & negar/inverter \\
\hline enumerar & contar/medir/listar \\
\hline abrir & conectar/anexar \\
\hline associar & unir /juntar \\
\hline mostrar & imprimir/exibir/listar \\
\hline criar & produzir/gerar/construir/formar \\
\hline retirar & eliminar/remover \\
\hline substituir & trocar/converter/atualizar \\
\hline
\end{tabular}

Contudo, esta solução não se torna totalmente funcional no contexto do presente trabalho, pois os relacionamentos semânticos existentes entre os termos vão muito além de simples sinônimos. Assim sendo, a utilização desta técnica, por si só, não mostrou-se interessante, forçando-se a sua complementação.

\section{Rede Semântica}

O conceito de uma rede semântica de termos torna-se mais interessante que o dicionário de termos, pois dentro de uma grande coleção, vários termos apresentam entre si alguma relação de proximidade. Por exemplo, o termo "substituir" e "remover" são semanticamente próximos, uma vez que ambos denotam troca. Aproveitando esta relação da linguagem natural, Carlo (1999), derivou uma rede semântica de termos, com o intuito de 
determinar a proximidade ou grau de similaridade entre os termos. Assim sendo, através da rede semântica, pode-se recuperar componentes similares aos desejados, os quais possuem em seus identificadores, termos semanticamente próximos ao identificador procurado.

Carlo (1999) propõe que a rede semântica é uma modificação do gráfico conceitual de pesos elaborado por Pietro-Díaz (1985), tornando-o mais simples e compreensível, eliminando a idéia de super-tipos e especificando a distância entre termos através da associação direta de pesos.

Segundo Carlo (1999), a rede semântica nada mais é que um grafo direcionado, cujos nós correspondem a termos específicos, e cujos arcos possuem pesos que determinam o grau de relacionamento entre os termos. Assim sendo, para cada termo, é possível identificar os demais termos que apresentam algum relacionamento semântico e/ou conceitual com o mesmo. A esta ligação é associada um valor (peso), não negativo, indicando o grau de relacionamento entre dois termos: quanto menor o peso, maior o nível de proximidade entre ambos. É de extrema importância ressaltar que estes pesos são derivados de maneira subjetiva de acordo com a experiência e a intuição do usuário. Assim sendo, observa-se que a rede semântica tem sua concepção manual, ao contrário de outros sistemas que empregam a indexação automática. Os valores dos pesos correspondem a estimativas que são utilizadas para medir a proximidade entre os termos, não possuindo assim, nenhuma analogia com o 'mundo real'.

Ostertag et al. (1992), mostram que alguns termos da rede semântica podem não estar diretamente conectados, indicando que não existe uma relação direta entre eles. No entanto, é possível estimar a distância ou grau de similaridade entre tais termos. Se considerarmos que a distância entre os termos $t_{1}$ e $t_{2}$ é definida como o peso do menor caminho entre $t_{1}$ e $t_{2}$ dentro 
da rede. Se nenhum caminho existe, a distância é dita infinita. Obviamente, se $t_{1}$ e $t_{2}$ forem o mesmo termo, a distância entre ambos é zero.

As redes semânticas são projetadas inicialmente baseadas na intuição e no conhecimento de um especialista de domínio (ED), ou seja, a rede semântica é projetada para cada domínio específico. Para cada termo $t$ de um atributo at são associadas distâncias a um pequeno conjunto de termos at que representam alguma similaridade com $t$. Estas associações definem grupos de termos intimamente relacionados. Um exemplo pode ser visto na Figura 12 que mostra os grupos associados aos termos substituir, modificar e adicionar.

A integração destes grupos define uma rede semântica combinada, a qual permite a comparação de termos que não estão relacionados diretamente em um grupo. A Figura 13 mostra uma rede semântica parcial definida pelos grupos mostrados na Figura 12. Com base nesta rede pode-se, por exemplo, estimar o grau de similaridade entre os termos 'substituir' e 'concatenar'.

Em uma rede semântica deste tipo as distâncias são fundamentais durante o processo de recuperação de artefatos. Caso um termo em uma consulta não seja exatamente nenhum dos termos disponíveis na coleção, o usuário tem a possibilidade de tentar encontrar na rede o próximo termo mais semelhante ao procurado. Assim sendo, consegue recuperar descrições de artefatos muito similares ao desejado, o que é uma característica fundamental para a metodologia empregada no presente trabalho. 


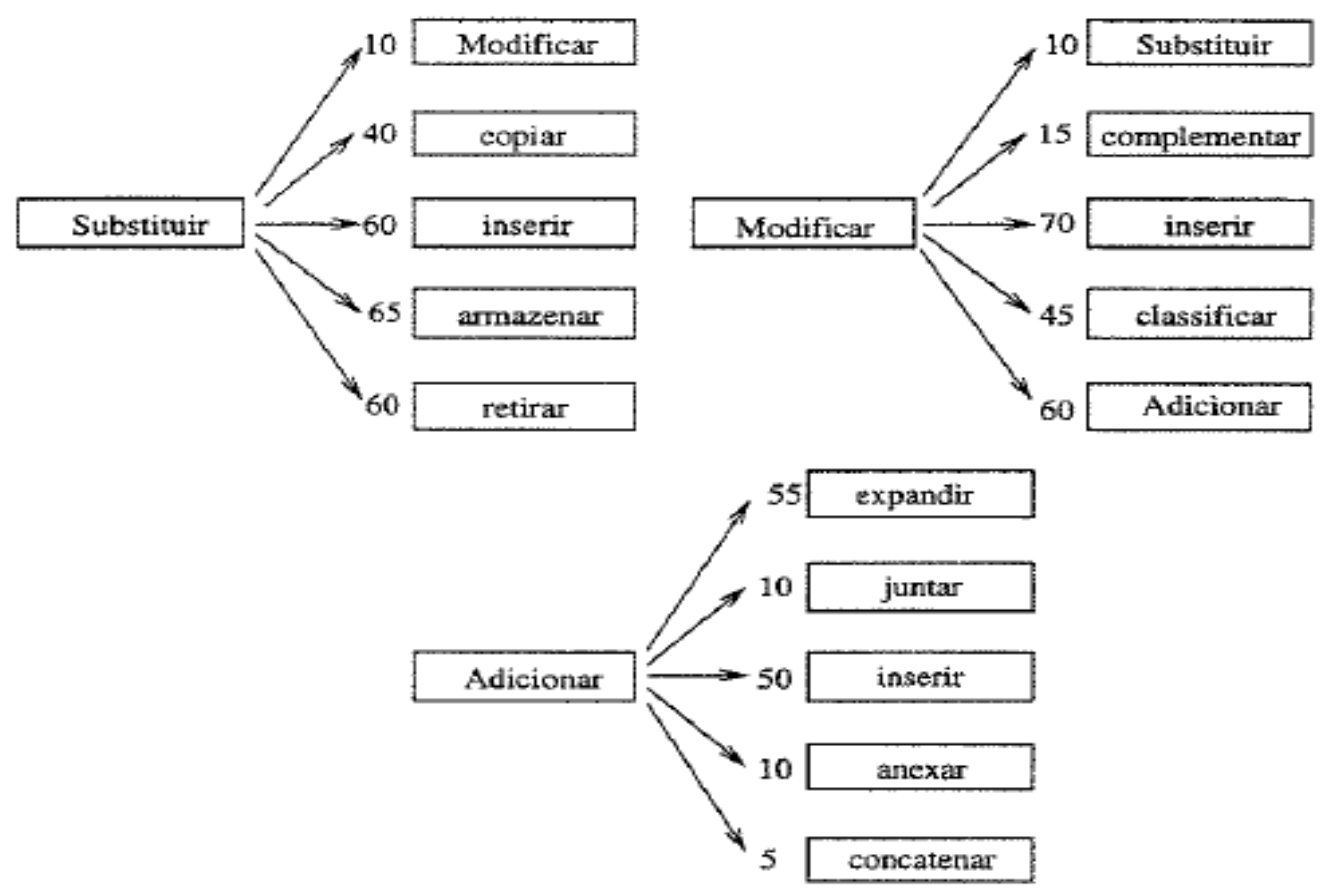

Figura 12: Grupos de termos relacionados (CARLO, 1999)

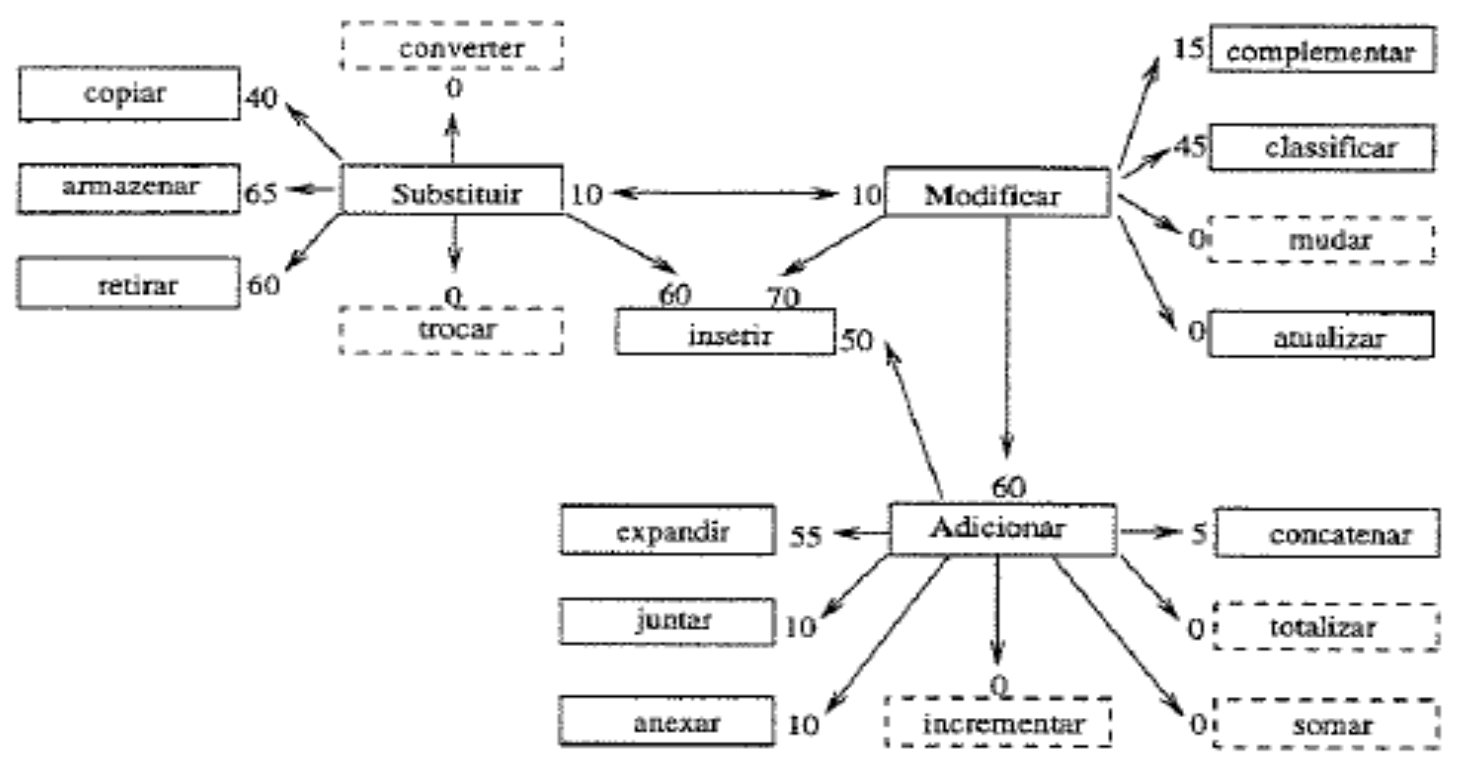

Figura 13: Associação de grupos de termos relacionados(CARLO, 1999) 
A rede semântica apresenta-se como uma forte candidata a ser utilizada neste trabalho, porém tem uma característica que faz com que sua utilização seja um tanto complicada, devido à dependência total e subjetiva do especialista de domínio, o qual deve determinar as distâncias existentes entre os termos. Contudo, existem projetos que tornam a rede semântica menos subjetiva. Uma alternativa é a das wordnets, que estão sendo desenvolvidas para diferentes idiomas. Wordnets são bases de dados onde unidades lexicais (palavras e expressões), pertencentes às categorias dos substantivos, verbos, adjetivos e advérbios, organizam-se por meio de relações semânticas, como sinonímia, hiperonímia, hiponímia, etc (LIMA; NUNES; VIEIRA, 2007).

O ideal seria juntar tanto a definição de dicionário de termos como os relacionamentos existentes na rede semântica. Para isso utiliza-se a técnica de indexação do tesauro, assunto da próxima seção.

\section{Tesauro}

Após o estudo dos conceitos de dicionários de termos e redes semânticas, fica claro que os mesmo precisam passar por uma remodelagem para ampliar sua usabilidade em sistemas que necessitam de informação semântica para a recuperação de qualquer tipo de informação. Assim sendo, optou-se por outra metodologia de trabalho que combine as características de dicionário de termos e de rede semântica. Esta metodologia baseia-se no tesauro.

Uri Miller define um tesauro como: "Um modelo léxico-semântico de realidades conceituais ou constituintes, expressas na forma de um sistema de termos e suas relações, que oferece acesso via diferentes aspectos e é usado como ferramenta de processamento e busca 
de uma unidade de recuperação de informação" (MILLER, 1997).

O termo tesauro tem suas origens provenientes do grego e do latim, cujo significado vem a ser "tesouro de palavras", já que o objetivo deste tipo de dicionário é oferecer uma riqueza em conceitos e suas relações semânticas, de forma a ter uma grande abrangência em um determinado domínio de conhecimento (PIZZATO, 2003).

Um tesauro pode contemplar um domínio de conhecimento específico ou pode até mesmo ser genérico. Os tesauros genéricos são normalmente criados manualmente, enquanto que a criação de tesauros de forma automática envolve o desenvolvimento de modelos de tesauros sobre um domínio específico (PIZZATO, 2003).

O tesauro também é uma técnica que se utiliza de um vocabulário controlado, pois procura minimizar as características da linguagem natural restringindo o vocabulário de indexação e consulta, de forma que uma idéia possa ser expressa somente de uma única maneira.

Um tesauro agrega os conceitos de dicionário de termos, ao permitir que termos sinônimos sejam relacionados com os conceitos da rede semântica, por possuir a característica de relacionar qualquer termo que tenha um relacionamento com outros termos do domínio. É importante observar que os relacionamentos existentes no tesauro não são como na rede semântica, ou seja, através da atribuição subjetiva de pesos, mas sim através de relacionamentos léxicos existentes entre os termos e definidos na estrutura de um tesauro. Portanto, um tesauro mostra-se mais usual que a rede semântica pois diminui a subjeção com que os termos estão relacionados. 


\section{Estruturação de Tesauros}

A estruturação de um tesauro é um tópico muito importante, pois ela definirá como o tesauro será utilizado, e se este tesauro oferece compatibilidade com outros tesauros, vantagens e limitações de utilização. A estrutura básica de um tesauro está baseada em um conjunto de relações semânticas entre os itens que o compõem. Jurafsky e Martin (2000) apresenta em seu trabalho os principais tipos de relações semânticas, mostradas a seguir:

- Homonímia: ocorre quando dois itens lexicais de significados distintos têm a mesma escrita e pronúncia. Como por exemplo o termo "cadeia", que pode ser interpretado como "casa de detenção" ou "um conjunto de lojas ou estabelecimentos pertencentes a um mesmo grupo".

- Sinonímia: ocorre quando duas palavras distintas em escrita e pronúncia têm o mesmo significado. Por exemplo o termo "toca-disco" que é sinônimo de "vitrola".

- Antonímia: ocorre quando duas palavras possuem significados contrários. Como por exemplo os adjetivos "feliz" e "triste".

- Hiperonímia: ocorre quando o significado de um lexema abrange o significado de outro lexema, ou seja, o significado de um é mais genérico que o significado de outro. Por exemplo, o termo "aeronave" é um hiperônimo de "avião".

- Hiponímia: é a relação inversa da hiperonímia. Ocorre quando um termo tem significado mais específico que outro. Por exemplo "tico-tico" é um hipônimo de "ave". 
- Meronímia: ocorre quando o significado de um lexema faz parte ou é uma porção do significado de outro lexema. Por exemplo, as palavras "capa" e "folhas" são merônimos de "livro".

Pizzato (2003), ressalta que estas relações são expressas de modos distintos em diferentes tesauros. Contudo, há algumas normas para a construção de tesauros, entre elas a ISO 2788 e a ANSI/NISO Z39.19, as quais tem como objetivo guiar o desenvolvimento de tesauros. Neste trabalho optou-se pela norma ISO 2788, a qual é descrita a seguir.

\section{Norma ISO 2788}

A Organização Internacional para Padronização (ISO) é uma instituição não governamental criada com a missão de promover o desenvolvimento de padronizações que facilitem a troca internacional de bens e serviços. A ISO desenvolve trabalhos no intuito de gerar normas internacionais, as quais são publicadas como padrões ISO. A norma para desenvolvimento de tesauros monolíngues é denominada ISO 2788.

Segundo Pizzato (2003), a estrutura estabelecida pesa ISO 2788 diferencia dois tipos de termos: (1) termo preferencial (TP), que deve ser utilizado como índice e deve representar um conceito único; e (2) termo não-preferencial (TNP), que remete o usuário a um termo preferencial sinônimo, ou quase-sinônimo.

Outras formas de referência entre palavras são definidas com o uso de ligações ou relações semânticas. A ISO define três tipos de relações semânticas: (1) equivalência; (2) hierarquia; (3) associatividade. 
A relação de equivalência, que representa sinônimos, quase-sinônimos e variantes lexicais (ex.: óptica e ótica), é expressa através das ligações semânticas USE e UF (used for). A relação USE é utilizada para ligar um TNP com um TP (ex.: entulho USE lixo) e a relação recíproca UF leva um TP a um TNP (ex.: lixo UF entulho).

A hierarquia é representada de acordo com as ligações semânticas BT (Broader Term) e NT (Narrower Term). A relação BT (hiperonímia) é utilizada para ligar um termo específico a outro termo mais genérico do mesmo (ex.: mamífero BT vertebrados), e a relação NT (hiponímia) é utilizada de forma contrária, ou seja, ligando um termo genérico a outro mais específico (ex.: planta NT árvore). As relações hierárquicas podem também representar a ligação entre um objeto e suas partes constituintes, isso através das ligações BTP (Broader Term Partitive) e NTP (Narrower Term Partitive). Estas relações ocorrem quando um termo é parte constituinte de outro (ex.: cordas BTP violão e teclado NTP teclas) (PIZZATO, 2003).

Na última relação semântica, a associatividade, enquadram-se os termos que não possuem relação de equivalência nem hierárquica, porém apresentam alguma ligação. Este tipo de relacionamento semântico é representado por RT (Related Term), onde as relações podem ser simétricas (ex.: professor RT estudante e estudante RT professor) ou assimétricas (ex.: briga RT raiva porém raiva RT briga não é verdadeira pois, quando ocorre briga normalmente existe raiva, porém nem sempre quando existir raiva ocorrerá uma briga).

Pizzato (2003) destaca que a relação RT é a mais complexa de todas, pois pode representar diversos tipos de informação como: tempo, lugar, produtos, causas, agentes, instrumentos, entre outros.

Foi necessária uma adequação da norma para a utilização do tesauro neste trabalho, pois simplesmente definir que um termo está associado (RT) com outro, poderá resultar em 
buscas com conteúdo irrelevante. Assim, definiu-se para relação de associatividade um valor entre 0 e 1 , onde 0 representa nenhuma associação e 1 representa uma associação perfeita. Esta prática foi importada do conceito de rede semântica e quem definirá essa "distância" entre os relacionamentos é o especialista de domínio.

\subsection{Considerações Finais}

Este capítulo apresentou um conjunto de assuntos relacionados com o desenvolvimento deste trabalho. Ao se abordar o tópico de sistemas distribuídos tem-se por objetivo formalizar o conceito da distribuição do sistema, ou seja, um sistema que esteja sendo utilizado aparentemente em um computador local, pode estar distribuído em vários computadores ao redor do mundo. Este tópico frisa também a possibilidade de se utilizar partes de sistemas de terceiros através da utilização de webservices, os quais são serviços disponíveis através de uma rede de computadores, local ou Internet, e acessados por aplicações que possuem permissão de acesso a este aplicativo. É importante destacar que os sistemas distribuídos colaboram no quesito reutilização de software, pois ao utilizar um sistema disponibilizado em forma de serviço (webservice) poupa-se trabalho de desenvolver um sistema que possui as mesma atribuições de um sistema já desenvolvido e operante.

Quanto às tecnologias de integração de sistemas, os conceitos mostram que não é uma tarefa trivial utilizar diferentes sistemas para a solução de um mesmo problema, mas mostram alternativas para que isso aconteça. Ao se utilizar o Java Message Service JMS API, podem haver dois tipos de comunicação entre sistemas, uma assíncrona e outra síncrona. Na primeira uma aplicação envia a mensagem para uma fila específica de mensagens localizada em um 
servidor dedicado a este tipo de comunicação. Quando desejar, a aplicação a qual se destina a mensagem, acessa sua fila, particular de mensagens e "lê" as mensagens que foram enviadas a esta, caracterizando assim uma comunicação assíncrona, pois não é necessário que o recebedor da mensagem esteja ativo no instante em que a mensagem é enviada. Por outro lado, na comunicação síncrona, uma aplicação envia uma mensagem para uma fila única de mensagens no servidor. Por sua vez a aplicação a qual se destina a mensagem deve, obrigatoriamente, estar conectada a esta fila para receber a mensagem, pois, caso contrário, outra aplicação pode receber esta mensagem e descartá-la por não se tratar de uma mensagem endereçada a esta terceira aplicação.

Já a tecnologia de agentes de software tanto integra como distribui aplicações, pois devido à sua mobilidade os agentes de software podem utilizar o processamento de vários computadores para a solução de um problema. Os agentes podem integrar sistemas quando recebem uma tarefa e, para que se cumpra o objetivo especificado nesta tarefa, o mesmo deve migrar entre os sistemas de uma rede a fim de, ao final de sua execução, trazer de volta ao usuário uma solução do problema. Desta forma, o agente integra os vários sistemas que disponibilizam uma interface para que os agentes trabalhem com os serviços disponibilizados. Tais serviços podem ser outros agentes ou qualquer outro tipo de sistema. Os agentes terão um papel fundamental para o desenvolvimento deste trabalho pois farão a integração do sistema local do desenvolvedor com o servidor de aplicações a serem reutilizadas, fazendo com que ambos os sistemas pareçam apenas um. Além disso, os agentes são responsáveis pela indexação e recuperação dos artefatos de software que poderão ser reconfigurados. 
Por outro lado, ao se descrever a tecnologia de Reflexão Computacional fez-se menção à API Java Reflection, desenvolvida pela Sun Microsystems, que é a responsável por fazer a reflexão dos objetos utilizados no desenvolvimento de um projeto. Neste projeto é importante destacar que serão utilizados os métodos de introspecção da API Java Reflection. Estes métodos permitem refletir sobre as características de um objeto como: atributos, métodos, construtores entre outros. Mas é importante lembrar que a reflexão computacional pode ser utilizada com outros objetivos como o de permitir que um objeto tenha suas características alteradas em tempo de execução.

Outro tópico abordado foi a Programação Baseada em Regras que apresenta alguns conceitos para tentar definir a Inteligência Artificial, e também para delimitar o problema para ser resolvido por especialistas, na verdade sistemas especialistas. Tais sistemas possuem uma ampla utilização durante a história, e também são aplicados em diferentes áreas. Este tipo de sistema tem por característica principal a utilização de uma base de conhecimento, ou seja, o mapeamento do conhecimento de um especialista humano traduzido em regras do tipo se...então.... Tais regras são interpretadas pelo motor de inferência, que levando em considerações algumas situações passadas a ele, através da interface com o usuário, chega a uma solução do problema.

Por fim, foi abordado o tópico de classificação de artefatos se software. Um assunto muito discutido na atualidade, principalmente sob o ponto de vista da reutilização de software. Neste tópico, foram discutidas as várias formas de classificar um artefato, tanto através de um vocabulário livre como através de um vocabulário controlado. Destacou-se neste tópico a utilização do vocabulário controlado, um vocabulário para cada domínio, e, além disso, as formas de classificação baseadas na estrutura dos componentes, ou seja, das informações 
obtidas através da introspecção dos projetos de software, e também baseadas na classificação por meio de informações semânticas, onde foram abordados os tópicos de dicionário de termos e a rede semântica de termos, dando um enfoque maior aos tesauros. Tesauros os quais englobam os conceitos de dicionário de termos e de rede semântica. Neste trabalho, os tesauros terão papel importante, pois indexarão os projetos inseridos nos repositórios. E por meio dos tesauros que as buscas de artefatos serão executadas para uma posterior reconfiguração. Busca que será atribuída aos agentes de software.

O próximo capítulo irá descrever a metodologia para o desenvolvimento de software reconfigurável. 


\section{Capítulo 3}

\section{Ambiente de Apoio ao Desenvolvimento de Software Reconfigurável}

\subsection{Considerações Iniciais}

Inicialmente, este capítulo apresenta a metodologia de desenvolvimento de software reconfigurável que foi proposta por Affonso (2009). Em sua metodologia, Affonso (2009), prevê um ambiente que facilite o desenvolvimento de software voltado a reutilização e reconfiguração. Para isso, prevê a utilização de um repositório de software, onde são armazenados os projetos já desenvolvidos. Na realidade este repositório é dividido em um conjunto de outros repositórios, cada um com objetivos distintos.

Após a contextualização da metodologia de desenvolvimento de software reconfigurável são abordados os módulos que devem apoiar tal metodologia, módulos estes especializados em armazenar, indexar e recuperar as informações dos projetos desenvolvidos com base na metodologia proposta por Affonso(2009). 
Este capítulo apresenta na seção 3.2 a Metodologia de Desenvolvimento de Software Reconfigurável proposta por Affonso. A seção 3.3 aborda os Módulos Auxiliares do Ambiente; esta seção está dividida em três assuntos principais: a subseção 3.3.1 aborda o Tesauro que é parte fundamental deste trabalho; a subseção 3.3.2 explica todo o processo para se incluir um novo projeto nos repositórios; já a subseção 3.3.3 apresenta a metodologia empregada na recuperação das informações dos projetos. Por fim a seção 3.4 traz as considerações finais do capítulo.

\subsection{Metodologia de Desenvolvimento de Software Reconfigurável}

O interesse fundamental do presente trabalho é apoiar e auxiliar a metodologia de desenvolvimento de software reconfigurável proposta por Affonso, Rossi e Rodrigues (2008), onde descrevem uma nova metodologia de desenvolvimento de software, baseada principalmente na reutilização e reconfiguração de softwares já desenvolvidos para outros projetos.

Em sua proposta, Affonso, Rossi e Rodrigues (2008) descrevem a utilização de um repositório de software, cujo objetivo é armazenar os artefatos de software produzidos em diferentes projetos. Tais repositórios servirão como uma biblioteca de projetos; assim, no momento do desenvolvimento de um novo projeto, os engenheiros de software deverão consultar esta biblioteca. Esta consulta deve, no entanto, ser realizada de forma otimizada, ou seja, os resultados dessa busca devem satisfazer ao máximo os interesses dos engenheiros de software. 
O repositório de artefatos de software idealizado por Rossi, Affonso e Rodrigues (2008) é composto por vários repositórios com diferentes objetivos como pode ser visto na Figura 14.

O repositório de características, ou repositório de informações, é construído a partir do código fonte dos projetos, como classes, componentes e serviços. Porém esse repositório não armazena o código-fonte do projeto, mas sim, as características desse projeto. Tais características são extraídas do projeto através de um método de introspecção, por meio da qual são recuperadas as classes, interfaces, heranças, atributos e seus tipos, métodos, tipos de retorno dos métodos, assim como seus parâmetros e tipos, entre outras características. Essas informações devem ser armazenadas de forma estruturada em um arquivo XML o qual será armazenado no repositório de características. Porém, este repositório é dividido em domínios, e a equipe de desenvolvimento (Especialista de Domínio, Engenheiro de Software e Engenheiro de Implementação) deve especificar a qual domínio este projeto pertence. Um modelo da divisão de domínios dentro do repositório de características pode ser observado na Figura 15.

O repositório de documentação começa a ser gerado desde a fase de análise de projeto, onde os engenheiros de softwares, auxiliados por uma ferramenta de modelagem, inserem tags de documentação seguindo o padrão javadoc (SUN-JAVADOC, 2009). Segundo Rossi, Affonso, Rodrigues (2008), nesta etapa é feita a descrição do projeto. 


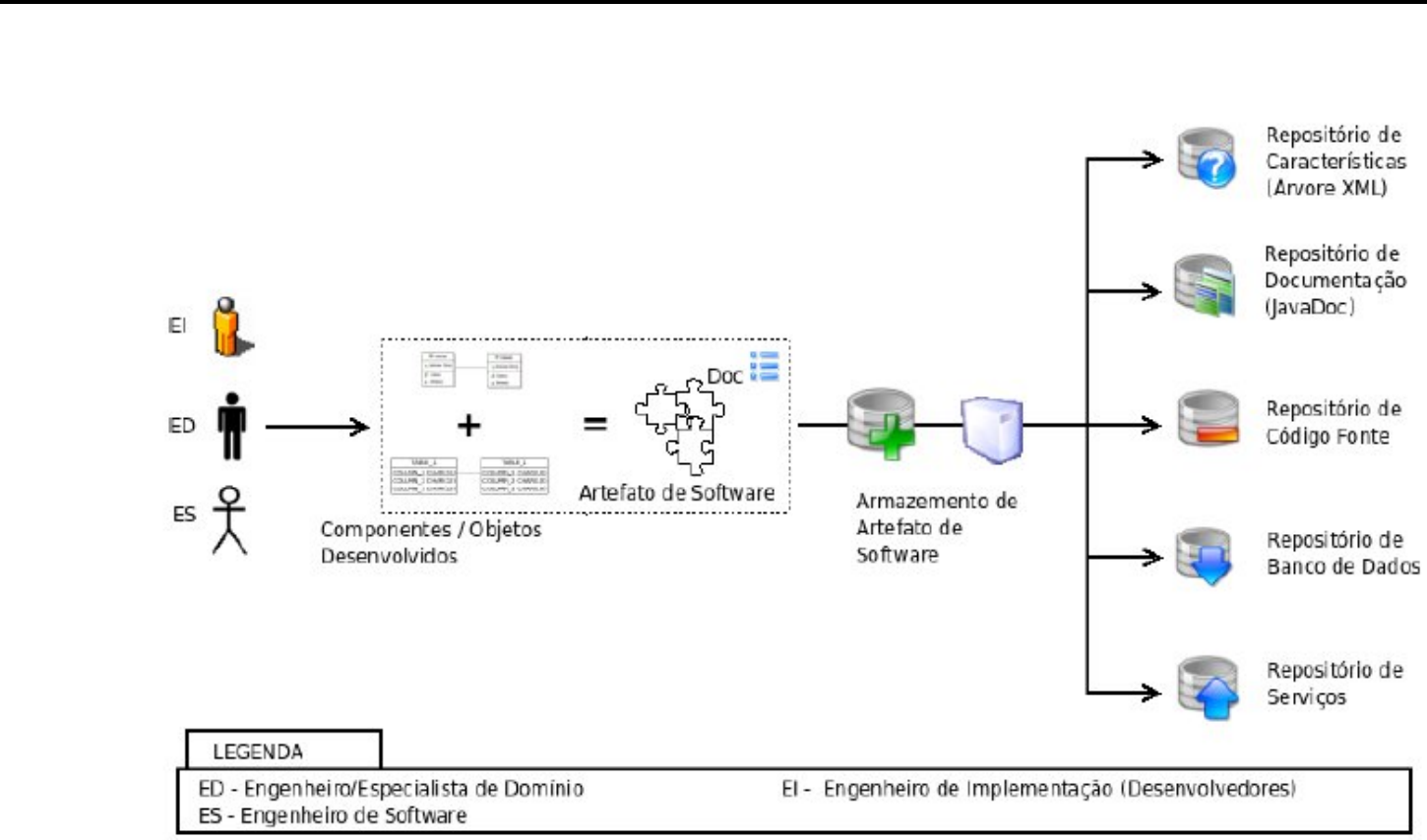

Figura 14: Repositório de Software (ROSSI; AFFONSO; RODRIGUES,2008)

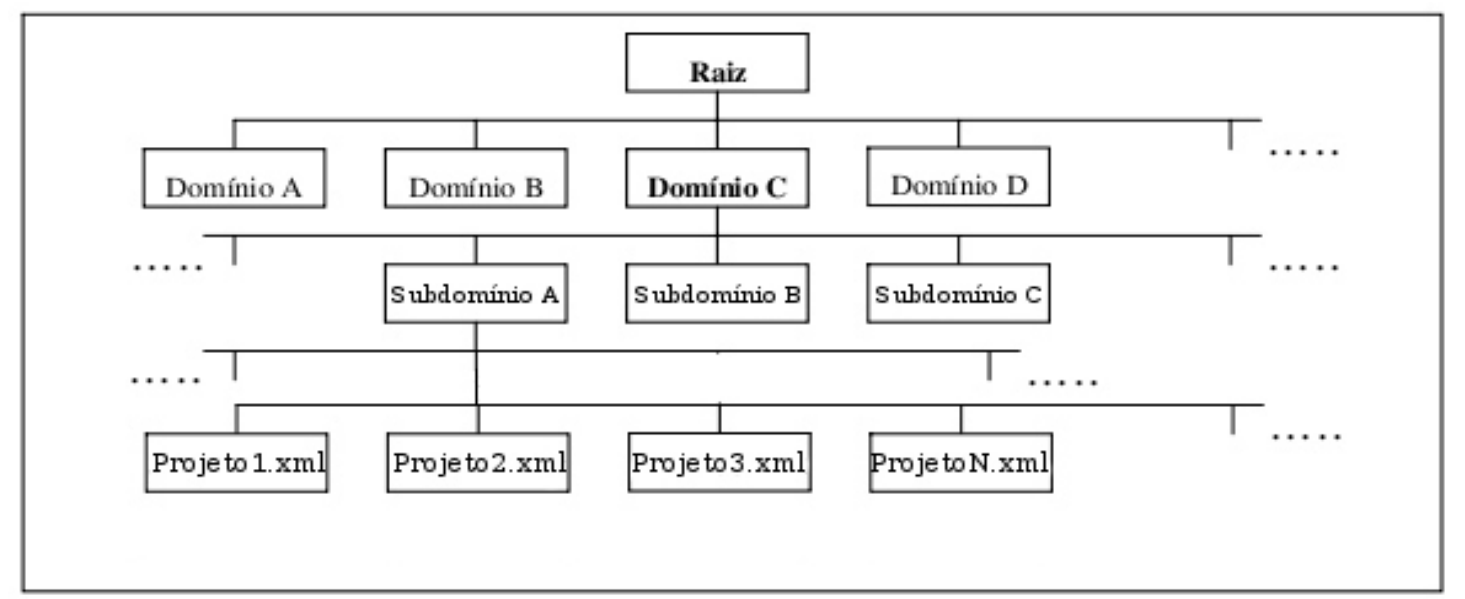

Figura 15: Estrutura do Repositório de Características

O repositório de código-fonte armazena os códigos-fonte gerados na implementação do projeto. Rossi, Affonso, Rodrigues (2008) salientam que este repositório é acionado somente quando é tomada uma decisão a respeito de qual artefato é selecionado pelos engenheiros de software e/ou invocado pelo ambiente em tempo de execução. 
O repositório de banco de dados é constituído por um conjunto de scripts SQLs, Structured Query Language, responsáveis por gerar a estrutura de armazenamento de objetos. Segundo Affonso, Rossi, Rodrigues (2008) estes scripts podem ser gerados de duas maneiras: automática ou manual.

O último repositório descrito por Rossi, Affonso e Rodrigues (2008) é o repositório de serviços, o qual é formado pelas funcionalidades mais genéricas que podem ser utilizadas em diversos sistemas com domínios distintos. Este repositório é alimentado quando uma funcionalidade do sistema pode ser reutilizada em outros sistemas; dessa forma, a equipe de desenvolvimento transforma uma funcionalidade específica de um sistema em um serviço disponível a outras aplicações, por meio de webservices.

Seguindo a metodologia de desenvolvimento de software reconfigurável proposta por Affonso, Rossi e Rodrigues (2008), o engenheiro de software pode realizar uma busca por informações nos repositórios de informações para selecionar o melhor objeto/componente/serviço que possa ser reutilizado no desenvolvimento de novos projetos. Este passo do desenvolvimento é representado pela Figura 16.

A metodologia de Affonso, Rossi e Rodrigues (2008) prevê que o desenvolvimento de novos projetos pode ocorrer de duas maneiras: manual, pelos engenheiros de software, e automática realizada por mecanismos automáticos (agentes de software e ferramentas) do ambiente. 


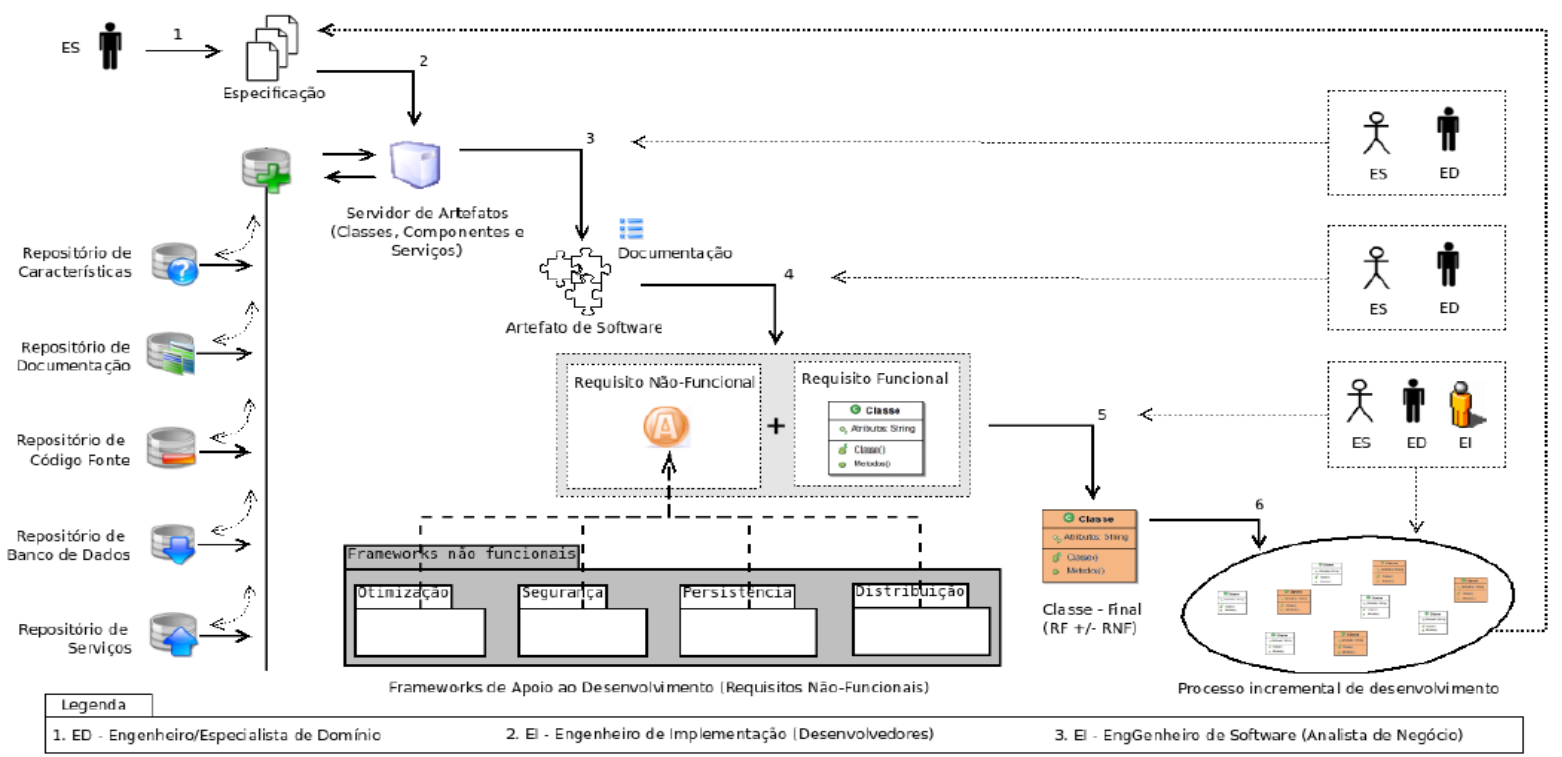

Figura 16: Metodologia de Desenvolvimento de Software Reconfigurável (AFFONSO; ROSSI; RODRIGUES, 2008)

No desenvolvimento manual, os engenheiros de software, conhecendo as especificações do sistema, fazem uma consulta ao repositório de software para verificar a existência de artefatos (classes, componentes e/ou serviços) que podem ser reutilizados e/ou reconfigurados para o novo projeto. Essa busca deve ocorrer de maneira transparente, pois diferentes repositórios de software (vários repositórios espalhados pelo ambiente) deverão ser consultados, apesar do engenheiro dever ter a impressão de estar executando a busca em um repositório local.

O desenvolvimento de forma automática ocorre no ambiente de execução. Nesse ambiente objetos que não podem executar as solicitações vindas de clientes, de objetos tutores, ou de monitores, encaminham uma requisição aos repositórios, que podem ou não atender ao cliente. Caso os repositórios não possam atender às solicitações, são disparados agentes móveis que farão uma busca por soluções pelo ambiente de execução e, quando as 
encontram, encaminham ao mecanismo de inteligência para decidir qual delas deve ser processada.

Para que a metodologia de desenvolvimento de software reconfigurável seja possível, ela deve ser apoiada em um conjunto de ferramentas capazes de diminuir a complexidade da busca, e, por outro lado, aumentar a satisfação dos resultados encontrados, evitando assim a perda de tempo do engenheiro na análise de resultados irrelevantes. Desta forma, quando um engenheiro de software inicia um novo projeto, o mesmo, tendo conhecimento das especificações do sistema, informa a um agente de software as características desejadas no artefato que busca. $\mathrm{O}$ agente, por sua vez, percorre todos os repositórios, mais especificamente os repositórios de características, em busca dos artefatos que mais se aproximam da especificação desejada. $O$ agente realiza a busca baseado na informação semântica existente nos requisitos informados pelo engenheiro. A Figura 17 demonstra este processo.

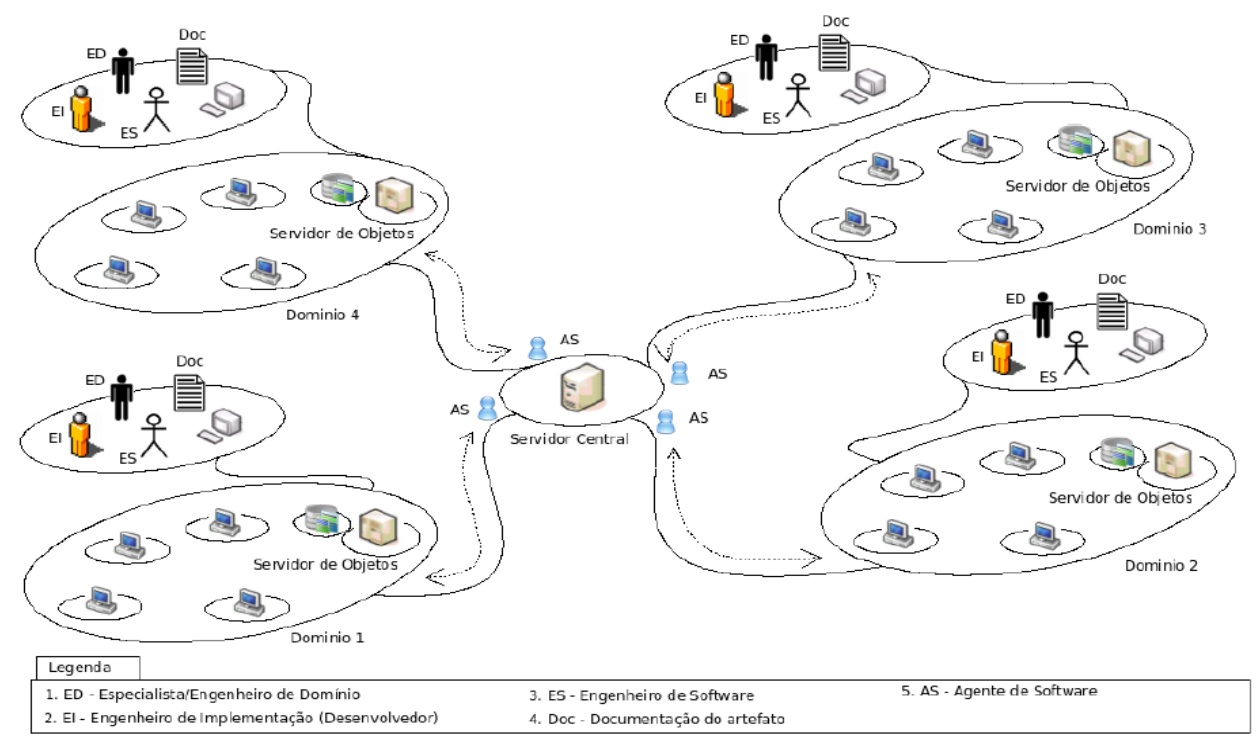

Figura 17: Ambiente de Desenvolvimento de Software Reconfigurável (AFFONSO, 2009) 
Assim, o ambiente proposto por Affonso, Rossi e Rodrigues (2008) necessita de algumas tarefas complementares, as quais fazem parte do presente trabalho. Essas tarefas serão tratadas como módulos que mais tarde serão incorporados ao trabalho inicial de Affonso (2009), o qual implementa o ambiente como um todo. Dentre os módulos abordados neste trabalho destacam-se duas tarefas principais. Primeiramente, a tarefa de inserção dos projetos nos repositórios. Nesta fase é necessário extrair as características dos projetos e também indexá-las a partir de um tesauro definido previamente. A segunda tarefa consiste da busca por artefatos nos repositórios. Esta busca é realizada por agentes de software que percorrem o tesauro em busca dos melhores resultados para serem apresentados aos engenheiros.

A seguir serão abordados os módulos que foram implementados neste trabalho.

\subsection{Metodologias Auxiliares ao Ambiente de Desenvolvimento de Software Reconfigurável}

Esta seção discute os módulos criados neste trabalho, e que são divididos em duas partes, os módulo para a inclusão de novos projetos e os módulos para a recuperação das informações de projetos. Os primeiros módulos são os responsáveis por incluir novos projetos no repositório de software. Já os módulos de recuperação consistem em uma busca com o objetivo de retornar somente resultados relevantes aos engenheiros. Ambos os módulos utilizar-se-ão de tesauros como indexadores, ou seja, o módulo que insere o projeto nos repositórios deve indexar as características do projeto em um tesauro. Por outro lado, o módulo responsável pela recuperação de projetos, realiza suas buscas nos tesauros específicos de cada domínio. 
Capítulo 3 - Ambiente de Apoio ao

Assim, antes da discussão da metodologia e dos módulos que auxiliarão a metodologia de desenvolvimento de software reconfigurável, faz-se necessária a explicação sobre como o tesauro é desenvolvido, pois o mesmo faz parte de todas as outras atividades deste trabalho.

\subsubsection{Tesauro}

\section{Criação do Tesauro}

Este trabalho utilizou o tesauro como ferramenta de indexação pois, como visto no Capítulo 2, o tesauro apresenta tanto as característica de um dicionário de termos (tratamento de sinônimos) quanto as características de uma rede semântica de termos (relacionamentos semânticos entre os termos). O tesauro definido neste trabalho é uma adaptação do tesauro proposto na ISO 2788.

O tesauro consiste de um arquivo do tipo XML onde estão armazenados todos os termos de forma estruturada. Deve-se ressaltar que existe um tesauro para cada domínio especificado, ou seja, o tesauro deve conter apenas os termos de um domínio restrito, termos estes que são definidos pelo Especialista de Domínio (ED).

Os termos do tesauro devem possuir pelo menos uma relação semântica, seja ela qual for. As relações semânticas previstas neste trabalho são as relações de equivalência, de hierarquia e de associatividade. Cada um dos termos possui uma referência para os termos que estão a ele relacionados.

Para entender melhor os relacionamentos do tesauro, a seção a seguir discute todos os relacionamentos previstos no tesauro. 


\section{Definição dos Relacionamentos}

O tesauro é um dicionário de termos que se diferencia de outros dicionários por tratar das várias relações semânticas existentes entre os termos. Relações que são assunto desta seção.

Inicialmente serão tratadas as relações de equivalência, que como visto anteriormente, são as relações que tratam dos sinônimos, quase-sinônimos e variantes lexicais. Ao definir um termo, o ED deve definir se este é um termo preferencial, ou seja, um termo que pode classificar todas as palavras sinônimas, quase-sinônimas e variantes lexicais. Se o termo for uma termo preferencial, o ED define todos os sinônimos deste termo existentes no domínio como sendo termos não-preferenciais ligados ao termo preferencial. Porém, se o ED identificar que o termo não representa um termo preferencial, deve identificar outro termo, dentre os sinônimos, para exercer essa função, assim, um termo preferencial pode possuir outro termo preferencial.

Para representar um termo preferencial, o ED usufrui da ligação semântica USE; por outro lado, para termos não preferenciais, utiliza da ligação UF (Used For). Um detalhe importante é que pode existir uma hierarquia entre os termos preferenciais e não preferenciais, ou seja, um termo preferencial pode estar ligado a vários termos não-preferenciais, que por sua vez são ligados a outros termos não-preferenciais. Um exemplo deste tipo de relacionamento semântico pode ser observado na Figura 18, onde o termo "Biologia" é um termo preferencial de "Ciências Biológicas" ("Ciências Biológicas" USE "Biologia"), que por sua vez é um termo preferencial de "Estudo da Vida" ("Estudo da Vida" USE "Ciências Biológicas"). No exemplo, pode-se abstrair que a recíproca também é verdadeira, como, por 
Capítulo 3 - Ambiente de Apoio ao

exemplo, o termo "Biologia" é usado para representar o termo "Ciências Biológicas" ("Biologia" UF “Ciências Biológicas"). Deve-se observar que todo termo pode possuir apenas um termo preferencial, porém pode ser o termo preferencial de vários outros termos.

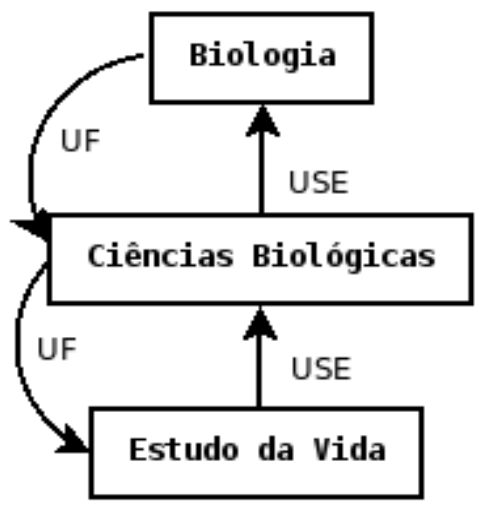

Figura 18: Representação dos relacionamentos de equivalência

O segundo tipo de relação semântica tratada são as relações de hierarquia, utilizadas para representar termos específicos e genéricos do domínio. Este tipo de relação trata também dos relacionamentos de particionamento, ou seja, termos que fazem parte da definição de outros termos. A definição do relacionamento entre o termo genérico e o específico dá-se pela ligação NT (Narrower Term); já o relacionamento entre os termos específico e genérico dá-se pela ligação BT (Broader Term). Exemplos destas ligações podem ser vistos na Figura 19, onde o termo "Planta" é dito como um termo genérico do termo "Árvore" ("Planta" NT "Árvore"). Para os relacionamentos de particionamento são utilizadas as ligações BTP (Broader Term Partitive) e NTP (Narrower Term Partitive), onde BTP liga a parte ao todo e NTP liga o toda com sua parte, como pode ser observado na Figura 19 nos relacionamentos entre os termos "Árvore" (todo) e "Caule", "Raiz" e "Folha" (partes). 
O último tipo de relação tratada, e também mais complexa que as demais, é a relação de associatividade. Nesta relação estão enquadrados todos os termos que não atendem a nenhuma das outras relações citadas. Esta relação é representada pela ligação semântica RT (Related Term), porém esta relação não define quão relacionados os termos estão. Optou-se, então, por uma adequação da ISO 2788, definindo para cada uma das relações de associatividade, uma "distância", a qual representa a proximidade do relacionamento. Como no dicionário de termos, esta "distância" é subjetiva e de responsabilidade do ED. A Figura 20 representa este tipo de relação.

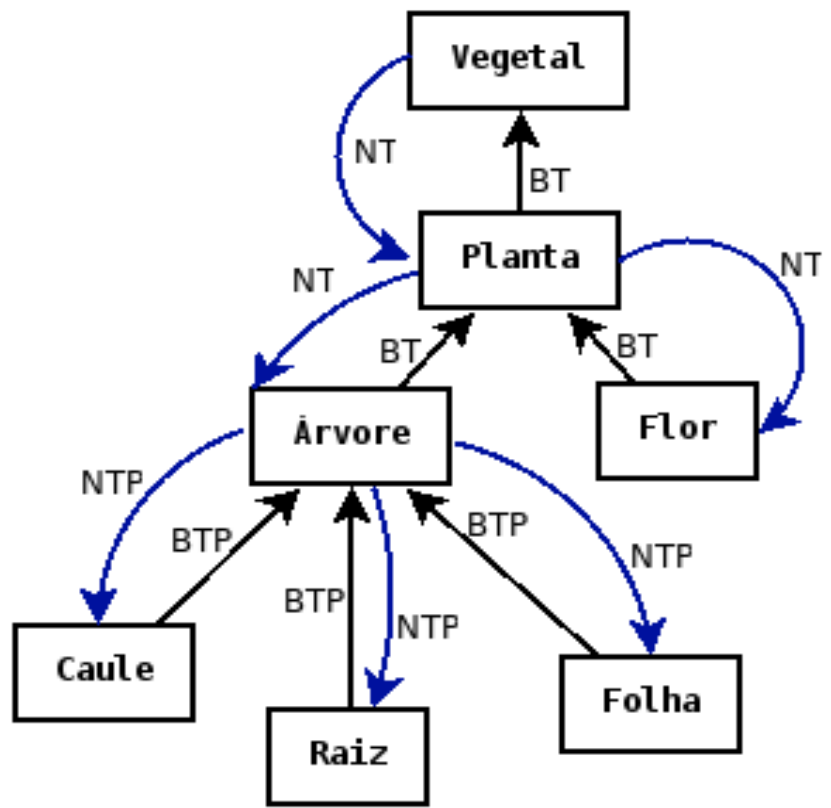

Figura 19: Representação dos relacionamentos de hierarquia

A Figura 20 representa os vários tipos de relações de associatividade. Dentre elas observa-se a relação entre os termos "Planta" e "Fotossíntese"; esta é uma relação de associatividade simétrica, pois "Planta" está relacionada com "Fotossíntese" ("Planta" RT “Fotossíntese") e "Fotossíntese" está relacionada com "Planta" ("Fotossíntese" RT "Planta"). 
Capítulo 3 - Ambiente de Apoio ao

Nesta relação observa-se uma "distância" de 0,9 , que foi atribuída subjetivamente e determina que os termos estão muito relacionados, pois não existe fotossíntese sem uma planta e não existe planta sem fotossíntese.

Por outro lado, a Figura 20 também contempla a relação de associatividade entre os termos "Planta" e "Hidroelétrica", palavras que sem uma análise profunda nunca estariam relacionadas. Porém, a relação entre elas é de associatividade assimétrica, pois existe a relação entre os termos "Planta" e "Hidroelétrica" ("Planta" RT "Hidroelétrica"), contudo, não existe relação entre "Hidroelétrica" e "Planta". Observa-se também que este relacionamento tem uma "distância" muito próxima de zero, o que indica que apesar de existir um relacionamento, os termos estão pouco, ou muito pouco, relacionados.

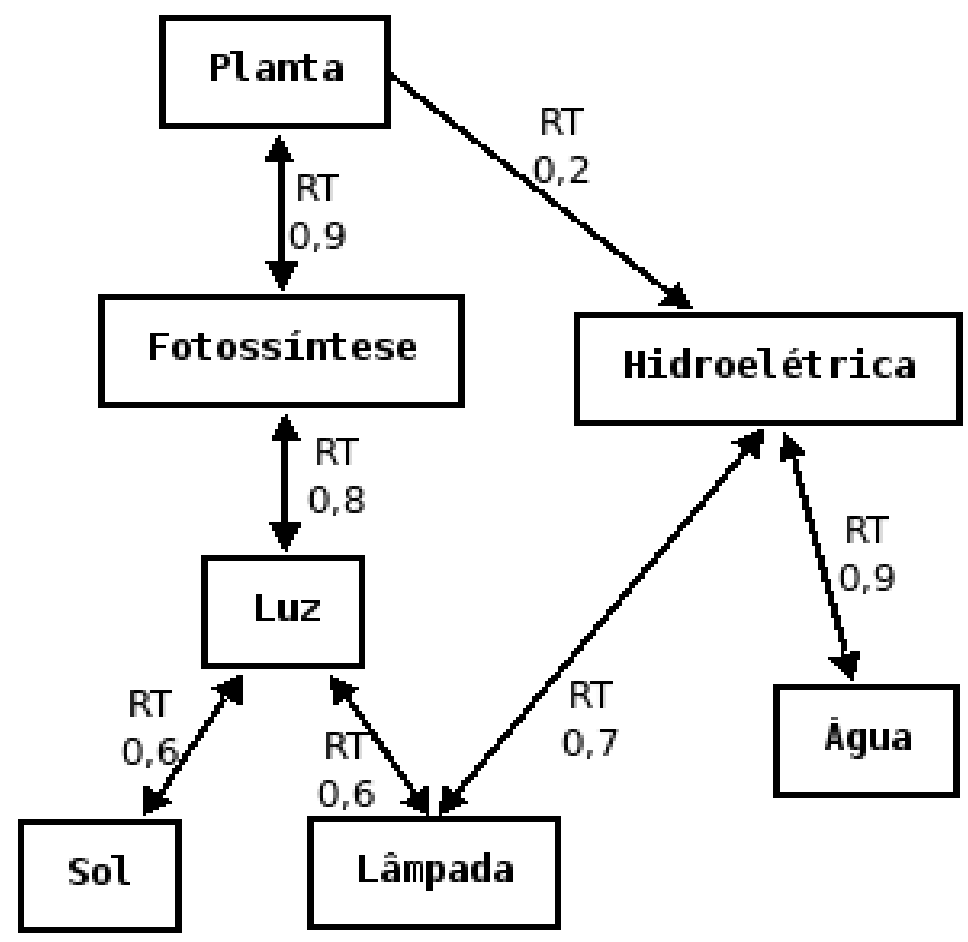

Figura 20: Representação das relações associatividade 


\section{Ferramenta de Construção e Manipulação do Tesauro}

A definição de um tesauro não é uma tarefa simples, pois envolve muitos conceitos e conhecimento sobre o domínio. Este esforço é compensado, no entanto, pela grande usabilidade apresentada pelo tesauro, não só neste trabalho como também pela exportação do mesmo para outro tipo de aplicação. Com o objetivo de facilitar a construção do tesauro, foi desenvolvida uma interface gráfica (Figura 22), a qual permite relacionar os termos entre si e, após a conclusão, exportar o tesauro para um arquivo XML.

A interface gráfica que pode ser observada na Figura 22, é responsável por determinar todas as relações semânticas existentes no tesauro. Vale ressaltar que, aparentemente, nem todas as relações são possíveis de serem feitas a partir da aplicação. Relações como UF (equivalência), NT (hierarquia, do genérico para o específico) e NTP (hierarquia, do todo para as partes) são feitas de forma automática ao se definir as relações contrárias a estas, no caso USE, BT e BTP, respectivamente.

Na Figura 22, que apresentada a interface gráfica de manipulação dos tesauros, pode-se observar a existência de quatro botões utilizados para definir as relações semânticas entre os termos, os quais estão listados em duas listas. Ao selecionar um termo na lista da esquerda, são exibidos todos os termos que possuem alguma relação semântica com este termo, e ainda, é possível definir novas relações. Por exemplo, para definir que um termo é um termo preferencial de outro, seleciona-se o termo preferencial na lista da esquerda e o nãopreferencial na lista da direita e pressiona-se o botão "Termo Preferencial é", neste momento, é definido que o termo da lista da direita usa o termo da lista da esquerda como preferencial, ou seja, uma relação semântica do tipo USE. Da mesma forma, é definido o caminho inverso, 
ou seja, o termo da esquerda passa a possuir uma relação semântica de USED FOR, para representar que é utilizado por outro termo.

Seguindo um raciocínio semelhante, pode-se definir as relações semânticas de hierarquia, através dos botões "Termo Genérico De" e "Termo Faz Parte De", onde o primeiro define as relações do tipo NT e BT (genérico e específico), e o segundo as relações de NTP e BTP (todo e parte). O último botão permite relacionar termos que não possuem outras relações semânticas possíveis. Porém, ao se pressionar o botão "Termos Relacionados", é necessário que se defina a proximidade entre os termos. Esta proximidade pode ser definida através de valores entre 0 e 1 .

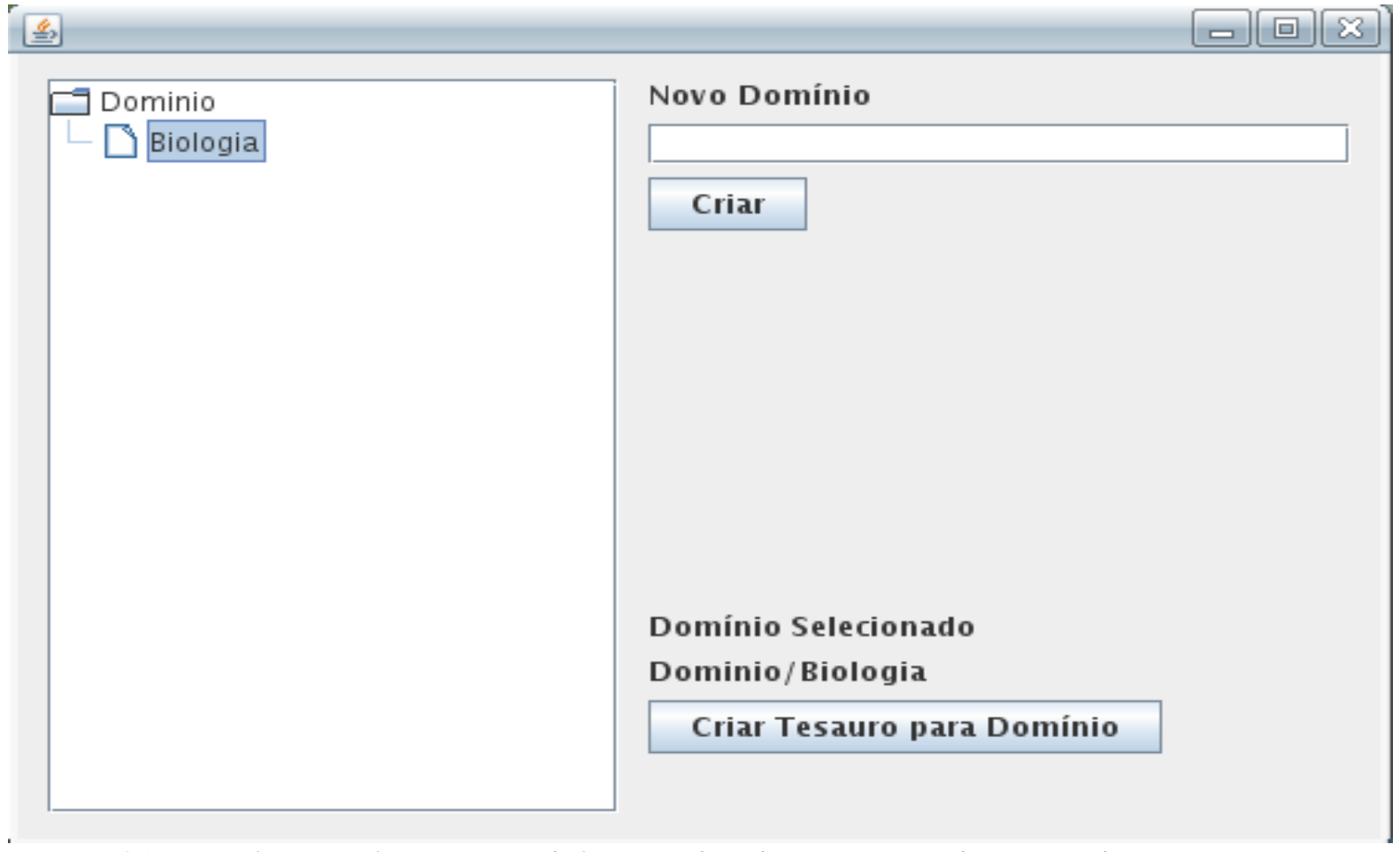

Figura 21: Interface gráfica para a definição dos domínio tratados no ambiente

Apesar do tesauro ser um arquivo XML, durante o processo de desenvolvimento, ele consiste em um conjunto de classes relacionadas entre si. A classe de maior importância para o tesauro é a classe de define os termos. Nessa classe estão definidos todos os 
relacionamentos entre um termo e os outros. Contudo, os relacionamentos existentes são, em sua maioria, unários, ou seja, ocorrem apenas entre os objetos uma classe. Isso porque a classe "Termo" se relaciona com a classe "Termo" várias vezes. Assim sendo, apresentar a modelagem deste sistema não trará nenhuma contribuição. A Figura 23 apresenta a parte do código fonte em linguagem java para que se possa compreender a forma com que as relações semânticas são tratadas.

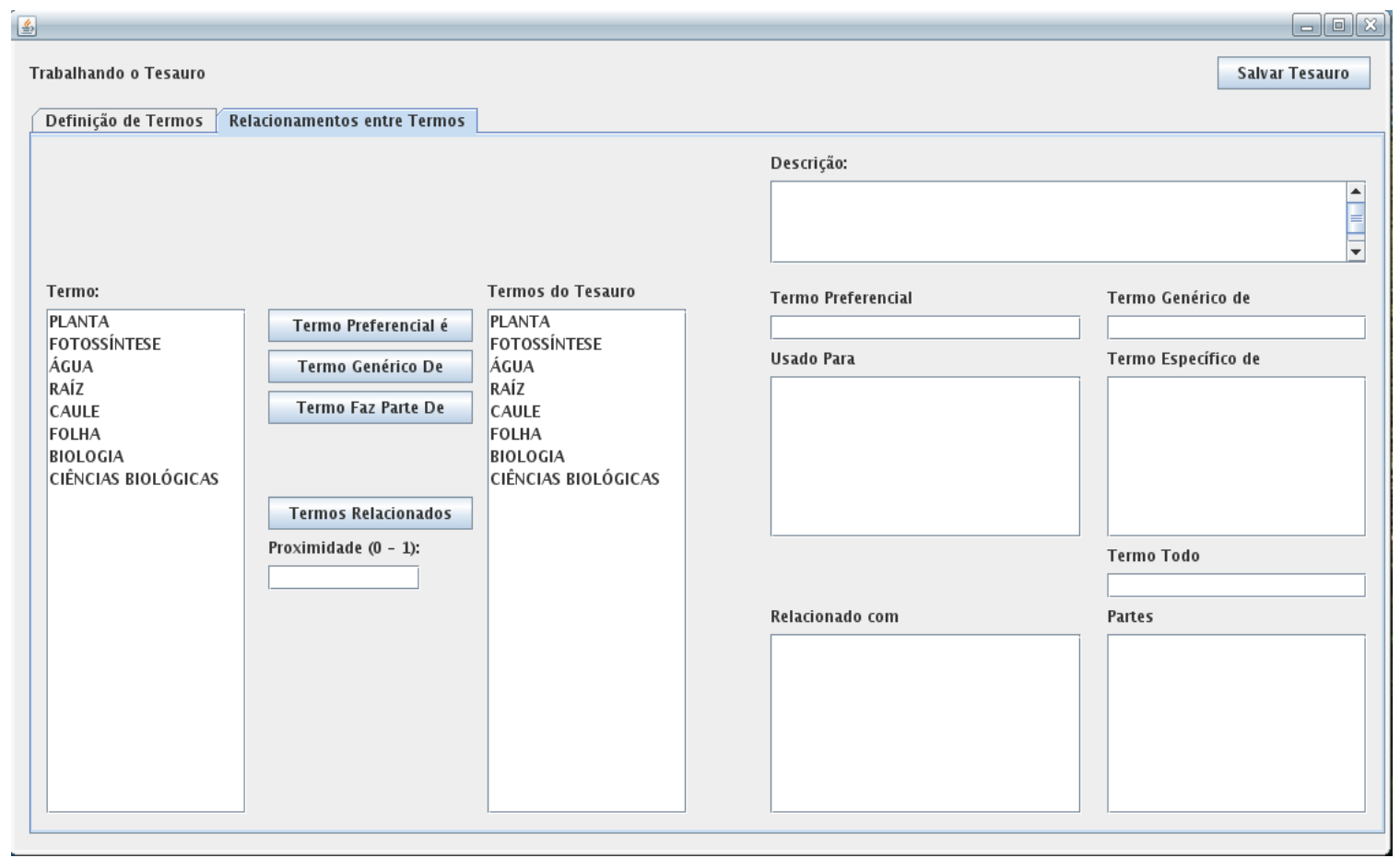

Figura 22: Interface para definir as relações semânticas do tesauro

Após entender como funcionam as relações semânticas dentro do tesauro, a Figura 24 apresenta um exemplo simples da estrutura do arquivo XML gerado. Este arquivo deve conter todos os termos e relações do tesauro. É importante observar que além das relações semânticas, existem também referências para o projeto e para a classe. Estas referências são utilizadas no momento em que o projeto é indexado pelo tesauro, assunto abordado adiante. A 
Capítulo 3 - Ambiente de Apoio ao

Figura 25 apresenta as relações que um termo pode ter. Observa-se que todos os relacionamentos são unários, ou seja, entre o próprio termo.

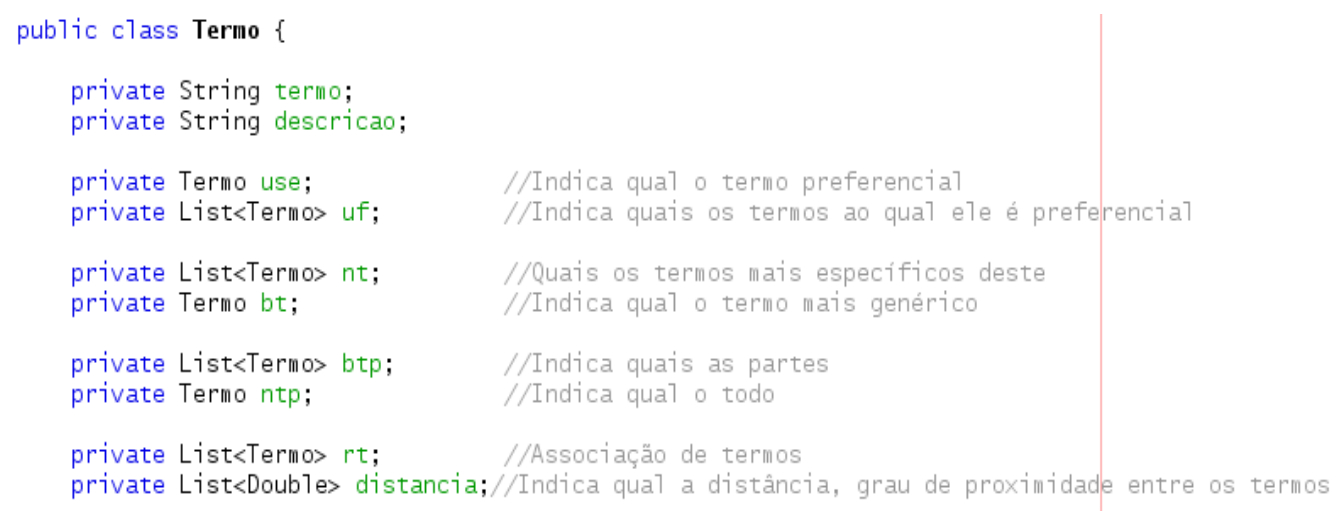

Figura 23: Parte da Codificação que representa os relacionamentos do tesauro

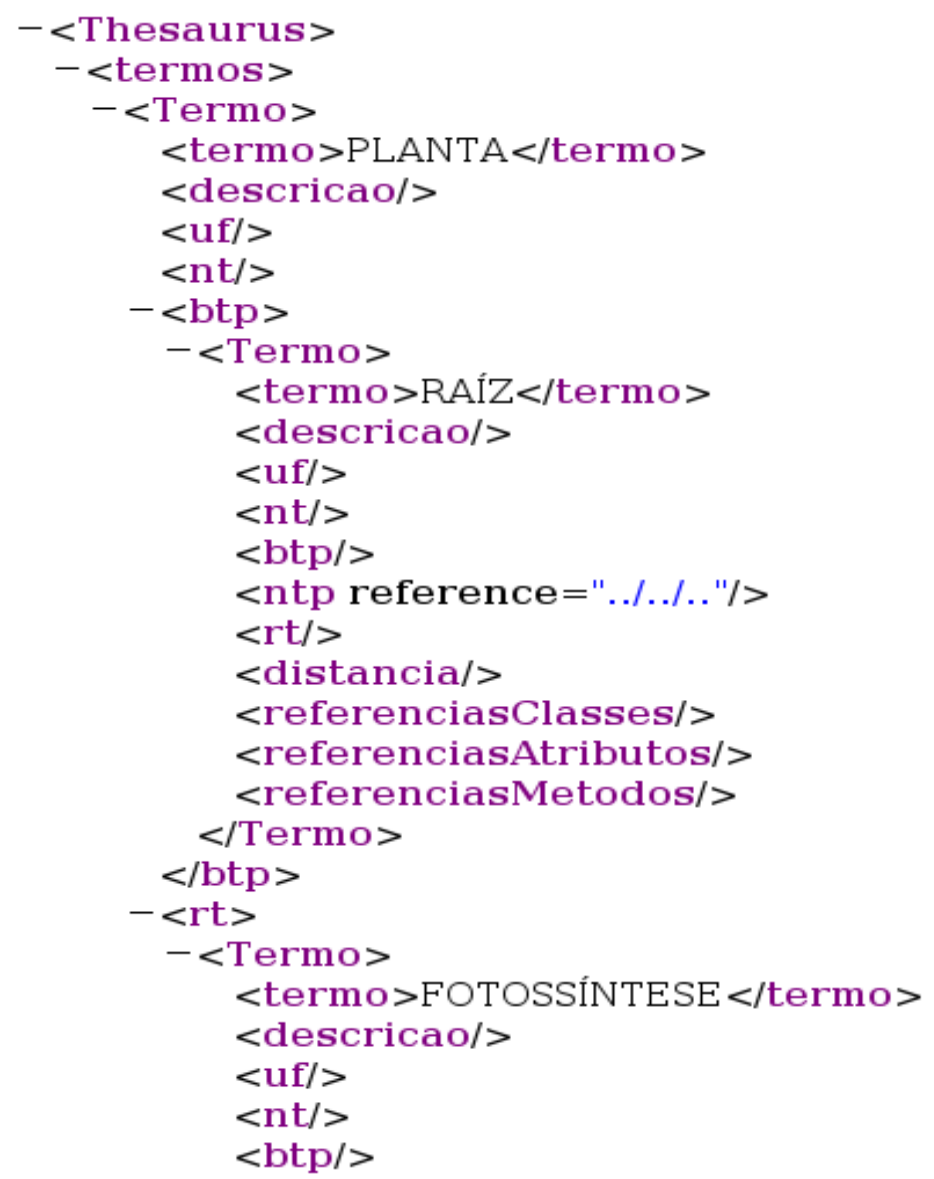

Figura 24: Fração de arquivo XML que representa um tesauro 


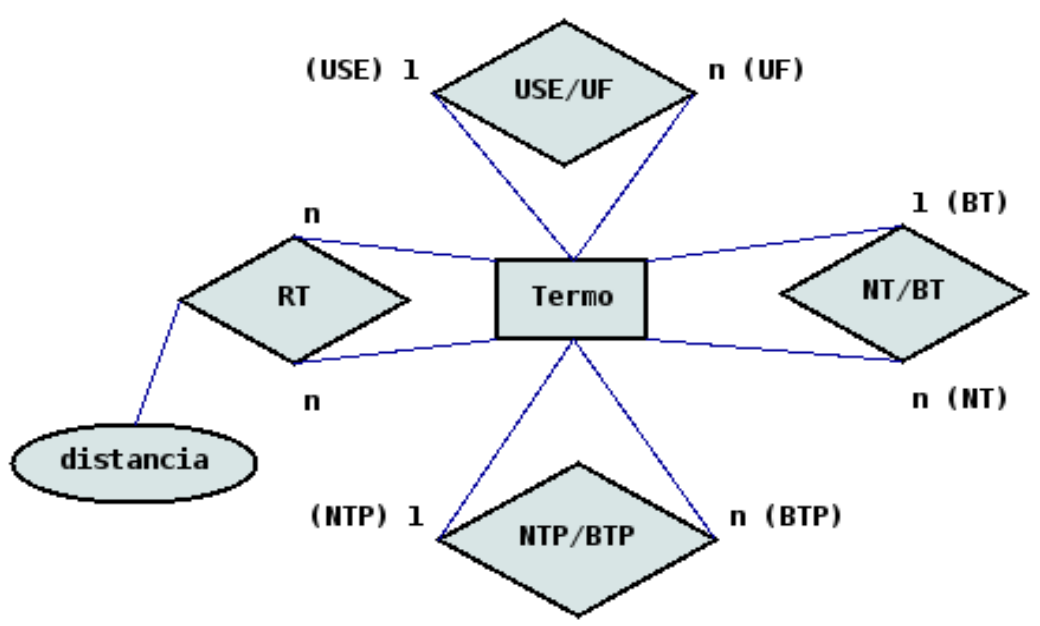

Figura 25: Relacionamentos entre termos do tesauro

\subsubsection{Inclusão de Novos Projetos}

A metodologia proposta por Affonso, Rossi e Rodrigues (2008) define que os projetos devem estar disponíveis para consulta em um repositório de características. Sendo assim, é necessário primeiramente extrair as características de um projeto, depois indexá-lo junto ao tesauro daquele domínio, e por fim armazená-lo nos respectivos repositórios. O funcionamento de cada uma destas tarefas é descrito a seguir.

\section{Reflexão de Projetos}

Neste trabalho, o termo reflexão está sendo utilizado como introspecção, ou seja, a capacidade que um software tem de refletir sobre sua própria estrutura. Desta forma, o objetivo deste módulo é extrair todas as características de um projeto. Vale lembrar que na metodologia de desenvolvimento de software reconfigurável, proposta por Affonso, Rossi e Rodrigues (2008), é previsto que os projetos sejam compostos por objetos puros, ou seja, 
Capítulo 3 - Ambiente de Apoio ao

objetos livres de requisitos não-funcionais. Dessa forma, os objetos devem atender apenas aos propósitos de lógica do projeto.

Ao realizar a introspecção de um projeto, extrai-se diretamente do código fonte toda a estrutura do software (classes, atributos, métodos, etc). Estas informações são inseridas em uma instância do meta-modelo elaborado. Este meta-modelo é capaz de representar toda a estrutura de um projeto de software representando não apenas os nomes de classes, métodos e atributos, mas também os relacionamentos existentes entre as classes. Assim, neste metamodelo estão incluídas todas as características relevantes do projeto. Este meta-modelo pode ser observado na Figura 26.

O ponto inicial deste meta-modelo corresponde à classe "Project", que possui uma relação (um - para muitos) com a classe "Clazz", que é o ponto central do meta-modelo. Por sua vez, cada classe do sistema pertence a um pacote "Package", podendo ou não ter uma classe pai "SuperClazz", e podendo ou não implementar uma ou mais interfaces "Interface" e, finalmente, possui um conjunto de características "Attribute" e comportamentos "Method". Além dos comportamentos que uma classe pode ter, também é possível representar os construtores "Constructor" de uma classe, estes métodos são os responsáveis por instanciar o objeto no momento de sua criação. Cada característica possui um tipo de dados que a qualifica e, cada método, possui um tipo de dados de retorno e seus parâmetros "Parameter". O metamodelo representa também a possibilidade de uma classe implementar uma interface "Interface" e suas assinaturas de métodos "Signature". Destaca-se nesse modelo a classe "ReflectManager", que é uma classe funcional, responsável por realizar a extração de características dos sistemas e a instancia do meta-modelo. 


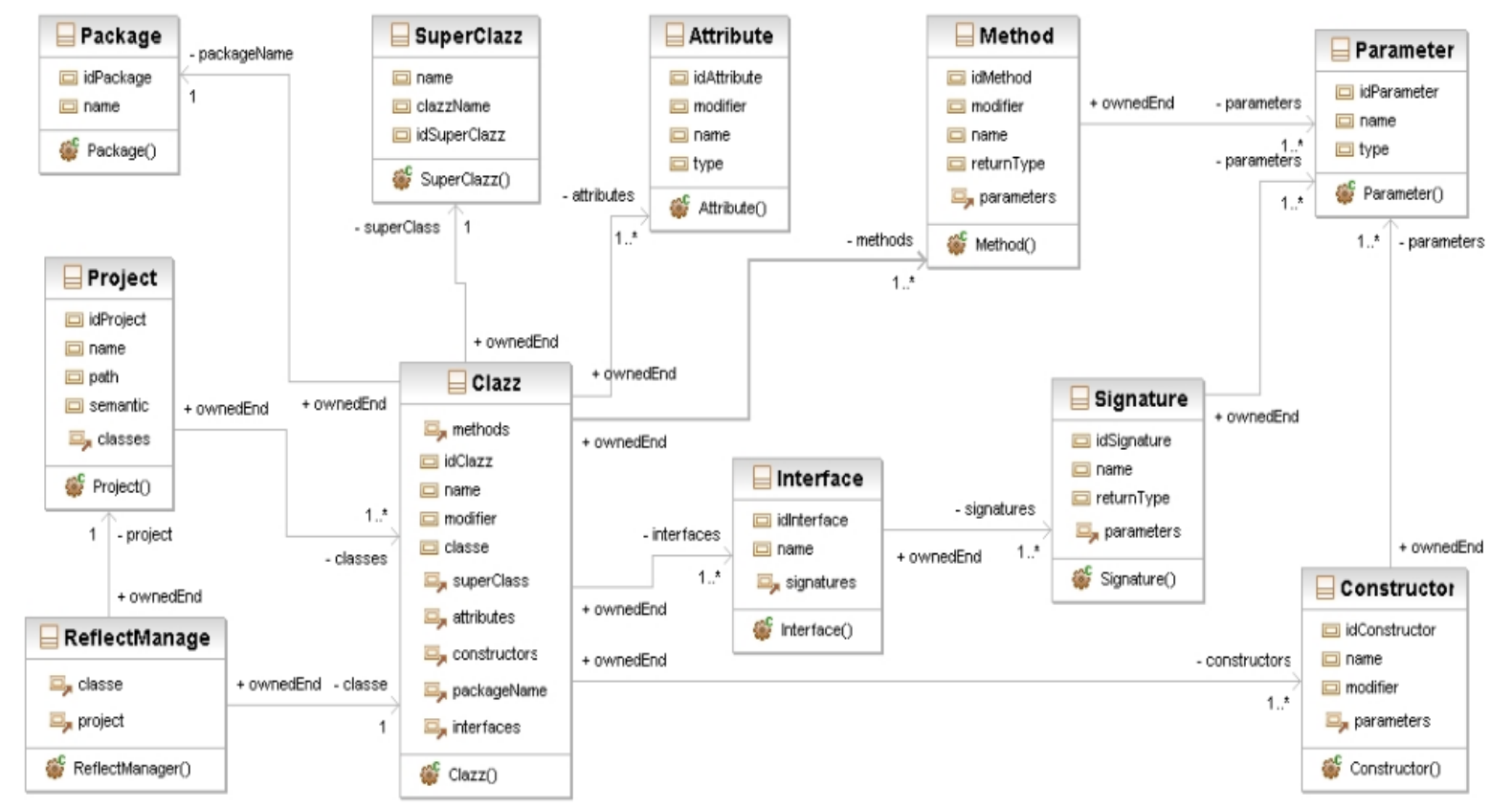

Figura 26: Meta-modelo gerado pela extração de características dos projetos

Quando um projeto é disponibilizado no repositório de software, os métodos da classe “ReflectManager" são encarregados de compilar todo o código fonte do projeto e, a partir do código compilado, extrair as características do projeto, gerando em seguida um arquivo XML, que é a instancia do meta-modelo. Essa operação é obrigatoriamente realizada, pois o processo de introspecção é realizado sobre o código compilado.

Como exemplo deste processo, pode-se observar a Figura 27, que contém o código fonte de uma classe simples. Após o processo de introspecção é gerada uma instancia do meta-modelo com as informações desta classe, e posteriormente gerado o arquivo XML que pode ser visto na Figura 28. 
Capítulo 3 - Ambiente de Apoio ao

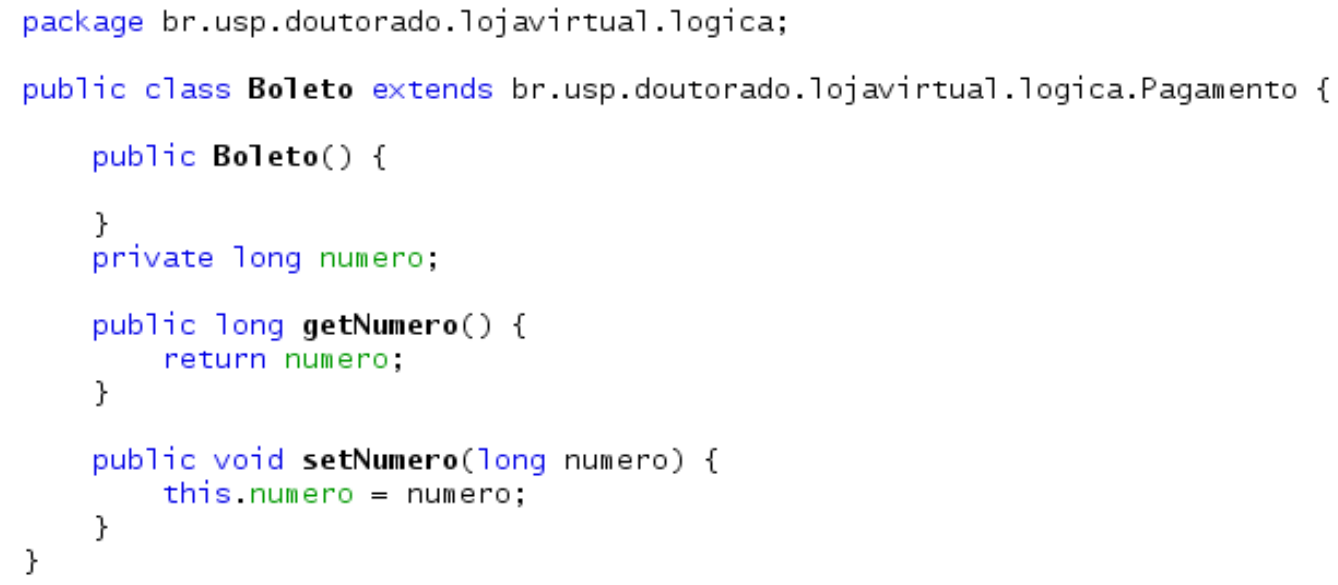

Figura 27: Exemplo de introspecção - classe Boleto

\section{Metodologia de Indexação dos Projetos}

Após a introspecção do projeto, ele está pronto para ser indexado. Para isso, é necessário saber a qual domínio o projeto pertence, pois só assim será possível recuperar o tesauro correto para o processo de indexação. Lembrando que o responsável por definir os termos do tesauro é o especialista de domínio (ED).

Outro fato a ser destacado é que os engenheiros de software e desenvolvimento devem utilizar-se dos termos definidos pelo ED no tesauro para a definição dos identificadores dos métodos, atributos e classes. Isso se faz necessário para justificar o trabalho do ED e também para maximizar a usabilidade do tesauro. Contudo, caso algum termo não especificado no tesauro seja utilizado, o usuário é avisado que aquele termo não será indexado, e que o ED poderá indexá-lo posteriormente de forma manual. 


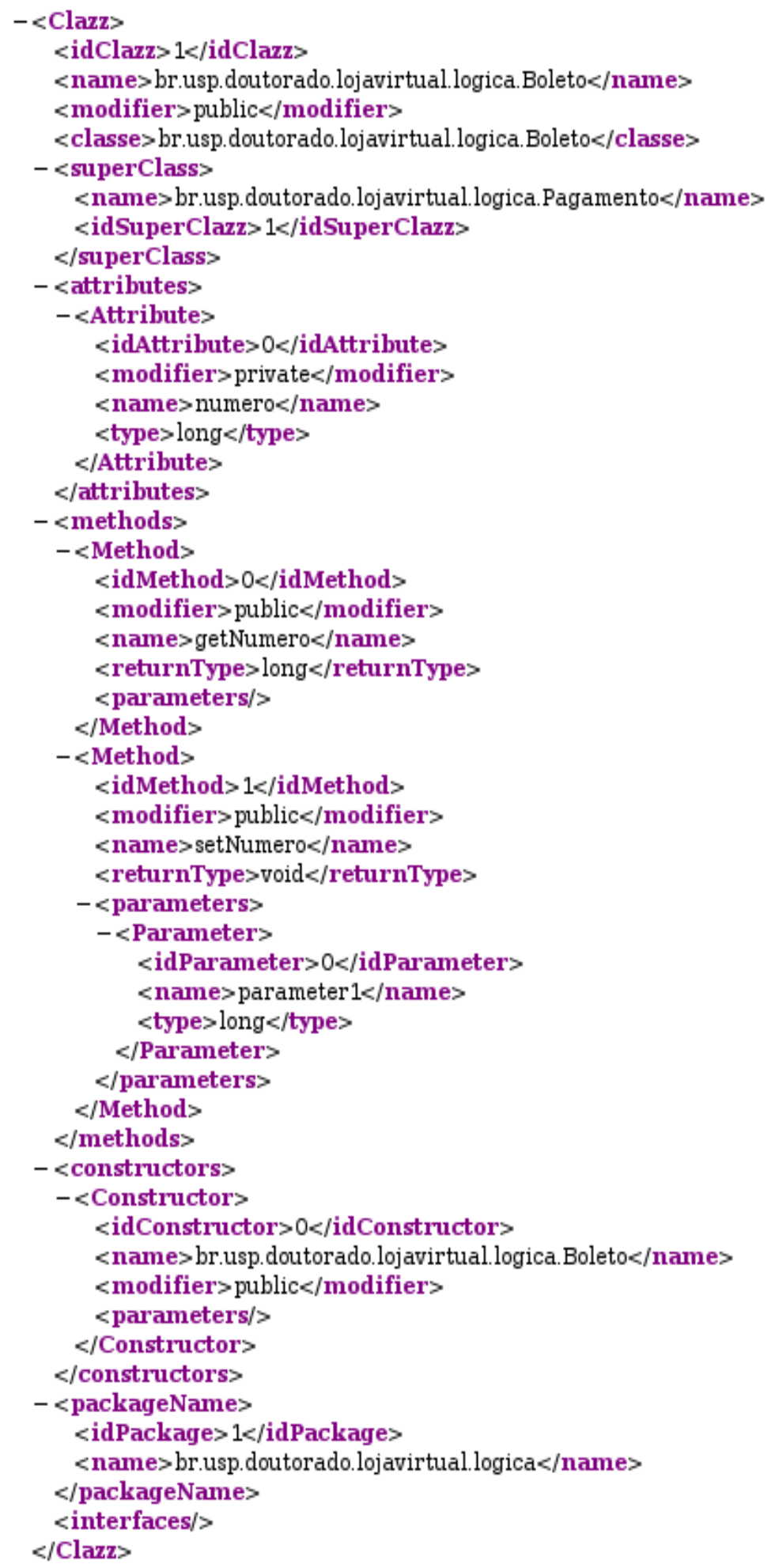

Figura 28: Arquivo XML gerado a partir da introspecção da classe Boleto 
Com o tesauro correto e com as características do projeto, pode-se iniciar a indexação. Esse processo associa aos termos do tesauro referências para o projeto e para a classe que o termo indexa. Detalhe importante é que apesar de sempre analisar os termos dos atributos, métodos e classes, a indexação será feita sempre para uma classe. Isso se justifica pois raramente um método terá alguma funcionalidade fora de sua classe original; assim, as classes são tanto o objeto indexado como também serão os objetos retornados pela busca.

$\mathrm{O}$ fato de indexar consiste em associar a um termo o identificar único do projeto e o identificador único de cada classe. Esses identificadores são gerados durante a fase de introspecção. O identificador do projeto é seqüencial, ou seja, a cada novo projeto inserido no repositório, incrementa-se este identificador.

Quando inicia a indexação, o sistema seleciona cada um dos termos existentes no projeto e percorre o tesauro em busca do termo selecionado. Caso o encontre, verifica se este possui um termo preferencial, ou seja, se existe alguma relação de equivalência entre termos. No caso de possuir, inicia-se um processo recursivo que realiza a busca pelo termo preferencial. Tanto no caso de não existir um termo preferencial, ou de ter encontrado este termo, inclui-se uma referência na lista de referências do termo. As demais relações semânticas existentes não são consideradas no momento de indexação e sim no momento de recuperação da informação do tesauro. 


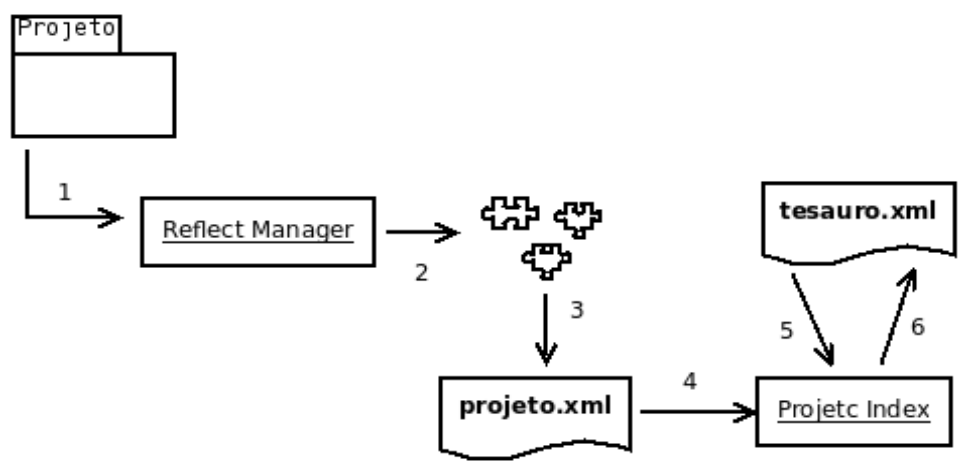

Figura 29: Arquitetura do processo de indexação

A Figura 29 ilustra todo o processo de indexação de um projeto. Assim que um projeto é inserido no ambiente (1), a ferramenta "Reflect Manager" extrai todas as características do projeto (2), criando uma instancia do meta-modelo. A partir da instancia do meta-modelo é gerado um arquivo que contém todas as características do projeto (3). Neste momento é invocada a ferramenta de indexação de projetos, "Project Index" (4), que recupera o tesauro no domínio apropriado (5). A “Project Index" inicia então a indexação, inserindo referencias do projeto nos termos do tesauro. Após indexar todos os termos, o tesauro é atualizado e volta a ser armazenado em um arquivo XML (6).

Este trabalho está totalmente baseado em serviços de agentes de software, pois são os agentes que realizam as tarefas de introspecção, indexação e disponibilização do projeto no repositório de software. Neste trabalho foram apenas implementados agentes locais, ou seja, toda a metodologia foi testado em uma única máquina. A distribuição deste ambiente será um assunto abordado na seção de trabalhos futuros.

Quando um usuário nomeia um agente para inserir o projeto no repositório, o agente carrega consigo o código fonte do projeto. Este, por sua vez, dispara outro agente, o qual fará 
o processo de introspecção e passará para outro agente o arquivo contendo o meta-modelo gerado. Este último fará todo o processo de indexação do projeto no tesauro.

Vale lembrar que um agente é um programa que possui alguns comportamentos. Estes comportamentos são as tarefas atribuídas aos agentes. A API JADE discutida na seção 2.3.2 foi de grande valia para este trabalho, diminuindo a complexidade da implementação dos agentes.

\subsubsection{Recuperação de Informação dos Projetos}

A segunda fase deste trabalho consiste em integrar um sistema de recuperação de informação (RI) à aplicação. Este sistema de RI precisa encontrar as classes que foram capazes de atender às solicitações do engenheiro de software. O sistema deve, com base nos parâmetros informados, realizar a busca no tesauro, analisando os termos e comparando com os projetos disponíveis.

\section{Metodologia de Busca}

Para iniciar a busca, a equipe de desenvolvimento deve informar os parâmetros da busca. Estes parâmetros são os termos existentes no tesauro de um domínio específico. $\mathrm{O}$ usuário deve, então, selecionar todos os termos que farão parte da busca. Para uma melhor compreensão pode-se observar a Figura 30, que mostra a interface de busca. 


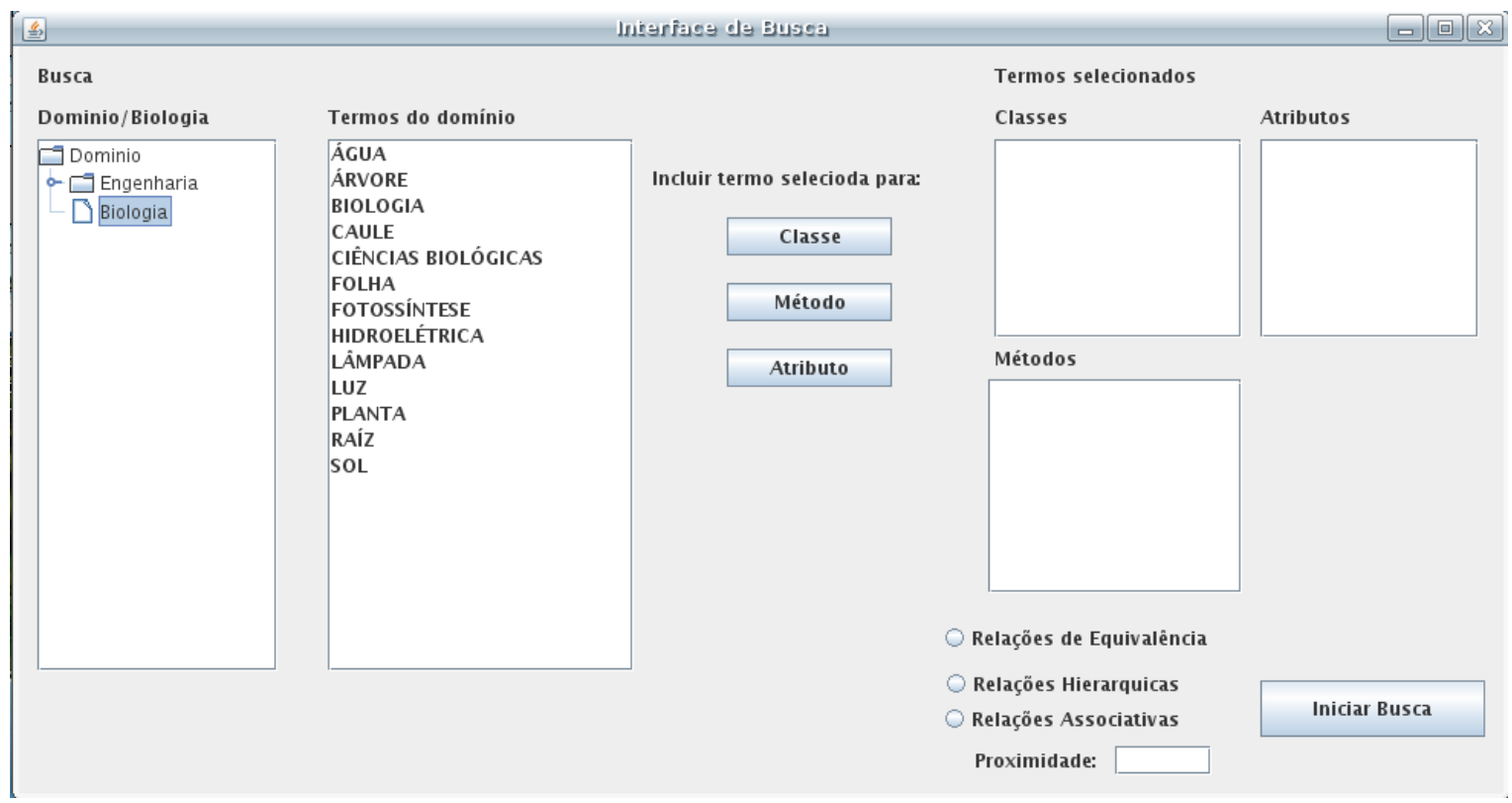

Figura 30: Exemplo da estrutura da interface de busca

Observa-se na Figura 30 que quando o usuário seleciona um domínio, todos os termos do tesauro daquele domínio são carregados em uma lista. Todas as palavras que o usuário pode utilizar para realizar a busca constam nesta lista. Não é previsto que o usuário digite as palavras desejadas, pois o mesmo pode especificar palavras que não pertencem ao domínio e consequientemente não constam no tesauro, o que remeterá a termos que não possuem relação semântica com os termos definidos para aquele domínio. Por isso, o usuário deve selecionar os termos que deseja buscar.

A seleção de termos pode se dar em três categorias: (1) Classes, onde são especificados os termos que se deseja para o nome da classe; (2) Métodos, onde são definidos os termos que se deseja para o nome dos métodos e; (3) Atributos, onde são determinados os nomes dos atributos. Pode-se selecionar o mesmo termo várias vezes, uma vez por categoria, pois pode-se desejar uma classe que possua um atributo ou um método com nomes iguais ou equivalentes. Outro ponto, é que pode-se deixar de especificar qualquer uma das categorias. 
Capítulo 3 - Ambiente de Apoio ao

No entanto, quanto melhor especificado forem as categorias melhor será o resultado obtido pela busca. É importante salientar que esta é uma busca do tipo “OR”, ou seja, a busca não tenta satisfazer todas as categorias, mas sim maximizar os resultados. Isso porque traz como resultados as classes que atendem uma ou outra categoria.

Além disso, observa-se na Figura 30 a existência de três diferentes tipos de busca em função das relações semânticas existentes no tesauro. O primeiro tipo de busca utiliza apenas as relações de equivalência definidas no tesauro. Este tipo de busca retorna os resultados mais satisfatórios, pois a busca é realizada no tesauro analisando-se apenas os sinônimos, quasesinônimos e variantes lexicais dos termos especificados como parâmetros da busca.

Esta busca consiste em localizar o termo especificado como parâmetro de busca no tesauro, após sua localização, coletá-se todas as referencias que este termo possui. Após esta coleta, verifica-se se o termo possui um termo preferencial, caso possua, inicia-se um algoritmo repetitivo que "navega" pelos termos preferenciais do termo inicial, coletando todas as referencias indexadas. Como dito anteriormente, os resultados deste tipo de pesquisa é mais restrito, pois deixa de observar as relações de hierarquia e de associatividade existentes no tesauro. A Figura 31 exemplifica este processo.

Na Figura 31, observa-se que o Desenvolvedor de Software (DS) especifica ao sistema quais os parâmetros são desejados para que o software seja reconfigurado (passo 1). Ao serem definidos o parâmetros, o mecanismo de busca inicia seu trabalho (passo 2). Inicialmente o mecanismo de busca recupera o tesauro do domínio especificado pelo DS. Com o tesauro recuperado, a primeira providência é localizar o termo desejado pelo DS "Termo B". Localizado o termo, o mecanismo cataloga todas as classes que são indexadas pelo termo (“Classe 3" e "Classe 4"). O passo seguinte consistem em analisar se o termo possui um 
termo preferencial, ou seja, uma relação de equivalência (“USE"). No exemplo, o "Termo B" possui um termo preferencial, o "Termo A". Assim, o mecanismo de busca inicia a análise no “Termo A" (passo 2.1), catalogando as classes indexadas por ele (“Classe 1" e "Classe 5") e, novamente verificando a existência do termo preferencial. Este processo se repete até que não hajam mais termos preferenciais. Ao final deste procedimento, o mecanismo de busca devolve uma lista contendo todas as classes encontradas (passo 3).

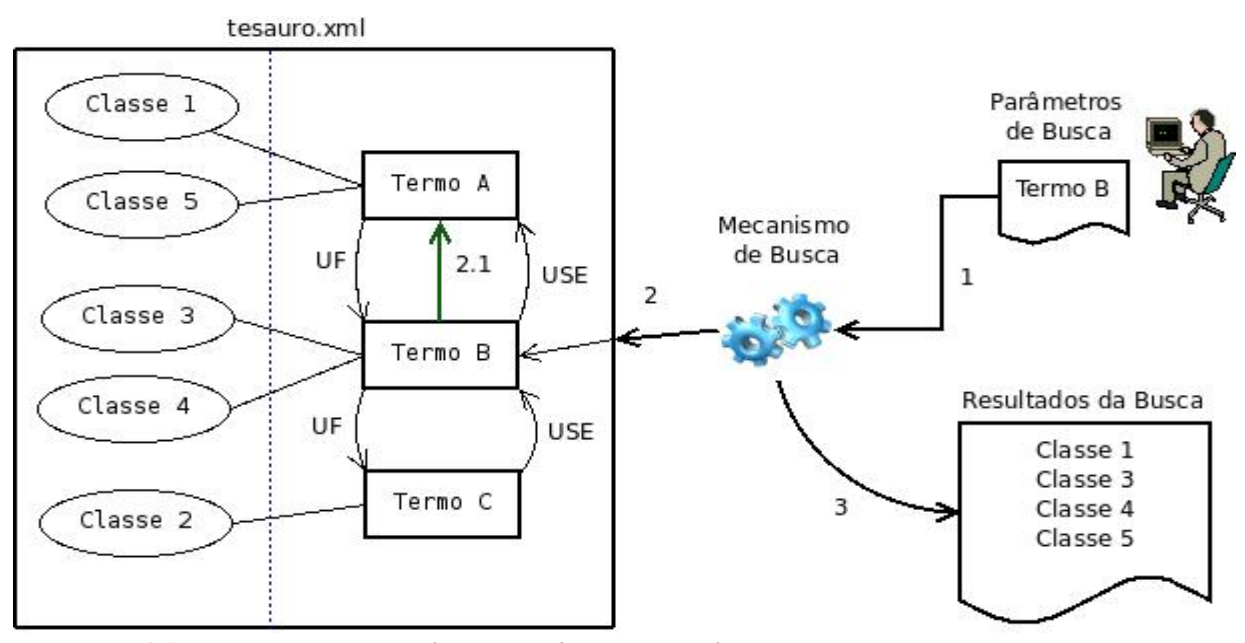

Figura 31: Busca por Relações de Equivalência

O segundo tipo de busca, a busca por relações hierárquicas, assemelha-se ao primeiro tipo de busca citado anteriormente, pois realiza o processo de busca nos termos equivalentes e também nos termos hierárquicos, sejam eles relacionados como genérico e específico, ou ainda como todo e parte. Para as relações hierárquicas são feitas quatro diferentes análises.

Antes de realizar a análise hierárquica dos termos, são coletadas todas as referências que o termo encontrado possuir. A primeira analise hierárquica verifica se o termo possui alguma relação do tipo BT, ou seja, se possui algum termo genérico. Caso possua, inicia-se um processo recursivo no qual coletam-se as referências e analisa-se se o termo possui outro 
relacionamento BT, e assim por diante, até que não existam mais relações hierárquicas do tipo BT. Este tipo de análise se justifica pois geralmente os termos genéricos podem indexar classes relevantes à busca.

A segunda análise hierárquica é feita em todos os termos NT, ou seja todos os termos mais específicos do termo atual. Deve-se lembrar que um termo pode possuir apenas um relacionamento BT (genérico), e vários relacionamentos NT (específico), ou seja, uma lista. Isso porque um termo pode ser genérico de vários outros termos. Nesta análise, coletam-se todas as referências existentes nos termos diretamente relacionados com o termo da busca, não analisando outras relações semânticas que os termos específicos possam possuir. A justificativa deste processo é a possibilidade de encontrar uma grande quantidade de resultados irrelevantes ao usuário.

Para ilustrar este processo, pode-se observar a Figura 32. Observa-se que ao especificar os parâmetros de busca, o mecanismo de busca inicia a análise dos termos do tesauro. Como no exemplo, o "Termo $D$ ” é o parâmetro, a análise é iniciada por este termo. É importante observar que no tesauro o "Termo $D$ " não indexa nenhuma classe, o que em algumas outras metodologias de busca retornaria um conjunto vazio de resultados. Desta forma, não existem classes no "Termo $D$ " para serem catalogadas, assim é iniciada a primeira análise, onde verifica-se a existência de termos genéricos. Neste exemplo, o "Termo B" é um termo genérico do "Termo D", neste caso, são catalogadas todas as classes indexadas pelo "Termo B" ("Classe 3" e "Classe 5") e refeita a análise. Agora o termo genérico do "Termo B" é o "Termo A", de onde são coletadas todas as classes indexadas por ele ("Classe 1" e "Classe 5"). Nota-se que a "Classe 5" será catalogada duas vezes, pois é indexada pelos termos 
“Termo A" e "Termo B". Este fato não foi contemplado no presente trabalho, mas quando uma classe for referenciada mais de uma vez, pode-se fazer uma análise de relevância, pois aparentemente, uma classe que é recuperada várias vezes deve ser um resultado mais relevante que outras classes. Como o “Termo D”, que é o parâmetro inicial da busca não possui nenhum termo específico (relação NT), a busca é encerrada e os resultados apresentados ao DS. Contudo, se “Termo D" possui-se algum termo específico (NT) seria feita a segunda análise, onde seriam catalogadas todas as classes indexadas pelos termos que possuem um relação NT com “Termo D”.

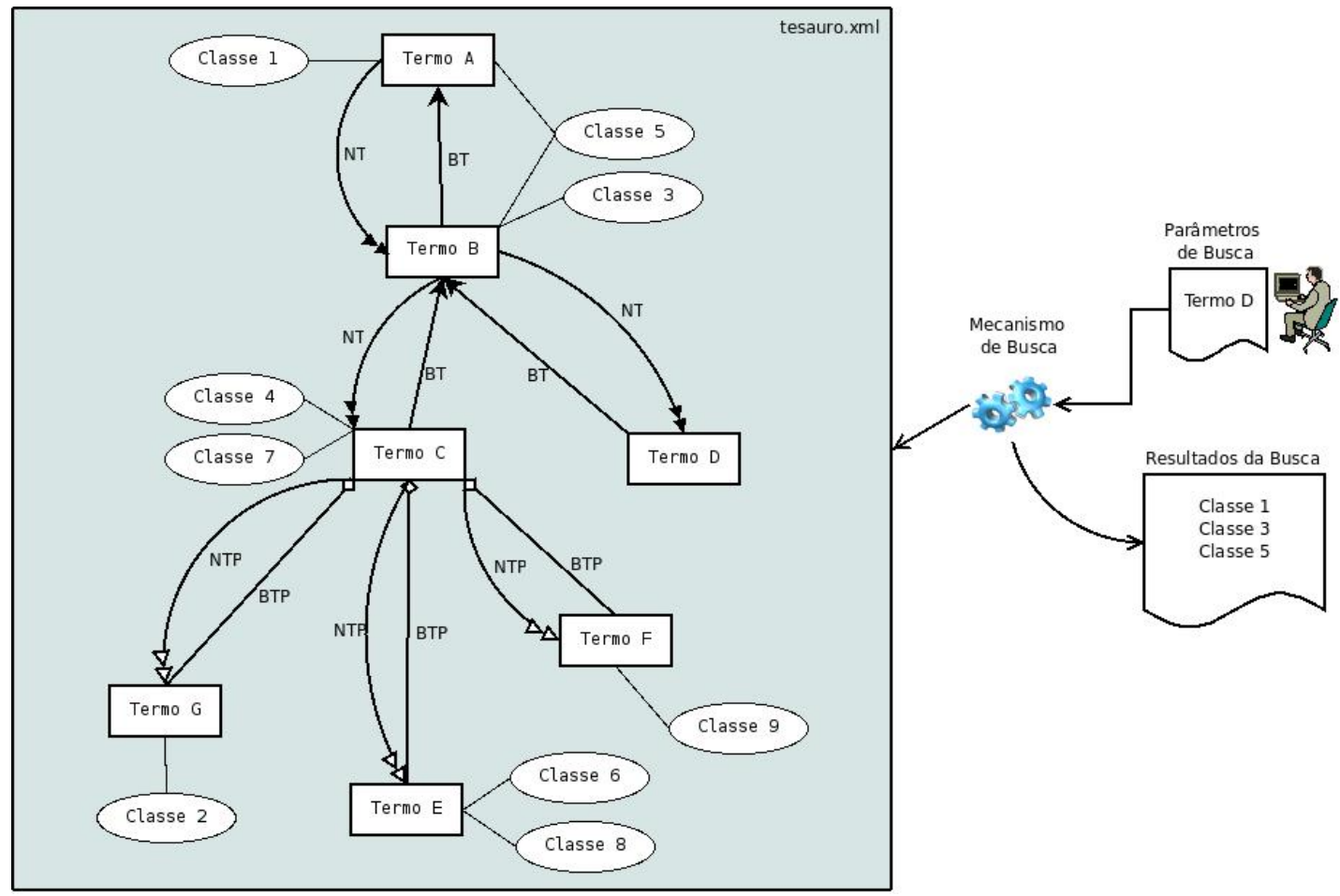

Figura 32: Busca Por Relações de Hierarquia

A terceira análise dá-se nos relacionamentos do tipo BTP, ou seja, na relação semântica de todo, o que indica que o termo atual é parte de um termo que representa algo maior. Neste caso, inicia-se um processo recursivo onde extrai-se as referências do termo e, em seguida, 
Capítulo 3 - Ambiente de Apoio ao

analisa-se o termo que representa o todo (relação BTP). Este processo é feito enquanto os termos forem parte de outro termo.

A quarta e última análise hierárquica é realizada nas relações NTP, que são as relações que indicam as partes de um termo. Nesta análise são catalogadas todas as referências dos termos diretamente ligados ao termo pelo relacionamento NTP. Assim como na análise das relações NT, não são consideradas outras relações semânticas que os termos parte possam possuir.

Estas duas últimas análises podem ser exemplificadas também pela Figura 32. Se por exemplo, o DS especifica-se como parâmetro de busca o termo "Termo C", seriam resultado desta busca todas as classes indexadas pelos termos "Termo C", "Termo E", "Termo F" e “Termo G". Isso porque os termos "Termo E", "Termo F" e "Termo G" são partes de "Termo C", ou seja possuem uma relação NTP com o "Termo C".

O último tipo de busca é realizada nas relações de associatividade. Para esta busca necessita-se da especificação da proximidade desejada dos termos (vide Figura 30). A definição desta proximidade deve-se exatamente pela característica imposta ao tesauro proposto neste trabalho, onde é definido, pelo $\mathrm{ED}$, o quão próxima é a relação associativa de um termo com o outro. Este tipo de busca realiza todas as buscas possíveis, que incluem as buscas por relações de equivalência, relações de hierarquia e também realiza a análise dos termos com relações de associatividade. A proximidade que o usuário deve informar são valores em uma escala de 0 a 10. Esta escala é convertida em números entre 0 e 1, pois assim estão definidas as relações de associatividade do tesauro neste trabalho.

Para análise das relações de associatividade, o sistema analisa quais termos estão 
relacionados com o termo especificado. Após esta análise são incluídos aos resultados todas as classes referenciadas pelos termos que possuem uma "distância" maior ou igual ao parâmetro de proximidade especificado pelo usuário.

Para exemplificar esta busca, a Figura 33 mostra que os parâmetros de busca são o “Termo C" e a distância é 7. Como no tesauro as relações de associatividade possuem distâncias no intervalo de 0 e 1, o parâmetro distância será dividido por 10, que neste caso resulta em 0.7. O mecanismo de busca inicia seu trabalho a partir do "Termo C", coletando todas as classes por ele indexadas ("Classe 6"). Na sequência, o mecanismo de busca analisa todas as relações de associatividade (RT) que o termo possui, porém só enfoca as relações que possuem distância maior ou igual a distância definida pelo DS. Assim, a única relação válida para o exemplo é entre o "Termo C" e o "Termo B". Agora o mecanismo cataloga todas as classes indexadas pelo "Termo B" (“Classe 1" e "Classe 3") e realiza uma análise entre todas as relações do “Termo B" que possuem distância maior ou igual a 0.7. Este processo é repetido até que não existam mais termos com relação de associatividade com distância maior ou igual a especificada pelo DS.
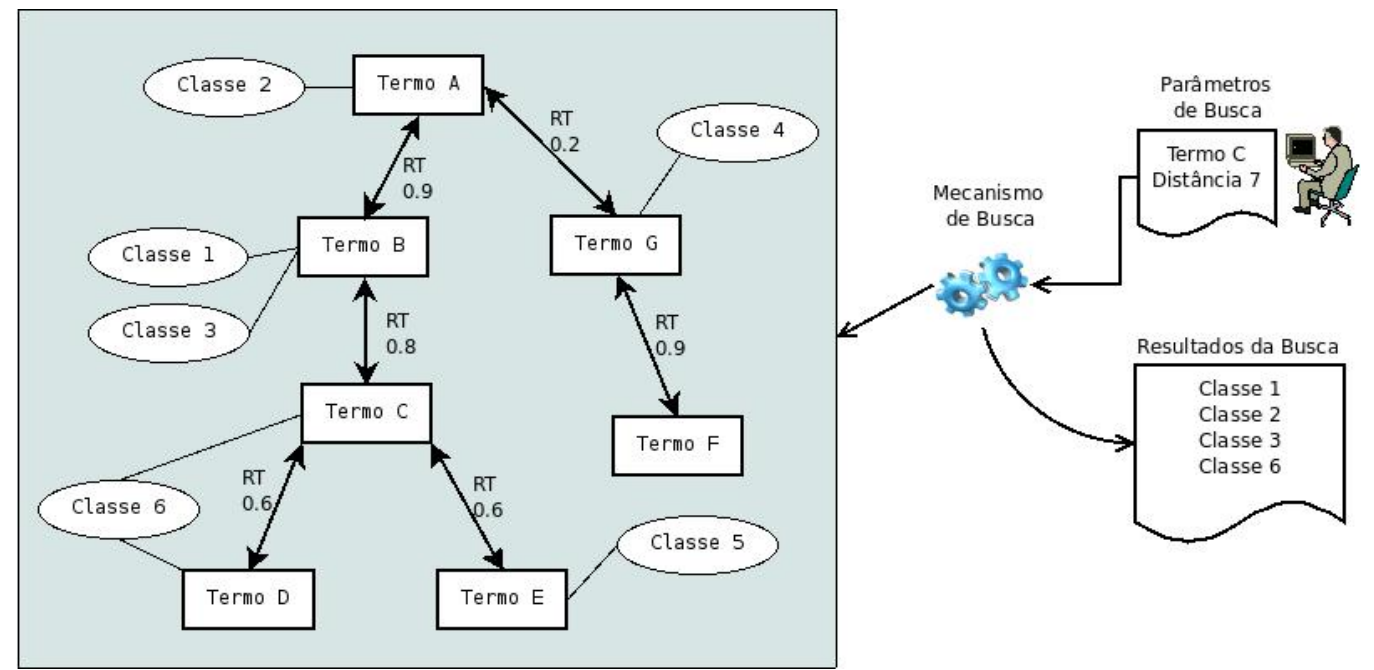

Figura 33: Busca por Relações de Associatividade 
A quantidade de classes trazidas como resultado deste último tipo de busca será muito maior que dos outros dois tipos. Apresenta, contudo, uma maior riqueza de conteúdos, pois pode trazer resultados não previstos pelos usuários. O ponto negativo é que o usuário deverá fazer uma análise individual dos resultados.

Os agentes de software já foram assunto do trabalho quando se tratava da inclusão de um novo projeto no repositório de software, porém eles voltam a ser tratados neste trabalho no momento da busca. Isso porque eles são os responsáveis por realizar todo o procedimento de busca citado na seção anterior.

O usuário nomeia um agente de software no momento em que termina de especificar os parâmetros e inicia a busca. Nesse instante, um agente de software é disparado em direção ao repositório de software, mais especificamente ao repositório de características. Neste repositório, analisa o tesauro do domínio especificado, coletando uma lista com as classes que podem atender aos requisitos. Este processo utiliza a metodologia de busca descrita na seção anterior.

Após recolher todas as referências, o agente percorre o repositório de código fonte a fim de coletar o código das classes candidatas a serem reconfiguradas. Findado este processo, o agente retorna ao usuário e exibe as classes que foram recuperadas, para que o usuário possa fazer a escolha de qual classe utilizar.

\subsection{Considerações Finais}

Este capítulo descreveu brevemente parte da metodologia proposta por Affonso, Rossi 
e Rodrigues (2008), levantando tarefas que precisavam ser associadas à metodologia para aumentar a sua usabilidade, pois não é possível reconfigurar e/ou reutilizar um software se não sabe-se com qual artefato de software fazê-lo. Assim, este capítulo abordou de forma modular as ferramentas e metodologias empregadas no apoio à reconfiguração de software.

O primeiro assunto abordado foi uma descrição da metodologia empregada por Rossi, Affonso, Rodrigues (2008), descrevendo o repositório de software, que na verdade é um conjunto de outros repositórios como: (1) repositório de características, onde são armazenadas as informações estruturais dos projetos; (2) repositório de código fonte, no qual são armazenados todos os códigos desenvolvidos no projeto; (3) repositório de documentação que armazena os modelos e documentos gerados na fase de análise e desenvolvimento dos projetos; (4) repositório de banco de dados, responsável por armazenar todos os scripts de criação de manutenção dos banco de dados utilizados nos projetos; (5) repositório de serviços, que são utilizados para armazenar os requisitos não funcionais de um projeto que foram transformados em serviços e disponibilizados para outros projetos.

A metodologia de Affonso, Rossi e Rodrigues (2008) também define que os projetos devem ser organizados de acordo com o seu domínio; assim, a organização dos repositórios de características é feita seguindo este padrão. Inicialmente Affonso, Rossi e Rodrigues (2008) haviam proposto que para a recuperação das informações dos projetos, deveria ser empregada uma tecnologia de agentes especialistas como, por exemplo, a API Drools, que basicamente trabalha com um conjunto de regras do tipo se...então... em um motor de inferência. No entanto, após alguns testes com esta proposta observou-se que os resultados não eram satisfatórios, pois a busca realizada sobre as regras geradas eram buscas exatas, ou seja, não havia nenhuma forma de extrair qualquer informação dos parâmetros passados para a busca. 
Capítulo 3 - Ambiente de Apoio ao

Assim, optou-se por utilizar-se de uma técnica que considera a informação semântica dos projetos. Iniciaram-se, assim, alguns testes.

O primeiro teste foi realizado utilizando um dicionário de termos, o qual consiste simplesmente da definição de um termo e de relacionar a ele todos os seus sinônimos. Entretanto, essa técnica mostrou-se limitada pois tratava apenas dos sinônimos de um termo.

Devido à limitação do dicionário de termos, outra técnica foi testada, agora uma rede semântica de termos. Esta rede permite que se relacionem vários termos, ou seja, os termos poderiam estar ligados uns aos outros formando uma rede semântica. O problema desta técnica fica na definição da rede, pois, na ligação de um termo a outro, é necessário definir uma "distância" entre os conceitos dos termos, e esta por sua vez é feita de forma subjetiva pelo especialista de domínio.

Finalmente optou-se pela utilização de um tesauro para fazer a indexação dos termos. O tesauro engloba tanto as características de um dicionário de termos (capacidade de lidar com sinônimos) quanto as características de uma rede semântica, pois permite que sejam tratados os mais variados tipos de relacionamentos semânticos. O tesauro proposto neste trabalho utiliza-se de três tipos de relações semânticas, a saber: relação de equivalência, relação de hierarquia e relação de associatividade.

Também foi assunto deste capítulo a tarefa de incluir projetos nos repositórios. Essa tarefa é realizada por agentes de software, que ao receberem a tarefa de incluir o projeto nos repositórios, fazem uma introspecção no projeto a fim de extrair todas as características deste projeto. O resultado desta introspecção é um arquivo do tipo XML que contêm toda a informação estrutural do projeto como classes, métodos, atributos, heranças, entre outros. Nesta fase, os agentes também são responsáveis por indexarem o projeto no tesauro. Esta 
Capítulo 3 - Ambiente de Apoio ao

indexação é feita a partir da análise dos termos empregados no projeto e das relações semânticas existentes no tesauro. Somente após estes passos é que o projeto será inserido no repositório de software.

Por fim, este capítulo abordou como é realizada a recuperação das informações dos projetos. Essa tarefa também é desenvolvida por agentes de software que, após coletarem os parâmetros de busca especificados pelo usuário, percorrem o tesauro do domínio determinado catalogando todos as classes que atendem às especificações do usuário.

No Capítulo 4 será feita a apresentação dos resultados comparando o trabalho com outros trabalhos correlatos, assim como levantar alguns temas para discussão. 


\section{Capítulo 4}

\section{Resultados e Discussões}

\subsection{Considerações Iniciais}

O objetivo deste capítulo é a apresentação dos resultados obtidos fazendo um comparativo com outros trabalhos. Porém como a metodologia de desenvolvimento de software reconfigurável é uma área que pode ser considerada recente, os trabalhos comparados serão da área de reuso de software. Isso porque ao se reconfigurar um software, pode-se interpretar que o software está sendo reutilizado, porém de forma modificada (reconfigurada).

Este capítulo também apresenta alguns trabalhos relacionados pelo aspecto da reutilização de software.

\subsection{Resultados e discussões}

O objetivo inicial deste trabalho foi a formalização de uma metodologia e um ambiente 
que viabilizasse o desenvolvimento de software reconfigurável proposto por Affonso, Rossi e Rodrigues (2008). Como visto anteriormente, reconfigurar um software significa reutilizá-lo fazendo alguma adaptação, a qual pode ser o acréscimo de funcionalidades e/ou de características.

O primeiro resultado obtido foi a definição de um meta-modelo. Este meta-modelo é capaz de representar toda a estrutura existente em um projeto. É possível, inclusive, representar todos os relacionamentos existentes entre as classes. Dentre as características estruturais, o meta-modelo é capaz de representar: nome do projeto, nome das classes, modificador de cada classe, atributos e métodos pertencentes as classes, tipo e modificadores de cada atributo, tipo de retorno e todos os parâmetros, inclusive o tipo, de cada método, métodos construtores e seus parâmetros, e o pacote a que cada classe pertence. Dos relacionamentos entre as classes, o meta-modelo representa a associação de classes, a qual dáse por meio dos atributos; as generalizações (heranças), sendo possível representar a classe que herda características das demais classes; também é possível representar a implementação de interfaces que uma classe realiza. O meta-modelo é um dos pontos-chave do desenvolvimento pois segundo Pressman (2000), um repositório deve possuir um metamodelo, ou seja, um modelo de informação, que descreva a estrutura, relacionamentos e semântica dos dados armazenados. Assim, o meta-modelo se justifica, pois todo o repositório estará baseado nele.

Para que o meta-modelo seja instanciado, desenvolveu-se um sistema capaz de extrair todas as características de um projeto e disponibilizá-las no meta-modelo. Este sistema realiza um processo de introspecção no projeto, coletando todas as informações necessárias para o meta-modelo. Esta introspecção é possível através da propriedade de reflexão que um 
software pode fazer de si mesmo. Assim, este sistema de introspecção pode ser contado como outro resultado efetivo do trabalho.

Como o meta-modelo não é capaz de representar a semântica existente entre os termos da estrutura dos projetos, foi adotado um tesauro como forma de representar tal semântica. $\mathrm{O}$ tesauro também é um dos resultados deste projeto. O tesauro é um dicionário que representa as relações semânticas existentes entre os termos de um domínio específico. Devido à grande quantidade de termos, um tesauro representa apenas um destes domínios por vez. Assim é possível definir vários tesauros, os quais são desenvolvidos para representar um domínio de forma particular.

Um ponto a ser questionado é a utilização do tesauro como indexador, pois outras tecnologias poderiam atender a esta funcionalidade como um dicionário de termos ou uma rede semântica de termos.

Um dicionário de termos é capaz de realizar a representação de muitos termos de um domínio, e permite que os termos sinônimos sejam catalogados e utilize-se como indexador apenas o termo representativo. Um exemplo de utilização de um dicionário de termos pode ser durante a representação do termo "adicionar", que pode ser considerado um termo representativo dos termos "incrementar", "somar" ou "totalizar". O problema desta tecnologia está em sua simplicidade, pois um dicionário deste tipo é capaz de representar apenas sinônimos, contudo, outras relações semânticas podem existir entre os termos de um domínio.

Já a rede semântica de termos permite a representação de relações semânticas entre os termos. A rede é um grafo direcionado, cujos nós correspondem aos termos, e cujos arcos possuem pesos que representam o grau de relacionamento entre os termos. Contudo, a 
utilização desta tecnologia é inviável pois o grau de relacionamento entre os termos deve ser definido de forma manual e subjetiva, deixando a cargo do especialista de domínio a sua definição. Contudo, existem tecnologias que viabilizam sua utilização, mas que não foram focadas neste trabalho. Assim, devido ao fato das relações semânticas serem abstratas, esta tecnologia não foi utilizada no trabalho. Fez-se necessária, dessa forma, a adoção de uma tecnologia que permitisse tanto a representação de sinônimos quanto a representação de relações semânticas, nesse caso o tesauro.

Um tesauro permite a representação de três tipos de relações semânticas: (1) relação de equivalência, que trata os sinônimos ou quase-sinônimos; (2) relação hierárquica, que trata das relações entre termos genéricos e específicos, e também relações partitivas, ou seja, quando um termo é parte de outros e; (3) relação de associatividade, quando o termo possui um relacionamento com outro porém, não se enquadra nas relações (1) ou (2).

Para que o tesauro se apresente-se como uma ferramenta adequada, adotou-se uma adaptação da ISO-2788 em sua definição. O tesauro proposto pela ISO-2788 prevê as relações de equivalência (USE e UF), as relações hierárquicas (NT, BT, NTP e BTP) e as relações de associatividade (RT). Porém para a relação RT não é definida nenhuma escala que indique se um termo é muito ou pouco relacionado a outro. Desta forma, adaptou-se o tesauro para que ao definir uma relação de associatividade, defina-se também a proximidade semântica entre os termos. Essa proximidade é definida por números no intervalo entre 0 e 1, onde 1 representa termos muito relacionados e 0 representa nenhuma relação. Esta adaptação mostrou-se eficaz, pois permitiu representar toda e qualquer relação semântica existente no domínio.

O tesauro é utilizado em duas fases do projeto. A primeira no momento de indexar um novo projeto que será inserido no repositório; a segunda, no momento em que é necessário 
recuperar alguma informação existente no repositório. O tesauro funciona como um índice, o qual possui uma referência para os projetos inseridos nos repositórios.

Obteve-se ainda a estrutura do repositório de software, que na verdade é um conjunto de vários repositórios (características, código-fonte, documentação, etc). Neste trabalho foram enfocados os repositórios de característica e de código-fonte. O repositório de características é responsável por armazenar o meta-modelo contendo a estrutura dos projetos inseridos no repositório. Já o repositório de código-fonte armazena o código da aplicação.

Através da junção do tesauro com os repositórios, obteve-se um mecanismo de armazenamento e busca de artefatos de software. Este mecanismo apresenta algumas características como:

- Precisão na recuperação de artefatos. Esta característica foi possível pois com a utilização do tesauro é possível que se analise apenas os termos que possuem alguma relação semântica com o termo da pesquisa. Desta forma, como resposta às pesquisas realizadas os resultados, quando existirem, serão, em sua maioria, sempre relevantes. Assim, obteve-se um quesito básico para qualquer busca, que é trazer de volta ao usuário somente o que ele pode aproveitar, deixando resultados irrelevantes de lado;

- Auxílio na formulação da pesquisa. Esta característica facilita na montagem da busca que o usuário deseja fazer. Isso foi possível graças a interface gráfica montada, onde os termos que podem ser pesquisados são coletados no tesauro, e não permitem que o usuário informe termos que não pertencem ao domínio especificado pelo tesauro. Desta forma, o usuário estará sempre pesquisando por termos existentes em um domínio específico, não sendo possível selecionar termos que não fazem parte do domínio; 
- Descrição dos componentes. O mecanismo de busca e recuperação, auxiliado por agentes de software, descreve o projeto de software através da indexação do metamodelo, assim a descrição dos projetos passa a ser a estrutura do software;

Analisando os requisitos apresentados na seção 2.6, sobre os requisitos desejados para um repositório de software, e comparando com os resultados deste projeto, observa-se que apenas o requisito de segurança não foi atingido plenamente, isso porque não foi empregado esforço suficiente a este requisito, devido a dedicação aos outros requisitos. Desta forma, o mecanismo de busca e recuperação pode ser considerado plenamente satisfatório e eficiente, tanto para o trabalho com reconfiguração, quanto para trabalhos na área de reuso.

O mecanismo de busca e recuperação possui ainda outra característica que precisa ser destacada. $\mathrm{O}$ fato de permitir a recuperação de componentes white-box, ou seja, caixa branca. Este tipo de componente permite que o usuário tenha acesso direto ao código-fonte, diferentemente da maioria dos trabalhos relacionados, onde os mecanismos de busca fornecem apenas componentes do tipo black-box (caixa preta), nos quais é permitida a reutilização, porém não é possível que o código-fonte seja estudado e/ou modificado, impossibilitando assim qualquer tipo de reconfiguração.

E, por fim, tem-se os agentes de software, os quais fazem toda a integração entre as funcionalidades do ambiente. Os agentes foram implementados utilizando-se o framework JADE, que provê várias facilidades de implementação como a mobilidade, fato de extrema importância a este trabalho.

Os agentes são os responsáveis por receber um projeto de software, fazer o processo de introspecção no projeto, extraindo assim todas as informações necessárias para a definição do meta-modelo e também para indexar o projeto ao tesauro. Após este processo, os agentes são 
encarregados de inserir o projeto no repositório.

Também é tarefa dos agentes de software realizar as buscas por artefatos. Os agentes recebem os parâmetros de busca e vasculham o tesauro recolhendo todas as referências que possuem algum tipo de relação com os parâmetros. Ao final da busca o agente retorna ao usuário todos os resultados obtidos.

Com estas obervações, conclui-se que os resultados obtidos alcançaram o objetivo inicial do trabalho, pois definem um ambiente que viabiliza a implantação da metodologia proposta por Affonso, Rossi e Rodrigues (2008) e permite que outros projetos voltados ao reuso façam uso deste ambiente.

\subsection{Comparação com Trabalhos Correlatos}

Rossi (ROSSI, 2004) apresenta em seu trabalho uma Ferramenta de Apoio à Reutilização de Componentes de Software, denominado pela autora como FARCSoft. Esta ferramenta está totalmente relacionada com o presente trabalho pois apresenta uma metodologia completa de desenvolvimento de software voltada ao reuso, não abordando apenas um repositório de componentes como a maioria dos trabalhos consultados. Contudo, o mecanismo de classificação desse trabalho baseia-se em facetas, diferentemente do presente trabalho que utiliza-se do tesauro. Outra diferença é que o reuso empregado no trabalho está voltado a componentes do tipo caixa-preta. Mas a similaridade entre os trabalhos é clara, mesmo tendo objetivos distintos. 


\subsection{Considerações Finais}

O presente capítulo apresentou os resultados obtidos pelo trabalho, que vão desde a fase de introspecção de projetos, onde utilizou-se das tecnologias de reflexão e gerou-se um meta-modelo baseado na estrutura interna do software, passando pela fase de indexação, onde os artefatos são indexados em um tesauro. Tesauro esse que deve ter sua construção prévia e baseada no domínio, chegando na fase de pesquisa, onde os artefatos são pesquisados. 


\section{Capitulo 5}

\section{Conclusões}

\subsection{Considerações Iniciais}

Esta dissertação de mestrado está relacionada com a tese de doutorado de Affonso (AFFONSO, 2009), ambos desenvolvidos no Departamento de Engenharia Elétrica da Universidade de São Paulo. A presente pesquisa é uma contribuição à metodologia proposta por Affonso, Rossi e Rodrigues (2008) e tem o objetivo de ser incorporada à ferramenta ReflectTools ${ }^{\circledR}$ desenvolvida pelo citado autor.

\subsection{Conclusões}

A metodologia de trabalho apresentada mostrou-se eficiente para o auxílio ao desenvolvimento de software reconfigurável e também para ser incorporada por projetos que estejam voltados ao reuso de software. Assim, conclui-se o trabalho com um ambiente operante e eficiente para a busca e recuperação de artefatos de software do tipo white-box (caixa branca) e que traz, entre as contribuições científicas, a utilização de tesauros como 
indexadores de projetos; a utilização de agentes de software como ferramentas de integração do sistema, e ainda, um meta-modelo capaz de representar a estrutura e os relacionamentos existentes em um projeto de software baseado na linguagem JAVA.

\subsection{Limitações}

O presente trabalho apresenta, no entanto, algumas limitações, dentre as quais pode-se destacar:

- Os projetos de software suportados pela metodologia devem ser exclusivamente desenvolvidos utilizando a linguagem JAVA;

- O mecanismo de busca e recuperação realiza a busca em apenas um domínio especificado, sendo interessante que outros domínios sejam consultados, pois podem existir projetos de software semelhantes em domínios distintos;

\subsection{Trabalhos Futuros}

Dentre os trabalhos futuros estão:

- definir um mecanismo de segurança mais eficiente de acesso para os repositórios e o mecanismo de busca;

- realizar testes utilizando repositórios distribuídos em diferentes máquinas. Utilizando-se das tecnologias de agentes móveis e sistemas multi-agentes para realizar a integração destes repositórios;

- realizar um estudo de como, a partir de um repositório de software, gerar um tesauro e realizar a indexação dos projetos existentes neste repositório. Fazendo assim, 
o processo inverso ao estudado nesta dissertação;

- realizar testes envolvendo um número maior de projetos e de maior complexidade, gerando assim resultados mais expressivos quanto a precisão da busca;

- comparar os resultados do mecanismo de busca baseado em tesauro com outros trabalhos que apresentem uma arquitetura semelhante, porém onde o mecanismo de busca esteja baseado em ontologias.

\subsection{Lista de Trabalhos Publicados}

- ROSSi, E. G.; AFFOnSO, F. J.; RODRIGUES, E. L. L., Ambiente de apoio ao desenvolvimento de software reconfigurável baseado em agentes de software e busca inteligente de informações. In: 7 Congresso Nacional de Pesquisadores, 2008, São Carlos. 7 Congresso Nacional de Pesquisadores. São Carlos: UNICEP, 2008. v. 7.;

- AFFONSO, F. J.; ROSSI, E. G.; RODRIGUES, E. L. L., Reconfiguração de Objetos Distribuídos Utilizando Regras para Classificação e Recuperação de Informações. Revista Multiciência (ISSN: 1413-8972), São Carlos. Volume 9: 38-53, 2008.

- RAYMUndo, E. M.; ROSSI, E. G. RODRIGUES, E. L. L., Análise de Intersecção entre Imagens Pré Processadas com Metodologia Retinex e Imagens Pré Processadas com Metodologia de Realce de Bordas. In: 7 Congresso Nacional de Pesquisadores, 2008, São Carlos. 7 Congresso Nacional de Pesquisadores. São Carlos: UNICEP, 2008. v. 7.; 
- ROSSi, E. G.; AFFOnSO, F. J.; RODRIGUES, E. L. L., A Engenharia de

Software no Desenvolvimento de Sistemas Orientados a Agentes de Software. In: $6^{\circ}$ Congresso Nacional de Pesquisadores, 2007, São Carlos. $6^{\circ}$ Congresso Nacional de Pesquisadores, 2007;

- AFFOnSO, F. J.; ROSSI, E. G.; RODRIGUES, E. L. L., Reutilização de Software Apoiada pela Metodologia de Desenvolvimento de Software Reconfigurável. In: $6^{\circ}$ Congresso Nacional de Pesquisadores, 2007, São Carlos. $6^{\circ}$ Congresso Nacional de Pesquisadores, 2007;

- AfFOnSO, F. J.; ROSSi, E. G.; RODRIGUES, E. L. L., Processamento de Imagem Orientada a Serviço e Distribuído apoiado por Mecanismo de Compactação. In: $6^{\circ}$ Congresso Nacional de Pesquisadores, 2007, São Carlos. $6^{\circ}$ Congresso Nacional de Pesquisadores, 2007;

- ROSSI, E. G.; AFFONSO, F. J.; RODRIGUES, E. L. L., Transformada de Gabour no Reconhecimento de Texturas Auxiliada por Redes Neurais Artificiais. In: $6^{\circ}$ Congresso Nacional de Pesquisadores, 2007, São Carlos. $6^{\circ}$ Congresso Nacional de Pesquisadores, 2007;

- JAQUES, O. V., ROSSI, E. G., Análise de Formas Multi Escala com Curvograma Multi Scale Curvegram Analysis. In: $6^{\circ}$ Congresso Nacional de Pesquisadores, 2007, São Carlos. $6^{\circ}$ Congresso Nacional de Pesquisadores, 2007;

- AFFOnso, F. J.; ROSSI, E. G.; PENTEADO, R. A. D., Diretrizes para Reengenharia Baseada em Componentes de Sistemas Legados em Delphi para WEB. In: $6^{\circ}$ Congresso Nacional de Pesquisadores, 2007, São Carlos. $6^{\circ}$ Congresso 
Nacional de Pesquisadores, 2007;

- JAQUES, O. V.; ROSSI, E. G.; AFFONSO, F. J.; RODRIGUES, E. L. L., Identificação Biométrica Através da Geometria da Mão Utilizando Redes Neurais Artificiais. In: $6^{\circ}$ Congresso Nacional de Pesquisadores, 2007, São Carlos. $6^{\circ}$ Congresso Nacional de Pesquisadores, 2007;

- AFFONSO, F. J.; ROSSI, E. G.; RODRIGUES, E. L. L., Reconfiguração de

Aplicações Distribuídas utilizando RMI-Remote Method Invocation. In: 5o Congresso Nacional de Pesquisadores, 2006, São Carlos. $5^{\circ}$ Congresso Nacional de Pesquisadores, 2006;

- AFFOnSO, F. J.; ROSSI, E. G.; RODRIGUES, E. L. L., Armazenamento de

Imagens Médicas utilizando Serviço de Diretórios. In: $5^{\circ}$ Congresso Nacional de Pesquisadores, 2006, São Carlos. $5^{\circ}$ Congresso Nacional de Pesquisadores, 2006; 


\section{Referencia Bibliográfica}

AFFONSO, F. J. Metodologia para Desenvolvimento de Software Reconfigurável Apoiada por Ferramentas de Implementação: Uma Aplicação em Ambiente de Execução Distribuído e Reconfigurável. 2009. 191f. Tese (Doutorado em Engenharia Elétrica) Departamento de Engenharia Elétrica, Universidade de São Paulo, São Carlos, 2009.

AFFONSO, F. J.; ROSSI, E. G.; RODRIGUES, E. L. L., Reconfiguração de Objetos Distribuídos Utilizando Regras para Classificação e Recuperação de Informações. Revista Multiciência (ISSN: 1413-8972), São Carlos. Volume 9: 38-53, 2008.

BELlifEMINE, F., CAIRE, G. \& GREENWOOD, D. Developing Multi-Agent Systems with JADE. ISBN: 978-0-470-05747-6. Reino Unido: John Wiley \& Sons, Ltd, 2004.

BERNARDES, M. C. Avaliação do Uso de Agentes Móveis em Segurança Computacional. 1999. 119f. Dissertação (Mestrado em Ciência da Computação) - Instituto de Ciências Matemáticas e de Computação, Universidade de São Paulo, São Carlos, 1999.

CARLO, R. Classificação e Seleção de Componentes de Software Concorrentes. 1999, 106f. Dissertação (Mestrado em Engenharia Elétrica e Computação) - Departamento de Engenharia Elétrica de Computação e Automação Industrial, Universidade de Campinas, Campinas, 1999.

DEITEL, H. M. \& DEITEL P. J. Java: Como programar. ISBN 85-7605-019-6. 6 a Edição, Prentice Hall, 2005.

FERNANDES, A. P. Reflexão Computacional. Disponível em $<$ http://attila.urcamp.tche.br/ acauan/art_ccei_rc.html>. Acessado em 02 de setembro de 2009.

FRANKLIN, S. \& GRAESSER, A. Is It An Agent, or Just a Program? A Taxonomy for Autonomous Agents. In: Proceedings of the Third International Workshop on Agent Theories, Architectures, and Languages. Springer-Verlag, 1996.

GARCIA, V. C. et al. Especificação, Projeto e Implementação de uma Arquitetura para um Engenho de Busca de Componentes. In $5^{\circ}$ Workshop de Desenvolvimento Baseado em Componentes, 2005, Juiz de Fora-MG.

GIRARDI, R.A.D.A. Framework para coordenação e medição de web services modelados com Learning Objects para ambientes de aprendizado na Web. 2003. 111f. Dissertação 
(Mestrado em Informática) - Departamento de Informática e Centro Técnico e Científico da Pontifícia Universidade Católica do Rio de Janeiro, Rio de Janeiro, 2003.

HAASE, K. Java Message Service API Tutorial. Sun Microsystems, Inc., 2002. Disponível em <http://java.sun.com/products/jms/> Acessado em: 03 de junho de 2009.

HUGO, M. \& GADOTTI, R. Protótipo de um ambiente de monitoramento e apresentação de programas Java utilizando Reflexão Computacional, 2003. Disponível em $<$ http://www.inf.furb.br/seminco/2003/artigos/127-vf.pdf>. Acessado em: 08 de junho de 2009.

JURAFSKY, D.; MARTIN, J. H. Speech and Language Processing: An Introduction to Natural Language Processing, Computational Linguistics and Speech Recognition. Upper Saddler River, NJ: Prentice-Hall, 2000.

LIMA, V. L. S.; NUNES, M. G. V.; VIEIRA, R. Desafios do Processamento de Línguas Naturais, 2007. Disponível em <http://www.inf.pucrs.br/ linatural/Docs/Desafios.pdf>. Acessado em: 07 de setembro de 2009.

LUCENA, P. S. Semantic Agent, uma plataforma para desenvolvimento de agentes inteligentes. 2003. 151f. Dissertação (Mestrado em Ciência da Computação) - Instituto de Ciências Matemáticas e de Computação, Universidade de São Paulo, São Carlos, 2003.

LUCRÉDIO, E. S. A. e PRADO, A. F. A Survey on Software Components Search and Retrieval. In R. Steinmetz and A. Mauthe, editors, 30th IEEE EUROMICRO Conference, Component-Based Software Engineering Track , pages 152-159, Rennes - France, 2004. IEEE/CS Press.

LUGER, G. F. Inteligência Artificial: Estruturas e Estratégias para a Solução de Problemas Complexos. ISBN-10: 8536303964, 4ª edição, Porto Alegre: Bookmann, 2004.

MAES, P. Software Agents Tutorial. ACM Conference on Human Factors in Computing Systems, p. 194 - 195, 1997, Atlanta, Georgia.

MELO, C. O. Reutilização de Software: Classificação e Seleção de Artefatos Reutilizáveis, 2004. Monografia da Disciplina Tópicos em Ciência da Computação. Instituto de Matemática e Estatística - Universidade de São Paulo. Disponível em : $<$ http://www.ime.usp.br/ yw/2004/mac5701i/monografias/claudia-acvm.pdf>. Acessado em 08 de junho de 2009.

MELLO, C. A. S. Metadados para Apoio à Recuperação de Componentes de Software baseada em Agrupamento por RedeNeural. 2005. 59f. Dissertação (Mestrado em Ciência da Computação) - Centro de Ciências Exatas e de Tecnologia, Universidade Federal de São Carlos, São Carlos, 2005. 
MILLER, U. Thesaurus Construction: problems and their roots. Information Processing \& Management, v.33, n.4, p. 481-493, 1997.

MORAIS E SILVA, L. A. Estudo e Desenvolvimento de Sistemas Multiagentes usando JADE: Java Agent Development Framework. 2003. 97f. Monografia (Graduação em Bacharelado em Informática) - Centro de Ciências Tecnológicas, Universidade de Fortaleza, Fortaleza, 2003.

NASCIMENTO, R. S. Tecnologias de Inteligência Artificial na Administração do Conhecimento. Universidade Federal de Mato Grosso do Sul, Dourados, 2001

NUMAZAKI, E \& WAENY JR.; J. C. C. JMS - Java Message Service Teoria e Prática. ISBN: 85-7502-151-6. Florianópolis: VisualBooks, 2004.

NWANA, H. S. Software Agent: An Overview. Knowledge Engeneering Review, v. 11, n. 3., p 205-244, 1996.

OSTERTAG, E.; HENDLER, J.; PRIETO-DIÁZ, R.; BRAUN, C. Computing Similarity in a Reuse Library System: An AI-based Approach. ACM Transactions on Software Engineering and Methodology, v.1, n.3, p. 205-228, 1992.

OYAMADA, M.S. \& ITO, S.A. Aglets: Agentes Móveis em Java, 1998. Universidade do Rio Grande do Sul. Disponível em <http://www.inf.ufrgs.br/gppd/disc/cmp134/trabs/ T2/981/Aglets/aglets.html>. Acessado em 02 de setembro de 2009.

PAULA, A. C. M. P. Integração de Modelos Baseados em Sistemas multi-agentes. 2005. 94f. Dissertação (Mestrado em Informática Aplicada) - Pontifícia Universidade Católica do Paraná, Curitiba/PR, 2005.

PENG, Y. Agents that Reason Logically, 1998. Notas de Aula Adaptadas de FININ, T; SCHULZ, A.G.; DYER C. Disponível em <http://www.csee.umbc.edu/ ypeng/AICourseOld/ Ch06.htm> Acessado em: 04 de junho de 2009.

PEREIRA FILHO, S. F. Avaliação de Ambientes Servidores para Agentes Móveis. 2001. 106f. Dissertação (Mestrado em Ciência da Computação) - Instituto de Ciências Matemáticas e de Computação, Universidade de São Paulo, São Carlos, 2001.

PIMENTA, A. Especificação Formal de uma Ferramenta de Reutilização de Especificações de Requisitos. 1998. 122f. Dissertação (Mestrado em Ciência da Computação) - Instituto de Informática, Universidade Federal do Rio Grande do Sul, Porto Alegre/RS, 1998.

PIZZATO, L. A. S. Estrutura Multitesauro para Recuperação de Informações. 2003. 92f. Dissertação (Mestrado em Ciência da Computação) - Faculdade de Informática - Pontifícia 
Universidade Católica do Rio Grande do Sul, Porto Alegre/RS, 2003.

PRESSMAN, R. S. Software Engineering: A Practitioner's Approach. ISBN: 0-07-114603-2. 4 a Edição, McGraw-Hill, 1997.

PRIETO-DIÁZ, R. A Software Classification Scheme. Relatório Técnico. Information and Computer Science - University of California, Irvine, 1985.

PRIETO-DIÁZ, R. \& FREEMAN, P. Classifying Software for Reusability. IEEE Software, v.4, n. 1, p. 6-16, 1987.

PRIETO-DIÁZ, R. Status Report: Software Reusability. IEEE Software, v.10, n. 3, p. 61-66, May, 1993.

PROENÇA, H. P. M. C. MARCS - Sistema multi-agentes para Controlo de Tráfego Ferroviário. 2003. 241f. Tese (Mestrado em Inteligência Artificial e Ciências da Computação) - Faculdades de Ciências, Economia e Engenharia, Universidade do Porto, Cidade do Porto, PT, 2003.

RED-HAT-JBOSS. Site oficial do JBOSS uma divisão da RED HAT. Disponível em $<$ http://www.jboss.com/>. Acessado em: 03 de junho de 2009.

RIBEIRO, M. B. \& ESCOBAR, M. S. Agentes e Ambientes de Programação para WEB: Uma Visão da Área. Pontifícia Universidade Católica do Rio Grande do Sul, Porto Alegre, 2006.

ROSSI, A C. Representação do Componente de Software na FARCSoft: Ferramenta de Apoio à Reutilização de Componentes de Software. 2003. 236f. Dissertação (Mestrado em engenharia) - Departamento de Engenharia de Computação e Sistemas Digitais - Escola Politécnica da Universidade de São Paulo, São Paulo, 2004.

ROSSI, E. G.; AFFOnSO, F. J.; RODRIGUES, E. L. L., Ambiente de apoio ao desenvolvimento de software reconfigurável baseado em agentes de software e busca inteligente de informações. In: 7 Congresso Nacional de Pesquisadores, 2008, São Carlos. 7 Congresso Nacional de Pesquisadores. São Carlos: UNICEP, 2008. v. 7.;

SEACORD, R. C.; HISSAM, S. A.; WALLNAU, K. C. AGORA: A Search Engine For Software Componets. IEEE Internet. November - December, 1998.

SENRA, R. D. A. Programação Reflexiva sobre o Protocolo de Meta-Objetos Guaraná. 2001. 164f. Dissertação (Mestrado em Computação). Universidade Estadual de Campinas Instituto de Computação, Campinas, SP, 2001.

SILVA, F. F. Raciocínio Baseado em Casos (RBC) Uma Abordagem Cognitiva. Universidade Federal de Santa Catarina, Área de Inteligência Artificial, 2001. 
SOUSA, F. C. \& GROTT, M. C. Utilização da Reflexão Computacional para Implementação de um Monitor de Software Orientado a Objetos em Java. In: VI Encontro de Estudantes de Informática do Estado do Tocantins, 2004, Palmas-TO.

SUGUMARAN, V.; STONEY, V. C. A Semantic-Based Approach to Component Retrieval. SIGMIS Database, v.34, n.3, p. 8-24, 2003.

SUN-JAVA. Site oficial da Sun microsystem sobre a tecnologia Java. Disponível em $<$ http://java.sun.com/j2se/1.5.0/docs/index.html>. Acessado em 20 de junho de 2009.

SUN-JAVADOC. Site oficial da Sun microsystem sobre a tecnologia Javadoc. Disponível em <http://java.sun.com/j2se/1.5.0/docs/api/ > . Acessado em 21 de junho de 2009.

SUN-JSR94. Site oficial da Sun microsystems sobre a tecnologia Java Rules. Disponível em <http://java.sun.com/developer/technicalArticles/J2SE/JavaRule.html>. Acessado em 08 de junho de 2009.

SUN-REFLECT. Site oficial da Sun microsystem sobre a tecnologia Reflect. Disponível em <http://java.sun.com/j2se/1.5.0/docs/guide/reflection/index.html>. Acessado em: 08 de junho de 2009.

TANENBAUM, A. S. Sistemas Operacionais Modernos. ISBN: 8587918575. 2 $2^{\mathrm{a}}$ Edição, Prentice Hall, 2003.

TAVARES, D. M. Avaliação de Técnicas de Captura para Sistemas Detectores de Intrusão. 2002. 110f. Dissertação (Mestrado em Ciência da Computação) - Instituto de Ciências Matemáticas e de Computação, Universidade de São Paulo, São Carlos, 2002.

W3C-XML. Site oficial do w3c, world wide web consortium - extensible markup language (xml). Disponível em <http://www.w3.org/XML>. Acessado em: 03 de junho de 2009.

WEBER-LEE, R. Pesquisa Jurisprudencial Inteligente. 1998. Tese(Doutorado em Engenharia). Universidade Federal de Santa Catarina, Florianópolis, 1998.

ZAREMSKI, A. M.; WING, J. M. Signature Matching: a Tool for Using Software Libraries. ACM Trans. Software. Eng. Methodol., v.4, n.2, p. 146-170, 1995.

ZAREMSKI, A. M.; WING, J. M. Specification Matching of Software Components. ACM Trans. Software. Eng. Methodol., v.6, n.4, p. 333-369, 1997. 


\author{
Universidade de São Paulo \\ Escola de Engenharia de São Carlos \\ Departamento de Engenharia Elétrica
}

Ambiente de Apoio ao Desenvolvimento de Aplicações

Distribuídas e Reconfiguráveis Utilizando Agentes de Busca e Classificação Inteligentes

Ednilson Geraldo Rossi

São Carlos - SP

2009 